\title{
NBER WORKING PAPER SERIES \\ KNOWLEDGE, STIGMA, AND HIV TESTING: \\ AN ANALYSIS OF A WIDESPREAD HIV/AIDS PROGRAM
}

\author{
Dean Yang \\ James Allen IV \\ Arlete Mahumane \\ James Riddell IV \\ Hang $\mathrm{Yu}$
}

Working Paper 28716

http://www.nber.org/papers/w28716

\author{
NATIONAL BUREAU OF ECONOMIC RESEARCH \\ 1050 Massachusetts Avenue \\ Cambridge, MA 02138 \\ April 2021, Revised August 2022
}

Corresponding author: Dean Yang (deanyang@umich.edu). Most importantly, we thank Faustino Lessitala for stellar leadership and field management throughout the project. Carolina Salvaterra, Danito Angorete, Fernando Padama, and Filipe Murgorgo made essential contributions in the field. Kyal Berends, Moustafa El-Kashlan, Sihang Cai, Ryan McWay, Jared Stolove, and Derek $\mathrm{Xu}$ provided first-rate research assistance. Lauren Tingwall's grant administration was worldclass. This study would not have been possible without the multi-year engagement and commitment of Nathaniel Lohman and Dionisio Matos of USAID, and of Michael Carter and Tara Chiu of the BASIS research program. Amy Aberra and Joshua Volle of USAID provided important context and feedback. We appreciate feedback from Michael Carter, Paul Gertler, Sharon Maccini, Grant Miller, and Stephen Smith. Our 2020 virtual summer interns - Sidi Cheng, Zhiyan Guo, Matthew Riddell, Maggie Wolf, Lana Yang-Maccini, and Pu (Priscilla) Zhao - gave us vital help with data entry. We appreciate the cooperation of World Education Inc./Bantwana, in particular Prince Mulondo Yosia, Karen Rowe, Tawanda Madhangi, and Obert Darara. This study's protocols were approved by Institutional Review Boards (IRBs) in Mozambique (Ministry of Health, approval number 2233/GMS/002/016) and at the University of Michigan (Health Sciences and Social and Behavioral Sciences IRB, approval number HUM00115541). Empirical analyses were pre-specified in a pre-analysis plan submitted to the American Economic Association's RCT Registry (AEARCTR-0003990). This research was funded by the United States Agency for International Development via the BASIS research program at University of California, Davis (grant numbers AID-OAA-L-12-00001, AIDOAALA-16-0004, and AID391A1500006). The views expressed herein are those of the authors and do not necessarily reflect the views of the National Bureau of Economic Research.

NBER working papers are circulated for discussion and comment purposes. They have not been peer-reviewed or been subject to the review by the NBER Board of Directors that accompanies official NBER publications.

(C) 2021 by Dean Yang, James Allen IV, Arlete Mahumane, James Riddell IV, and Hang Yu. All rights reserved. Short sections of text, not to exceed two paragraphs, may be quoted without explicit permission provided that full credit, including $(\subset)$ notice, is given to the source. 
Knowledge, Stigma, and HIV Testing: An Analysis of a Widespread HIV/AIDS Program

Dean Yang, James Allen IV, Arlete Mahumane, James Riddell IV, and Hang Yu

NBER Working Paper No. 28716

April 2021, Revised August 2022

JEL No. D10,D80,I12

\begin{abstract}
Using randomized methodologies, we study a common community HIV/AIDS program that seeks to promote HIV testing by improving knowledge and reducing stigmatizing attitudes. Contrary to expectations, the program has a substantial negative effect on HIV testing rates. We provide evidence of likely mechanisms behind the program's negative effect: it inadvertently increased misinformation about HIV transmission methods, and worsened HIV-related stigmatizing attitudes. Subsequent household-level randomized treatments providing correct information and addressing stigma concerns counteract the program's negative effect on HIV testing. These findings highlight the importance of improving knowledge and alleviating stigma concerns when promoting HIV testing.

Dean Yang

University of Michigan

Department of Economics and

Gerald R. Ford School of Public Policy

735 S. State Street, Room 3316

Ann Arbor, MI 48109

and NBER

deanyang@umich.edu

James Allen IV

Department of Economics and

Gerald R. Ford School of Public Policy

University of Michigan

735 S. State Street

Ann Arbor, MI 48109

alleniv@umich.edu

Arlete Mahumane

Beira Operational Research Center (CIOB)

Rua Correia de Brito 1323

Beira City

Sofala Province

Mozambique

cynthiwea@gmail.com

James Riddell IV

Department of Internal Medicine

University of Michigan Medical School

Ann Arbor, MI 48109

jriddell@umich.edu

Hang Yu

National School of Development

Peking University

hangyu@umich.edu
\end{abstract}

Research project website with supplementary material is available at https://fordschool.umich.edu/mozambique-research/fcc-hiv-aids 


\section{Introduction}

HIV testing plays a central role in global programs combating the HIV/AIDS pandemic (Granich et al., 2009). Widespread HIV testing in areas of high prevalence is important because people with HIV infection are often asymptomatic for years before the disease progresses to AIDS. When individuals are found to be infected with HIV, it is recommended that they immediately start antiretroviral therapy (ART) (WHO, 2017). Rapid initiation of ART lowers HIV plasma viral loads, providing private benefits for infected individuals in the form of better health outcomes (Ford et al., 2018). ${ }^{1}$ In addition, early initiation of ART has public health benefits due to a positive externality (Greenwood et al., 2019). During the asymptomatic phase, those with HIV infection can transmit HIV to others. Initiation of ART leads to reduced HIV viral loads and a much lower risk of transmitting HIV to sexual partners (Rodger et al., 2019).

While there has been substantial progress in expanding HIV testing around the world, testing rates remain far from achieving targets set by public health officials. The UN's 90-90-90 goals are widely-adopted objectives: $90 \%$ of people with HIV infection should be diagnosed, $90 \%$ of those diagnosed should be in treatment, and $90 \%$ of individuals in treatment should have an undetectable HIV viral load (United Nations, 2016). However, UNAIDS estimates that in 2019, of the 38 million people infected with HIV globally, about 7.1 million (19\%) are undiagnosed (UNAIDS, 2020).

We seek to shed light on the impact of a major type of HIV/AIDS program on HIV testing rates, and to understand the mechanisms underlying its effectiveness (or lack thereof). We focus on two mechanisms: alleviating imperfect information related to HIV and reducing HIV-related stigmatizing attitudes. We start with a simple theoretical model. Individuals decide whether to have an HIV test, trading off health benefits with social stigma costs of revealing one's HIV risk type to others. Individuals revealed to have high HIV infection risk are stigmatized (excluded from social interactions). Beliefs about HIV transmission affect the extent to which people are stigmatized if they are observed getting an HIV test and reveal themselves as having high risk of HIV infection. The less people believe that HIV is transmissible, the lower stigma, and the higher HIV testing. Conversely, if people believe that HIV is more transmissible, stigmatizing attitudes rise, and HIV testing falls.

With this model as a framework, we study a program in Mozambique, Força à Comunidade e Crianças (FCC, "Strengthening Communities and Children"), that aims to raise HIV testing rates by improving knowledge about HIV/AIDS and reducing HIV-related stigmatizing attitudes. FCC is a community-level program that implements home visits to households, as well as complementary interventions in communities and schools. The pro-

\footnotetext{
${ }^{1}$ In particular, treatment is significantly more complex, and mortality outcomes worse, when when HIV diagnosis is delayed and opportunistic infections develop (Simmons et al., 2013; Belay et al., 2017; Chen et al., 2017).
} 
gram is representative of a broad category of HIV/AIDS interventions, known as programs for "orphans and vulnerable children" (OVCs), that are funded by the U.S. Presidential Emergency Plan for AIDS Relief (PEPFAR). ${ }^{2}$

We designed a randomized controlled trial to estimate the causal impact of the FCC program on HIV testing rates and the mechanisms through which it operates. We specified our analyses in advance in a pre-analysis plan (PAP). The research design involves three stages of randomization, as presented in Figure 1. The sample is composed of 3,700 households that we have been following from a 2017-18 baseline through a 2019 endline survey. First, we randomized half of 76 communities to treatment (receiving the program) and half to the control group. Second, motivated by concerns about statistical power, we randomized a subset of households within treatment communities to a strong encouragement to participate in the FCC program ("FCC-enrolled" households). FCC-enrolled households received home visits by FCC community workers and were assessed for inclusion in various FCC components. FCC enrollment led them to have higher participation rates in the program than other households in treatment communities. ${ }^{3}$ An endline survey collected data on a range of household outcomes, including self-reported HIV testing in the household. As pre-specified, all treatment effects reported in this paper are the effect of being an FCCenrolled household in a treatment community, with the comparison group being households in control communities.

Immediately after the endline survey, our research staff then randomly assigned households to a set of "minitreatments" aimed at encouraging further HIV testing, or a minitreatment control group. The different minitreatments provide HIV-related information, seek to alleviate concerns about HIV-related stigma, and provide additional financial incentives for HIV testing. ${ }^{4}$ Our research staff implemented the minitreatment to which a household was assigned (if any), and then offered coupons to encourage household members to get HIV tests at the nearest health clinic. ${ }^{5}$

Our primary outcome of interest in this study is whether anyone in the household received an HIV test in the 14 days after the endline survey, measured by redemption of these encouragement coupons. As an administrative outcome, this measure of HIV testing is not subject to survey reporting biases. ${ }^{6}$

\footnotetext{
${ }^{2}$ PEPFAR is the world's largest source of funding for HIV/AIDS programs in developing countries (PEPFAR, 2020), with an annual budget ranging from $\$ 6.6$ to $\$ 6.9$ billion in 2015-2020 (US State Department, 2019).

${ }^{3}$ Other households not randomly selected for direct enrollment were exposed to the FCC program as well, but at lower rates. We pre-specified treatment effects on these "FCC-ambient" households as of secondary interest; results are presented in the Populated Pre-Analysis Plan (PAP). We provide the link to the Populated PAP in Section 5 below.

${ }^{4}$ The initial motivation for these minitreatments was to examine complementarity between the FCC program and more targeted interventions to raise HIV testing. As it turns out, these minitreatments end up revealing mechanisms through which the FCC program's (negative) effects on testing operate.

${ }^{5}$ Conditional on the individual getting an HIV test, the coupons were redeemable at the clinic up to 14 days later for a financial reward of 50 meticais (PPP US\$2.42).

${ }^{6}$ As pre-specified, we prioritize the coupon-redemption-based measure of HIV testing because treatment
} 
This research design yields several treatment effects. The treatment effect of primary interest is the impact of FCC enrollment on the coupon-based HIV testing measure. This is Comparison A in Figure 1, the testing rate of FCC-enrolled households in treatment communities who did not receive any minitreatments, minus the testing rate of households in control communities who also did not receive any minitreatments. This is the "pure" effect of the FCC program that is not clouded by any effects of minitreatments.

We find that the FCC program has a negative effect on HIV testing: -10.9 percentage points, relative to a base of 26.3 percent in the control group. This result is contrary to our pre-specified expectation of a positive impact on HIV testing. It is also contrary to the positive impact expectations of 73 experts surveyed in advance by DellaVigna et al. (2020) before our results were publicly known.

In pre-specified secondary analyses, we shed light on mechanisms behind the FCC program's negative effect on HIV testing. These analyses estimate the Comparison B treatment effect in Figure 1, comparing FCC-enrolled households in treatment communities with all households in control communities. Outcomes are potential mechanisms measured in the endline survey. ${ }^{7}$ We find that the program did not improve HIV-related overall knowledge, and in fact increased misinformation. Treated respondents became more likely to believe "myths" about HIV transmission (e.g., that HIV can be spread by shaking hands or by witchcraft). In addition, the program actually worsened HIV-related stigmatizing attitudes, measured by answers to survey questions on HIV-related stigma (such as whether one would buy vegetables from an HIV-positive vendor, or thinks that an HIV-positive person should be a teacher).

These findings are suggestive that the FCC program's negative impacts are due to worsened information and increased stigma. However, simply showing that the treatment leads to worsened information and increased stigma does not establish with certainty that these are mechanisms behind the program's impacts, since these outcomes could co-move with HIV testing without being mechanisms in the causal chain linking FCC enrollment with testing. The minitreatments we implemented after the endline survey provide more direct evidence that changes in information and stigma are mechanisms behind the FCC program's negative impact on testing.

The minitreatments provided information about HIV; information about HIV treatment (ART); both HIV and ART information; information to reduce concerns about HIV-related stigma; and a higher financial incentive to receive an HIV test. ${ }^{8}$ There was also a control

effects using this measure differ from treatment effects on self-reported HIV testing from the endline survey. Treatment effects on self-reported HIV testing are significantly more positive, likely due to experimenter demand effects.

${ }^{7}$ Comparison B is the appropriate comparison for the outcomes in the endline survey, as it maximizes sample size; the minitreatments were implemented after the endline survey and therefore cannot affect endline survey outcomes.

${ }^{8}$ The higher financial incentive for this minitreatment was 100 meticais per coupon, double the incentive offered to all other households. 
group that got no minitreatment. In analyses that were also pre-specified, we examine how these treatments affect the coupon-based measure of HIV testing. In Figure 1, these analyses involve comparing households in the grey-shaded "Pure Control" box among FCC-enrolled households (FCC-enrolled households receiving no minitreatment) with households in the five boxes just below it (FCC-enrolled households assigned to some minitreatment).

The minitreatments counteract the negative effect of the FCC program. Among FCCenrolled households, those getting an information minitreatment or the anti-stigma minitreatment have substantially higher HIV testing rates than the minitreatment control group. These findings further support the interpretation that the FCC program caused lower HIV testing by worsening knowledge and increasing stigmatizing attitudes; minitreatments targeting these mechanisms helped reverse the FCC program's negative effects on HIV testing.

Overall, our theoretical model encapsulates the mechanisms behind our empirical findings. The FCC program led to misinformation about the transmission of HIV, which worsened stigmatizing attitudes, and led to lower HIV testing rates. Minitreatments aimed at improving HIV-related information and reducing stigmatizing attitudes raised HIV testing rates.

Before our empirical results were known, we submitted the methods and data analysis plan for this study as a pre-results review paper to the Journal of Development Economics (JDE). The JDE accepted our pre-results review paper, committing to publish the complete paper with empirical results (regardless of the actual findings) as long as the treatments and data collection were implemented as pre-specified. We then submitted the JDE-accepted pre-results review paper as a pre-analysis plan (PAP) to the AEA RCT Registry. We implemented the treatments and data collection as pre-specified, and this paper is the complete paper with empirical results.

In this paper, we do depart from the pre-specified set of analyses by presenting a subset rather than all the analyses detailed in the JDE Stage 1 Proposal. We report all primary analyses detailed in the JDE Stage 1 Proposal, but only a selection of secondary analyses. We concisely overview the other secondary analyses in Section 5.3, and more fully in a Populated PAP (following Duflo et al. (2020)). We present only a subset of pre-specified results because of the unexpected negative treatment effect on our primary outcome of interest (HIV testing), which led us to focus on explaining potential mechanisms behind this unexpected result. We therefore focus in the paper on analyses of those potential mechanisms - HIV/AIDS-related information and stigmatizing attitudes. We report results for other secondary outcomes that are unlikely to represent potential mechanisms in the Populated PAP. ${ }^{9}$

The main contribution of this paper is to provide evidence on the importance of two intermediating mechanisms behind the efficacy of HIV/AIDS public health initiatives. We

\footnotetext{
${ }^{9}$ We find zero treatment effects on these other secondary outcomes; discussing those findings only in the Populated PAP therefore also helps streamline the paper.
} 
highlight the importance of 1) public health information, and 2) concerns about diseaserelated stigma. Our work is related to a large existing literature studying the role of information in health decision-making, and a much smaller literature on how stigma affects health decisions.

Studies of the role of information imperfections in health decision-making are reviewed by Dupas and Miguel (2016). In the HIV/AIDS context, provision of general HIV/AIDS information has been shown to affect knowledge, health behaviors, and demand for health goods (Duflo et al., 2015; Dupas, 2011; Godlonton et al., 2016; Ciancio et al., 2020; Kim et al., 2017; Chong et al., 2013; Banerjee et al., 2020). Smith et al. (2021) find that providing information that HIV treatment helps prevent transmission leads to higher HIV testing rates (Bor et al. (2021) provide a review of "treatment-as-prevention" interventions). Other studies have examined the impact of learning one's own HIV infection status (Delavande and Kohler, 2012; Gong, 2015). Our study is novel in finding that a major type of HIV/AIDS program can create misinformation. As such, our findings concord with the smaller number of studies that find that informational HIV/AIDS interventions can lead to misinformation or have harmful effects (Jamison et al., 2013; Godlonton et al., 2016; Friedman, 2018).

While there has been a great deal of interest in stigma in the context of the HIV/AIDS pandemic,${ }^{10}$ economics research on the topic is scarce. ${ }^{11}$ Prior work using randomized or experimental methodologies has shown that interventions can reduce HIV-related stigmatizing attitudes (Hoffmann et al., 2016; Lubega et al., 2019), thereby leading to higher rates of HIV testing (Derksen et al., 2020; Yu, 2021). Relative to this literature, our work is novel in finding that a major type of widely implemented HIV/AIDS program can actually worsen HIV-related stigmatizing attitudes, and that a simple anti-stigma intervention implemented later can offset the program's negative impacts on HIV testing.

This research also contributes to economic research on large-scale HIV/AIDS programs, of which PEPFAR is the largest funder worldwide. FCC is a representative example of PEPFAR programs for orphans and vulnerable children (OVC). U.S. law requires PEPFAR to spend $10 \%$ of its budget on OVC programs (US State Department, 2015). Among OVC programs, FCC is emblematic in key ways. The program delivers a multifaceted array of services through schools, as cornerstone institutions in communities. These school-based programs operate alongside household-level case management: visits to households by program workers who deliver informational and anti-stigma messaging, encourage HIV testing, assess household needs, and connect households and individuals with appropriate program components (USAID, 2012; US State Department, 2019).

Prior studies of PEPFAR programs have not exploited prospectively randomized research

\footnotetext{
${ }^{10}$ Mahajan et al. (2008) and Stangl et al. (2013) review public health research on HIV/AIDS stigma.

${ }^{11}$ Economists have studied stigma in other contexts (Moffitt, 1983; Vishwanath, 1989; Akerlof et al., 1996; Furuya, 2002; Ishida, 2003; O'Flaherty and Sethi, 2008; Bharadwaj et al., 2017); see Durlauf and Blume (2008) for a review.
} 
designs. In addition, past studies have not tracked defined households or individuals over time (from before to after program implementation), raising concerns about sample selection biases (Bryant et al., 2012). Bendavid et al. (2012) examine the impact of PEPFAR funding at the country level using a difference-in-difference approach, finding substantial reductions in adult mortality in Africa. A number of past studies have used randomized controlled trials to examine the impact of more targeted interventions related to HIV/AIDS, such as Thornton (2008), McCoy et al. (2017), Ssewamala et al. (2009), Ivers et al. (2014), Baird et al. (2011), Kiene et al. (2017), and Yotebieng et al. (2017). None of these have studied PEPFAR or community-level programs, or examined the interplay between knowledge, stigma, and HIV testing as we do.

\section{Theoretical Model}

We model the HIV testing decision as a one-sided signaling game with two players over two periods. Our model is a simplified version of the model in Derksen et al. (2020). Rational individuals decide whether to test for HIV. The benefit of testing is initiating treatment if one tests positive. The cost of testing includes revealing to others that one has a high probability of having HIV, and experiencing stigma as a result. We model stigma as being excluded from social interactions with others. Beliefs about HIV transmission affect the extent to which people are stigmatized (excluded from social interactions) if they are believed to at high risk for having HIV. If people start to believe that HIV is less transmissible, this leads to less stigma, and higher HIV testing.

Consider two players, $A$ and $B$, from two continua of individuals $\mathcal{A}=[0,1]$ and $\mathcal{B}=$ $[0,1]$, respectively. Each player $A$ has private information about his own type $\left(\theta_{a}, y_{a}\right) . \theta_{a}$ represents $A$ 's probability of being HIV-positive and it takes two values: $\theta_{a} \in\left\{\theta_{L}, \theta_{H}\right\}$, $0<\theta_{L}<\theta_{H}<1$ (low and high risk, respectively). The fraction of $\mathcal{A}$ with $\theta_{a}=\theta_{H}$ is $r . y_{a}$ is player $A$ 's valuation of social engagement. Each player $B$ is known to be HIV-negative and has a private valuation of social engagement, $y_{b} . y_{a}$ and $y_{b}$ follows the same distribution $\mathcal{G}$ with a positive support $(\mathrm{y},+\infty) . r$ and $\mathcal{G}$ are common knowledge.

In the first period, player $A$ decides whether to take an HIV test. $A$ 's action can be observed by individuals in $\mathcal{B}$. Player $A$ is then randomly matched with a player $B$ in a social activity. In the second period, player $B$ decides whether to interact with player $A$ (social inclusion) or not (social avoidance). We denote $A$ 's action as $t_{a} \in\{0:$ do not test, $1:$ test $\}$ and $B$ 's action as $m_{b} \in\{0:$ do not interact, $1:$ interact $\}$.

In period 1, player $A$ 's direct cost for taking a test is $c . c$ summarizes time and monetary costs as well as physical and psychological costs associated with the trip to taking a test. If testing positive, player $A$ receives ART treatment which brings a health benefit of $v .{ }^{12}$

\footnotetext{
${ }^{12}$ ART is only offered to those who are tested HIV-positive, and when offered, ART is free of charge.
} 
We denote $A$ 's real HIV status as $h_{a}$, which takes value 1 if positive and 0 if negative. The payoff for $A$ in period 1 is given by

$$
u_{a}^{1}\left(t_{a}\right)=t_{a}\left(h_{a} v-c\right) .
$$

The expected gain in period 1 for taking a test, $\mathbb{E}_{h_{a}}\left[u_{a}^{1}(1)-u_{a}^{1}(0)\right]$, is equal to $\theta_{a} v-c$. We make the following assumptions to restrict the parameter values:

$$
\begin{gathered}
\theta_{L} v<c<\theta_{H} v \\
\mathrm{y}<\theta_{H} v-c
\end{gathered}
$$

Assumption (1) states that a low-risk $\left(\theta_{a}=\theta_{L}\right)$ person does not have a high enough health-related incentive to take a test, but a high-risk person does. Assumption (2) means that the health benefit of testing is higher than the value of social engagement for at least some high-risk $A$.

In period 2, player $B$ forms a belief about $\theta_{a}$ based on the observed $t_{a}, \hat{\theta}_{b}\left(t_{a}\right)$. If $B$ chooses to interact with $A$, both players will receive utility from social engagement but $B$ also faces a cost due to potential HIV transmission from $A$. We denote $B$ 's perceived HIV transmission probability as $\hat{\tau} \in[0,1]$, and her health cost from HIV infection as $z$. If $B$ chooses not to interact, both players obtain no utility in this period. To sum up, in period 2 , player $A$ 's payoff is

$$
u_{a}^{2}\left(m_{b}\right)=m_{b} y_{a}
$$

and player B's payoff is

$$
u_{b}^{2}\left(m_{b}\right)=m_{b}\left[y_{b}-\hat{\tau} \hat{\theta}_{b}\left(t_{a}\right) z\right]
$$

We make further assumptions to bound parameter values:

$$
\operatorname{Pr}\left(y_{b}>\hat{\tau} \bar{h} z\right)=1 \text { and } \operatorname{Pr}\left(y_{b}<\hat{\tau} \theta_{H} z\right)>0,
$$

which means that no one in $\mathcal{B}$ would reject an unknown person from the general population, $\mathcal{A}$, for fear of HIV transmission; but at least some would avoid social interactions with a person of high risk.

Overall, the payoff function for player $A$ is ${ }^{13}$

$$
U_{a}=u_{a}^{1}\left(t_{a}\right)+u_{a}^{2}\left(m_{b}\right) .
$$

\footnotetext{
${ }^{13}$ Without loss of generality, we assume the intertemporal discount factor to be 1 .
} 
Proposition 1 There are two classes of pure strategy Perfect Bayesian Equilibria in this game. The first is a partially separating equilibrium. A fraction $S$ of individuals in $\mathcal{B}$ discriminate: they avoid $A$ who has sought an HIV test. The remaining fraction $(1-S)$ of individuals interact with any $A$. The second is a pooling equilibrium. A fraction $P$ of individuals in $\mathcal{B}$ interact if and only if $A$ has sought an HIV test.

In what follows, we characterize the partially separating equilibrium of the game where stigmatizing behavior (social avoidance) occurs, and defer the formal proof of Proposition 1 to the Appendix A.

First, consider player $A$ 's optimization problem given $S$. A chooses to take an HIV test or not to maximize his expected utility $\mathbb{E}_{h_{a}, m_{b}}\left[U_{a}\right]$ :

$$
\max _{t_{a} \in\{0,1\}}\left(\theta_{a} v-c-S y_{a}\right) t_{a}+y_{a} .
$$

His optimal strategy is to test if and only if

$$
y_{a}<\frac{\theta_{a} v-c}{S} .
$$

Combining Assumption (1), (2), and that $y_{a}>0$, we know that a player $A$ with $\theta_{a}=\theta_{L}$ never takes a test; and that some $\theta_{a}=\theta_{H}$ will take a test. Player $B$, with Bayesian updating, forms the belief of $\hat{\theta}_{b}\left(t_{a}\right)$ accordingly:

$$
\hat{\theta}_{b}(1)=\theta_{H} ; \hat{\theta}_{b}(0)<\bar{h} .
$$

Given $A$ 's strategy, now consider $B$ 's optimization problem. $B$ chooses $m_{b} \in\{0,1\}$ to maximize the payoff as in (3):

$$
\max _{m_{b} \in\{0,1\}} m_{b}\left[y_{b}-\hat{\tau} \hat{\theta}_{b}\left(t_{a}\right) z\right] .
$$

By Assumption (4) and belief (5), we know that when $t_{a}=0, B$ 's best response is $m_{b}=1$; while when $t_{a}=1, B$ 's best response is to interact if and only if

$$
y_{b}>\hat{\tau} \theta_{H} z
$$

Thus,

$$
S=\int_{\mathrm{y}}^{\hat{\tau} \theta_{H} z} \mathrm{~d} \mathcal{G} .
$$

Proposition 2 directly follows from (6).

Proposition 2 Stigmatization $S$ becomes more (less) severe as individuals' perceived HIV transmission risk $\hat{\tau}$ increases (decreases). 
In this equilibrium, the testing rate among the population $\mathcal{A}$ is given by

$$
R_{t}=r \int_{\mathrm{y}}^{\frac{\theta_{H} v-c}{S}} \mathrm{~d} \mathcal{G} .
$$

Expression (7) leads to the following proposition.

Proposition 3 A higher (lower) rate of stigmatization $S$ suppresses (encourages) HIV testing.

In sum, with knowledge (beliefs about the transmission of HIV) having such a central role in raising HIV testing, much can go wrong if a program inadvertently fails in its knowledgeraising objective, and instead creates misinformation. For example, a program could lead people to mistakenly believe that HIV is transmissible via mechanisms such as shaking hands or sharing food (which is not the case). If a program thereby leads people to believe that HIV is more transmissible, more people come to stigmatize those infected with HIV, and HIV testing falls. We now turn to the empirical analysis of the FCC program, which we interpret in the context of this model.

\section{Research Design}

\subsection{Country and Program Context}

Out of an estimated 36.9 million people living with HIV worldwide in 2017, 25.7 million are in Sub-Saharan Africa. The region also accounts for a dominant share of new HIV infections: 1.17 million out of a global 1.8 million in that year. In Mozambique in 2017, 2.1 million people out of a population of 29.7 million were living with HIV (7.1\%), out of which 170,000 were children (aged 14 or below). The country has an estimated 130,000 new HIV infections annually, of which $13.8 \%$ are children. Mozambique recorded 70,000 AIDS-related deaths in 2017, likely because only slightly more than half of HIV-infected patients have access to antiretroviral therapy (ART). Poor access and adherence to ART contributes to AIDS-related morbidity and mortality, as well as HIV transmission (to other adults as well as from mothers to children) (UNAIDS, 2019). Only an estimated $77 \%$ of Mozambicans with HIV infection know their status (UNAIDS, 2020). In our own Mozambican sample, nearly half of adults and $90 \%$ of children are reported to have never been tested for HIV.

The U.S. Government's most important program responding to the HIV/AIDS crisis is the President's Emergency Plan for AIDS Relief (PEPFAR). PEPFAR mandates that $10 \%$ its funding be devoted to programs benefiting children orphaned or made vulnerable by HIV/AIDS ("orphans and vulnerable children," or OVCs). ${ }^{14}$ In 2016, PEPFAR OVC

\footnotetext{
${ }^{14}$ The UN defines an "orphan" as a child who has lost one or both parents. An estimated 13.4 million
} 
programs supported 6.2 million OVCs and their caregivers worldwide (PEPFAR, 2017). ${ }^{15}$

\subsection{The Program}

The program we study, Força à Comunidade e Crianças (FCC, "Strengthening Communities and Children"), is a representative example of PEPFAR OVC programs. Its high-level aim is to improve families' and communities' ability to support, protect, and care for orphans and vulnerable children, their caregivers, and their households more generally.

The FCC program is composed of a number of interrelated components and is implemented in study districts by local implementing partner (LIP) organizations under contract to the international NGO World Education Inc. (WEI/Bantwana). ${ }^{16}$ Several FCC program components are school-based, and so programs are implemented in local communities surrounding a focal school. In each community, activities take place with the collaboration and advice of a Community Child Protection Committee (CCPC) whose membership includes community leaders, volunteers, and local government officials. ${ }^{17}$

The most widespread FCC program component is home visits by LIP staff known as "Case Care Workers" (CCWs) to households. Roughly $700 \mathrm{CCWs}$ work across the study communities. LIPs hire CCWs locally, in part based on recommendations by the CCPC and community leaders. In common with the local populations they serve, they typically have no more than a primary school education. Roughly $80 \%$ of CCWs are female. They range in age from 18 to 48, with most falling between 25 and 40 years of age. CCWs receive a stipend of 3,100 MZN per month (roughly US\$150), as well as in-kind compensation in the form of a bicycle, a work uniform, and cellphone airtime.

CCWs conduct home visits of OVC households, based on personal knowledge and recommendations of the CCPC. ${ }^{18}$ The home visit itself is a conduit for the dissemination of information and advice by CCWs. Household members may then participate in other FCC components, based on the results of the home visit. In home visits, CCWs conduct systematic vulnerability assessments, and households (and individuals therein) are then linked to appropriate programs and services in communities, schools, and health facilities. One of the most important results of these home visits is the referrals of individuals for HIV

children and adolescents (0-17 years of age) worldwide had lost one or both parents to AIDS as of 2015 . More than $80 \%$ of these children (10.9 million) live in sub-Saharan Africa (UNICEF, 2016). PEPFAR's 2008 reauthorization mandated it to spend $10 \%$ of its funds on OVC programs. PEPFAR OVC funding amounted to $\$ 3.58$ billion in total from 2015-2020 (PEPFAR (2017), PEPFAR (2020)).

${ }^{15}$ Reviews of research on OVCs include Bryant and Beard (2016), Goldberg and Short (2016), Nyberg et al. (2012), and Shann et al. (2013). Also see Evans and Miguel (2007), Case et al. (2004), Larson et al. (2013), and Whetten et al. (2015).

${ }^{16}$ LIPs are local non-government organizations (NGOs) operating in study areas.

${ }^{17}$ Program provinces and districts are: Manica province (Manica, Chimoio, and Gondola districts), Sofala province (Dondo and Nhamatanda districts), and Zambezia province (Namacurra and Nicoadala districts).

${ }^{18}$ CCWs were provided with a detailed "Home Visit Guide" detailing information they are expected to convey to households, covering health (HIV/AIDS in particular), education, nutrition, infant care, legal rights, savings, and psychosocial help. The home visit guide is included as part of our pre-analysis plan (PAP) at our AEA RCT Registry entry (https://doi.org/10.1257/rct.3990-5.0). 
testing at the local PEPFAR-funded health clinic. The expectation is that CCWs refer all FCC program beneficiaries (both adults and children of all ages) who do not know their HIV status for HIV testing, and that testing should be repeated every twelve months even upon a negative test result. The number of individuals referred to HIV testing is a key outcome indicator for the FCC program, monitored by PEPFAR in the context of achieving the UNAIDS 90-90-90 global goals (90\% of those with HIV diagnosed, $90 \%$ of those on ART, and $90 \%$ of those virally suppressed by 2020) (PEPFAR, 2017). Those testing positive for HIV are then referred to initiate antiretroviral therapy (ART) through the local clinic. CCWs in the community then follow up with individuals initiating ART to promote ART adherence on an ongoing basis. Because of the centrality of encouraging HIV testing in the FCC program, it is the primary outcome of interest in this study.

During home visits, CCWs seek to increase HIV testing rates via two mechanisms we examine explicitly: improving information and reducing stigma concerns. CCWs seek to improve FCC beneficiaries' information related to HIV/AIDS, such as methods of disease transmission, progression of the disease, treatment, HIV testing, and locations of health

clinics providing testing and treatment. Information is conveyed verbally and, at the LIP's discretion, on printed material given to the household. In addition, CCWs are expected to engage program beneficiaries in "sensitization" to address stigma related to HIV (both one's own stigmatizing attitudes, and fear of stigma from others). CCWs engage in discussions to reduce stigmatizing attitudes among program beneficiaries. They provide psychosocial support (PSS) and gradually gain program beneficiaries' trust over time in repeated interactions, with the expectation that reductions in fear of stigma will encourage people to be open to HIV testing, voluntarily disclose HIV-positive status to CCWs, and be open to future CCW follow-up promoting ART initiation and adherence.

Households are connected to other FCC program components after the home visits, based on needs assessments conducted by CCWs. These program components include Village Savings and Loan (VSL) groups and nutritional screenings of children. Many components are school-based, so children can also be included in these components through their schools. Relatively few households report participating in these other program components. For further details on these other program components, see Appendix B.

\subsection{Sample and Data}

The study timeline is shown at the bottom of Figure 1, illustrating key points in data collection and the randomized interventions. We provide an overview of data collection here, and provide details in Appendix C.

In the 76 study communities, we selected households for inclusion in the sample using random-route sampling, with route starting points at the focal school in each community. In keeping with the focus on the FCC program, we administered a "vulnerability assessment" 
(designed jointly with WEI/Bantwana) to identify OVC households. $71.68 \%$ of households were determined to be OVC households and were administered informed consent. If granting consent, they were included in our study sample. The vulnerability assessment and consent process for inclusion in the study sample occurred from May to November 2017. A subset of consenting households were randomly selected to be administered a comprehensive baseline survey, which was administered from May 2017 to March 2018. The primary role of the baseline survey in the study is as the source of data on HIV-related stigmatizing attitudes in the community for the anti-stigma minitreatment.

We administered an endline survey from May to November 2019. In both the baseline and endline surveys, the primary survey respondent is the head of household. For some questions (in particular, self-reported HIV testing, HIV knowledge, and HIV-related stigmatizing attitudes) we also surveyed other adults who were present at the time of the survey. The sample is composed of 3,658 households included in the endline survey. Household-level outcomes are reported by the primary household respondent or by aggregating reports of surveyed individuals.

The primary outcome of interest in this study is HIV testing at the household level. We focus on an objective, administrative measure of HIV testing by our study participants. ${ }^{19}$ At the end of the endline survey, our survey team recommended that individuals in the household be tested for HIV (if they had not had a test performed within the past three months) at their local health clinic within the next 14 days. Local health clinics in each study community collaborated with us to conduct the HIV testing and facilitated collection of testing data. To allow tracking of those who followed through with testing, households were given coupons redeemable for a financial incentive $(50 \mathrm{MZN})$ at the health clinic after having the HIV test. ${ }^{20}$ Coupons had a unique code for each household, allowing us to track their redemption. Households were given as many coupons as needed, for however many individuals did not know their status or who reported being HIV negative but were tested more than three months in the past. ${ }^{21}$ To receive the financial incentive after having their HIV test, individuals had to present the coupon to our research staff (also stationed at the health clinic), along with a form signed by clinic staff that the individual had just gotten an HIV test.

An indicator for at least one of a household's coupons being used (indicating at least one household member had an HIV test in the 14-day window after the endline survey) is our primary outcome variable. Because this outcome is a directly-observed, admin-

\footnotetext{
${ }^{19}$ This approach follows Kranzer et al. (2017).

${ }^{20} \mathrm{PPP} \$ 1$ was equal to 20.62 meticais (MZN) in 2018. $50 \mathrm{MZN}$ is approximately the daily cost of living for a poor household in Mozambique. In Mozambique, $62.4 \%$ and $81.5 \%$ of the population are under the $\$ 1.90$ and $\$ 3.20$ (2011 PPP) per day poverty thresholds, respectively (World Bank, 2020), and our study households are typically below these thresholds.

${ }^{21}$ We gave out a total of 11,304 coupons to individuals in the sample households. Of these, $28.6 \%$ were redeemed.
} 
istratively recorded health behavior, it avoids potential reporting biases associated with survey-reported HIV testing. Conceptually, it captures a household's receptiveness to a recommendation to be HIV tested. Programs such as FCC aim to not only facilitate an individual's first HIV test, but also to encourage individuals to be receptive to regular, repeated testing (consistent with Mozambican public health recommendations).

As a secondary outcome, we examine a self-reported measure of HIV testing: an indicator for anyone in the household having had an HIV test in the previous 12 months, reported in the endline survey (self-reported by adults, and reported by the primary caregiver for children under the age of 18). Prioritizing the coupon-based measure of HIV testing over the self-reported measure follows a decision rule we pre-specified in our PAP, stemming from the fact that treatment effects differ across the two measures (see section 4.2 below).

We also examine secondary outcome variables related to information and stigma mechanisms, reported in the endline survey. These outcomes are at the individual level, for all adult respondents of the endline survey. The information questions assess objective knowledge about HIV: correct transmission methods, incorrect transmission methods ("transmis-

sion myths"), protection methods, and treatment. Stigma questions measure stigmatizing attitudes towards HIV-positive individuals (would buy food from HIV-positive seller, would allow HIV-positive teacher, would keep a relative's HIV-positive status secret, would care for HIV-positive relative). The questions measuring stigmatizing attitudes are adopted from the AIDS Indicator Survey of the DHS Program, which have been used in Mozambique as well as other DHS countries since 2003 (INS, 2017). Figure 2 shows how responses to these questions have been evolving over time. There has been a substantial increase in HIVsupportive attitudes (reductions in stigma) in recent years for three of the questions, but increasing stigmatizing attitudes for the fourth (on keeping a relative's HIV-positive status secret). Please see Appendix D for the full list of information and stigma questions.

\subsection{Methodology}

We aim to estimate causal effects of the FCC program using a randomized controlled trial (RCT) methodology. Random assignment allows estimated relationships to be interpreted as causal effects, rather than simply correlations. Our approach involves a three-stage randomized controlled trial methodology to estimate causal effects of the FCC program, and to shed light on some of the mechanisms through which its effects operate.

Figure 1 displays the research design and timeline of the study. In November 2016, we randomly assigned 76 communities to be FCC treatment communities or control communities (Randomization Stage 1), after which WEI/Bantwana initiated the program in FCC treatment communities. FCC beneficiary counts in WEI/Bantwana's data indicate relatively smooth enrollment of FCC beneficiaries across quarters, from Q1 (Jan-Mar) 2017 to Q1 (Jan-Mar) 2018. The program then continued serving beneficiaries, remaining active 
through the period of our endline survey.

We administered informed consent and included households in the study sample from May to November 2017 for $98.7 \%$ of our eventual sample. ${ }^{22}$ Appendix Figure A.1 displays the number of households that were enrolled in the study sample by month. WEI/Bantwana's data indicate that about two-thirds to three-quarters of eventual FCC beneficiaries (depending on program subcomponent) had received their first contact with the program by Q3 (Oct-Dec) 2017. The fact that household enrollment into the study occurred after initiation of FCC program activities raises potential concerns about selection into treatment communities. We show in Section 5.1.1 below that observable characteristics of households show no relationship with FCC treatment, and that there is no impact of treatment on in-migration into treatment communities.

After households were enrolled in the study, households in treatment communities were randomly assigned to FCC-enrolled vs. FCC-ambient status (Randomization Stage 2), and afterwards CCWs conducted home visits to FCC-enrolled households. We implemented the endline survey from May to November 2019. At the end of the endline survey we randomly assigned households to the minitreatments (Randomization Stage 3) and offered all households encouragement coupons for HIV testing. We collected the HIV testing encouragement coupons up to each community's deadline (14 days after conclusion of the endline survey in a community). We now discuss each of the three stages of randomization in detail.

\section{Randomization Stage 1: Assigning FCC and Control Communities}

The FCC program is a community-level intervention, so the first stage was random selection of communities to receive or not receive the FCC program. FCC interventions are centered in primary and secondary schools, so geographic areas of interest are residential areas surrounding schools. (We refer to areas surrounding schools simply as "communities", each of which has a "focal school" where school-based program components are implemented.) WEI/Bantwana consulted with local implementing partners (LIPs) and government officials in the three provinces and seven districts in which the FCC program was to be implemented to identify a set of 76 communities deemed eligible for the program. These communities were chosen on the basis of being geographically proximate to ART sites (health clinics offering HIV testing and treatment), having sufficient populations of orphans and vulnerable children (OVCs), and having no other active donor funded HIV/AIDS programs. These 76 communities were then sorted into stratification cells of matched community pairs, sets of two communities that were very similar in terms of distance to ART sites, school type (secondary or primary), and student enrollments.

Within each matched pair, treatment status was randomly assigned to one community,

\footnotetext{
${ }^{22} 46$ households in one community (1.3\% of the sample) were enrolled in Mar 2018 due to an implementation error. For simplicity we refer to May-Nov 2017 as our household enrollment period.
} 
with the other school assigned to control status. Randomization of treatment status within matched pairs helps ensure balance in baseline characteristics between treatment and control units, so that treatment-control comparisons can then be credibly interpreted as causal effects of the program. This random assignment was carried out on the computer of one of the coauthors, one time, with no re-randomization. We communicated the result of the randomization to WEI/Bantwana in November 2016. The FCC program was then implemented in treatment communities, and not in control communities. Maps of the locations of FCC treatment and control communities can be found in Appendix E.

\section{Randomization Stage 2: FCC Enrollment within FCC Communities}

The second stage of randomization, at the household level, was implemented only within treatment communities. This randomization stage was motivated by concerns that treatment effect estimates based on generally comparing households in treatment and control communities would have low statistical power (because of low penetration of the program in treatment communities). This stage of randomization creates a subgroup in treatment communities, FCC-enrolled households, with relatively high take-up or participation in the FCC program. Estimates of the impact of the FCC program comparing FCC-enrolled households to households in control communities, therefore, have higher statistical power.

Among households in FCC communities who consented and were included in the study sample, a subset was randomly assigned to "FCC enrolled" status. GPS coordinates and household head's name and contact information of FCC-enrolled households were provided to WEI/Bantwana and their local implementing partners (LIPs). LIP staff (case care workers, CCWs) then conducted home visits to these households.

We carried out the randomization one FCC community at a time, with no re-randomization, on the computer of one of the co-authors, in November and December 2017. ${ }^{23}$ Seven-twelfths (58.33\%) of study households in each FCC community were assigned to FCC-enrolled status. ${ }^{24}$ Other households not randomly selected for direct enrollment, which we refer to as "FCC-ambient", end up being exposed to the FCC program at lower rates.

CCWs conducted home visits with FCC-enrolled households alongside their broader FCC responsibilities over the course of the following several months. Our research team supported LIPs with training in use of GPS devices to locate households using latitude and longitude

\footnotetext{
${ }^{23}$ By November 2017, we had completed all enrollments of households in the study sample necessary for randomization of FCC-enrolled status (Randomization Stage 2). The implementation of Randomization Stage 2 was spread out over November and December 2017, as we completed data cleaning and finalized the study sample before implementing the randomization, community by community. The one community whose 46 household study enrollments were delayed until March 2018 happened to have been a control community, so there was no Randomization Stage 2 for that community.

${ }^{24}$ Because the FCC-enrolled treatment was to be of primary interest, we chose to have the probability of FCC enrollment be slightly above half, to increase our statistical power to detect the FCC-enrolled treatment effect. The probability of seven-twelfths derived from the ratio of 35 out of 60 households in the targeted endline survey sample in each community. Due to attrition, we have fewer than 60 households per community in the ultimate sample for analysis in this paper.
} 
coordinates. WEI/Bantwana reported that CCWs had completed home visits to $44 \%$ of FCC-enrolled households by February 2018. This figure rose to $64 \%$ by May 2018, and $77 \%$ by their final update to our research team in November 2018 (six months before the start of the endline survey).

We pre-specified in our PAP that the causal effect of FCC-enrollment would be of primary interest, while the causal effect of FCC-ambient status would be of secondary interest. In this paper, we focus on effects of FCC-enrollment, and report FCC-ambient effects in overview in Section 5.3 below (with full detail in the Populated PAP).

\section{Randomization Stage 3: The Minitreatments}

In the third part of our randomized methodology, after households completed the endline survey, we randomly assigned them to one of five treatment conditions or a control condition. We refer to these post-endline-survey treatments as "minitreatments". The outcome variable of interest for the minitreatments is the redemption of the incentive coupon for HIV testing. This outcome is the only HIV testing outcome we observe after the minitreatments, because the self-reported measure is collected in the endline survey itself.

We originally conceived of these minitreatments as providing insight into whether the FCC program is complementary with or substitutable for more targeted interventions to promote HIV testing. The minitreatments turn out to help reveal likely mechanisms through which the FCC program's (negative) effects operate.

The minitreatments were randomly assigned, and then implemented by the same research staff member who had just administered the endline survey to the respondent. ${ }^{25}$ For further information about these treatments (including links to videos), please see Appendix F.

1. Anti-Stigma: Individual-specific information aimed at reducing concerns about HIVrelated stigma in the community. Past surveys in Mozambique have shown that many stigmatizing attitudes have fallen over time, as depicted in Figure $2 .{ }^{26}$ However, individuals tend not fully realize this. In a companion paper to this study in an overlapping sample, Yu (2021) shows that correcting such overly-pessimistic beliefs about stigma can encourage HIV testing. ${ }^{27}$ We ask endline-survey respondents about the fraction of

\footnotetext{
${ }^{25}$ When we started the endline survey, we had IRB approval for only the anti-stigma (item 1 below), HIV/AIDS information (2), and ART information (3) minitreatments, and were awaiting IRB approval of an amendment to add two additional treatments: HIV/AIDS and ART information combined (4), and high incentive for HIV testing (5). For the first 14 study communities (659 households), households were randomly assigned with one-fourth probability each to minitreatments 1, 2, 3, or control (item 6 below). After approval of the IRB amendment adding minitreatments 4 and 5, in the remaining 62 communities (2999 households), households were randomly assigned with one-sixth probability each to minitreatments 1 through 5 or control (6).

${ }^{26}$ Figure 2 shows improvements over time in three out of the four stigma measures that have been consistently used in the past AIS surveys. The anti-stigma minitreatment focuses on the three measures for which we can deliver positive news about the absence of HIV-related stigma. For each of these three questions, we correctly report that majorities in one's community have supportive (non-stigmatizing) attitudes.

${ }^{27}$ Similar "norm-based" interventions have been studied in contexts such as energy consumption (Schultz
} 
residents in their community they think hold specific stigmatizing attitudes towards people living with HIV. Respondents overestimating this fraction for any question are told the true (lower) value we collected from the baseline survey. ${ }^{28}$ Our theoretical model predicts that informing people that the rate of stigmatization against HIVpositive individuals is actually lower than they think can lead them to be more willing to get an HIV test. ${ }^{29}$

2. HIV/AIDS Information: Factual information about HIV/AIDS, delivered through a short video presented on a computer tablet, in a language chosen by the respondent. The video covers the negative health consequences of leaving HIV infection untreated, how HIV infection transmits, and how infected people may look and feel normal before the infection develops into AIDS.

3. Antiretroviral Therapy (ART) Information: Factual information about ART, delivered through a short video presented on a computer tablet, in a language chosen by the respondent. The video stresses that HIV infection is no longer a death sentence because free ART treatment is available and effective in helping people stay healthy and preventing transmission. The point that ART helps reduce transmission is potentially important, because this fact is often not widely known (Kaler et al., 2016). It explains that taking a test opens the door to access to ART for infected people.

4. Both HIV/AIDS and ART Information: The combination of items 2 and 3 above. Respondents assigned to this minitreatment are shown both the HIV/AIDS and ART Information videos, in that order.

5. High Incentive for HIV Testing: Each HIV testing coupon offered to the household provides a financial incentive of $100 \mathrm{MZN}$ or PPP $\$ 4.85$, instead of the 50 MZN (PPP $\$ 2.42$ ) coupons offered to all other households. This minitreatment helps scale the size of other minitreatment effects with respect to variation in financial incentives.

6. Control: None of the above minitreatments.

The minitreatments were randomly assigned on the computer of one of the co-authors one time, with no re-randomization. The randomization was stratified by unique combinations

et al., 2007), attitudes toward healthy sexual relationships (Banerjee et al., 2020), female labor force participation (Bursztyn et al., 2020), and social distancing to prevent COVID-19 transmission (Allen et al., 2021a).

${ }^{28}$ In later work in this same study population (Allen et al., 2021b), we show that correcting individuals' incorrect responses on health-related (COVID-19) questions has lasting positive effects on their knowledge on the same topics.

${ }^{29}$ The impacts of the anti-stigma treatment that we report in this paper differ from the results in $\mathrm{Yu}$ (2021) by focusing on the household level and examining interactions with the FCC-enrolled treatment. By contrast, Yu (2021) conducts analyses at the individual level and explores the anti-stigma minitreatment impacts (alone) in substantially greater depth. 
of community, FCC-enrolled status, and baseline asset level. ${ }^{30}$ Figure 1 presents the full cross-cutting set of treatments, indicating the number of households per cell.

\section{Hypotheses}

\subsection{Study Registration, Pre-Analysis Plan, and Pre-Results Re- view}

We registered this study on the AEA RCT Registry (ID AEARCTR-0003990) on March 8, 2019 (https://doi.org/10.1257/rct.3990-5.0). On that date, we uploaded our first preanalysis plan (PAP) to the registry. This date was prior to the endline survey and HIV testing coupon redemption, which were carried out between May and November 2019.

We had previously submitted our study as a Pre-Results Review Paper to the Journal of Development Economics (JDE). The JDE refereeing process led to minor changes to our pre-specified analyses. The JDE accepted our Pre-Results Review Paper on July 22, 2019 (Yang et al., 2019). We then uploaded the JDE Pre-Results Review Paper to our AEA RCT Registry as our second (and final) PAP on July 24, 2019. ${ }^{31}$ Both time-stamped PAPs are available for public viewing at our AEA RCT Registry record.

The submission of the second PAP was two months into the seven-month period covering the endline survey and HIV testing coupon redemption. No changes to the PAP between our first and second PAP submissions were informed by any analyses of endline or HIV testing coupon redemption data. Prior to submitting the second PAP, we had only conducted data quality control checks for feedback to enumerators in the field.

The differences between the first and second PAPs are as follows. In the first PAP, we stated two final outcomes of primary interest: 1) the coupon-based HIV testing measure, and 2) school attendance of children. We classified self-reported HIV testing as an outcome of secondary interest. In response to JDE referee and editor feedback, in the second PAP, we stated only one final outcome of primary interest: the combined measure of HIV testing (equal to one if either the coupon-based or self-reported HIV testing measure was equal to one, and zero otherwise). The two components of this HIV testing measure (self-reported and coupon-based) were individually listed as of secondary interest. We also stated in the second PAP the decision rule that if treatment effects differed across the self-reported and coupon-based HIV testing outcomes, we would base conclusions on the coupon-based measure. We also relegated child school attendance to be of secondary interest. ${ }^{32}$

\footnotetext{
${ }^{30}$ For stratification by baseline asset levels, we grouped households into three groups: above median of a baseline asset index, below median baseline asset index, and missing data on baseline asset index.

${ }^{31}$ Following acceptance based on pre-results review, the JDE allows authors to submit the full-length paper, with results, to other journals. Further details are available at http://jde-preresultsreview.org/.

${ }^{32}$ The second PAP also listed a few robustness tests recommended by referees ("Other Secondary Analyses"), the results of which we present in the Populated PAP.
} 
This paper reports on all primary analyses pre-specified in our second and final PAP, as well as a selection of secondary analyses. Remaining secondary analyses are described briefly in Section 5.3 below, and more fully in our Populated PAP. ${ }^{33}$ All empirical analyses in this paper are conducted exactly as pre-specified.

In the remainder of this paper, "PAP" refers to the second and final PAP.

\subsection{Primary Hypotheses}

HIV testing is the outcome variable of primary interest because it is a prerequisite for benefiting from the FCC program in the health domain. ${ }^{34}$ HIV testing opens the door to FCC interventions promoting ART treatment initiation and adherence. Our hypotheses related to HIV testing focus on household-level outcomes because the intervention components related to HIV testing are delivered at the household level (not at the individual level).

The primary question of interest in this study is: what is the impact of FCC enrollment on HIV testing? We address this question by estimating the causal effect of a household being randomly assigned to enrollment in the FCC program. In estimating this effect, all households in control communities serve as the control group. ${ }^{35}$ We hypothesized in our PAP that FCC enrollment would have a positive effect on HIV testing.

Our primary outcome of interest is an indicator that at least one of a household's HIV testing coupons has been redeemed. This is a household-level variable equal to 1 if at least one of a household's encouragement coupons was presented at the local health clinic for the HIV testing incentive payment before the 14-day deadline, and 0 otherwise. Note that even if an individual had been tested before (early in the implementation of the FCC program in the community), it is desirable (and consistent with the country's public health protocols) for them to be tested again later (and therefore follow our testing recommendation and redeem the coupon). Programs such as FCC aim not only to facilitate an individual's first HIV test, but to encourage them to be open to regular, repeated testing.

In presenting this coupon-based HIV testing measure as our primary outcome of interest, we are following a decision rule pre-specified in our PAP (page 11): if treatment effects on the coupon-based HIV testing measure differ significantly from treatment effects on the self-reported HIV testing measure, we would base our conclusions on the coupon-based

\footnotetext{
${ }^{33}$ We follow Duflo et al. (2020), assembling the full set of pre-specified analyses in a Populated PAP document. The Populated PAP can be accessed at our record in the AEA RCT Registry (ID AEARCTR0003990).

${ }^{34}$ Our HIV testing outcomes include both adults and children. Adults' HIV status is an important determinant of the outcomes of children in their households. HIV testing can lead adults to learn they are HIV positive, leading them to initiate ART, with positive effects on children in their households. HIV testing is also important for children (those aged below 18), in particular after puberty and sexual debut leads to non-trivial rates of new HIV infection. There are also much lower but nonzero rates of HIV infection from mothers (or other household members) to younger children.

${ }^{35} \mathrm{FCC}$-ambient households in treatment communities are the subject of secondary analyses, discussed briefly in Section 5.3 and more extensively in the Populated PAP.
} 
measure. We pre-specified this decision rule because of concerns that the self-reported testing measure may be subject to reporting biases due to experimenter demand effects (Orne, 1962; Rosenthal, 1966; Zizzo, 2010; De Quidt et al., 2018). Experimenter demand effects may lead testing to be differentially overstated in the endline survey by treated households. Because the coupon-based measure is an administrative outcome, it is immune from reporting biases. Coupons were only redeemable with written confirmation of having just had an HIV test. ${ }^{36}$

While we focus on the coupon-based HIV testing measure, we also show treatment effects on the self-reported HIV testing measure. This outcome is an indicator equal to 1 if at least one household member is reported in the endline survey to have had an HIV test in the last 12 months, and 0 otherwise. In addition, we show treatment effects on the composite HIV testing measure that is equal to 1 if HIV testing (self-reported) is equal to 1 or HIV testing (coupon-based) is equal to 1 , and 0 otherwise. ${ }^{37}$

\subsection{Secondary Hypotheses}

A number of pre-specified secondary hypotheses are of interest, in particular outcomes representing potential mechanisms. We hypothesized in the PAP that FCC-enrollment would lead to improvements in HIV-related knowledge and reductions in HIV-related stigmatizing attitudes.

In addition, we hypothesized that the minitreatments would have positive effects on HIV testing overall, and that these effects would be smaller among FCC-enrolled households (i.e., that the minitreatments and FCC enrollment would be substitutes). ${ }^{38}$

\subsection{Multiple Hypothesis Testing}

To conduct correct statistical inference in the context of testing multiple hypotheses, we do the following. To reduce the number of hypotheses tested, following Finkelstein et al. (2010) and Almeida et al. (2014), we construct indices of HIV-related knowledge and HIV-related stigmatizing attitudes. Within sets of related coefficients, we report p-values adjusted for the familywise error rate on each coefficient, following the List et al. (2019) method, modified to allow inclusion of control variables by Barsbai et al. (2020).

We pre-specified our multiple hypothesis test (MHT) adjustments incompletely (and with some errors) in the PAP. We describe here the MHT adjustments we carry out in each table, making clear which adjustments were pre-specified, which were not, and how we have

\footnotetext{
${ }^{36}$ Please refer to Appendix C.3 for further details on the coupon-based testing measure.

${ }^{37}$ In our PAP we said that this composite outcome would be our primary outcome variable of interest if treatment effects on its components (self-reported HIV testing and coupon-based HIV testing) were similar. Our decision rule leads us to downgrade this composite measure to secondary status.

${ }^{38}$ We will see that the opposite turns out to be the case, revealing ways in which the FCC program was deficient in the areas of information and stigma.
} 
rectified pre-specification errors. We follow the PAP whenever possible, and otherwise have sought to remain true to the spirit of the pre-specified MHT adjustments.

- Table A.3. As pre-specified, we report MHT-adjusted p-values within the set of the three coefficients on Treatment status in Columns 1-3.

- Table 1. As pre-specified: 1) we adjust p-values within the set of two coefficients on Treatment in column 1 (coupon-based HIV testing measure) and 3 (self-reported HIV testing measure), and 2) we do not adjust the p-value on Treatment in column 4 (combined HIV testing measure), since the outcome in that regression combines information from the outcomes in columns 1 and 3. We pre-specified this MHT adjustment presuming the primary outcome of interest would be the combined HIV testing measure. We did not pre-specify what MHT correction we would apply if we followed the pre-specified decision rule that leads us to prioritize the coupon-based HIV testing measure over the combined measure. Now that we are in this case, a more natural approach would be to apply the MHT adjustment among the three coefficients on Treatment in columns 1, 3, and $4{ }^{39}$ For coefficients in Column 2, we report p-values adjusted for MHT across all five coefficients in that column. ${ }^{40}$

- Tables 2 and 3. First, we reduce the number of outcomes by creating indices of overall knowledge, knowledge subindices by topic, and stigmatizing attitudes. Second, when we examine multiple outcomes (knowledge subindices and the separate stigma questions), we apply MHT adjustments within outcome families (the knowledge and stigma families separately). In the PAP, we said that we would apply MHT adjustments within one family of the 33 knowledge questions, and separately within the family of four stigma questions. Due to an oversight, we did not pre-specify creation of indices. Analyses of the indices should therefore be taken as exploratory, but we note that analysis of such indices is a widely-used approach to addressing MHT concerns (Finkelstein et al. (2010), Almeida et al. (2014)).

Table 2. We apply no MHT adjustment to the coefficient p-value in Column 1; the overall index incorporates information from all knowledge questions, so the single coefficient on Treatment in this regression reveals impacts on overall knowledge. We apply MHT adjustments within the set of five Treatment coefficients in Columns 2-6.

Table 3. MHT adjustments in this table are analogous to those we apply in Table 2: we do not adjust the coefficient p-value in Column 1, and we adjust coefficient pvalues within the group of four coefficients in Columns 2-5.

\footnotetext{
${ }^{39} \mathrm{Such}$ an adjustment would lead to even larger p-values, strengthening the conclusion of null Treatment (FCC-enrolled) effects in these regressions.

${ }^{40}$ Column 2 estimates Equation 9, which was not pre-specified in our PAP; it is a simplified version of pre-specified Equation 11 below, and simply highlights Comparison A, the pure effect of the FCC program. The MHT adjustments we apply to the coefficient p-values in Column 2 (Equation 9), Table 1 are analogous to the MHT adjustments we apply to the coefficient p-values in Column 2 (Equation 11), Table 4.
} 
- Table 4. The MHT adjustment we pre-specified in our PAP was incomplete: when stating the set of coefficients we would consider as a group when adjusting p-values, we listed just three out of five of the minitreatment coefficients (and interaction terms), ${ }^{41}$ and we neglected to include the coefficient on the main effect of Treatment in the set of coefficients listed. We now conservatively adjust p-values within a larger set of coefficients than pre-specified: for Column 1, we apply MHT adjustment to p-values within the group of all six coefficients presented; for Column 2, do the same within the group of all 11 coefficients presented.

\section{Empirical Analyses}

We estimate impacts of Treatment (FCC-enrolled) status using ordinary-least-squares regression analyses, with the following regression equation:

$$
\mathcal{Y}_{i j s}=\alpha+\beta \text { Treatment }_{i j s}+\lambda \text { FCCambient }_{i j s}+\gamma_{s}+\varepsilon_{i j s}
$$

$\mathcal{Y}_{i j s}$ is the post-treatment outcome for individual or household $i$ in community $j$ in stratification cell (matched pair) s. Treatment $t_{i j s}$ is the indicator that community $j$ was randomly assigned as an FCC community, and that household $i$ was randomly assigned to FCC-enrolled status in that community ( 1 if so, and 0 otherwise). FCCambient ${ }_{i j s}$ is the indicator for a household being in a treatment community but not randomly assigned to FCCenrolled status (1 if FCC-ambient, and 0 if not). (Both Treatment ${ }_{i j s}$ and FCCambient Fijs are equal to zero for anyone in a control community. In other words, Treatment ${ }_{i j s}$ and FCCambient ${ }_{i j s}$ partition households in treatment communities into two mutually exclusive subgroups.) $\gamma_{s}$ is a fixed effect for stratification cell $s .{ }^{42} \epsilon_{i j s}$ is a mean-zero error term. We cluster standard errors at the level of 76 communities (Moulton, 1986). For each coefficient we report p-values after making corrections for multiple hypothesis testing (MHT) (as described in Section 4.4).

The coefficient $\beta$ is the primary treatment effect of interest. It is the intent to treat (ITT) effect of assignment to FCC-enrolled status. The coefficient $\lambda$ is the corresponding effect of being in an FCC treatment community but not being assigned to FCC-enrolled status; as pre-specified, this is of secondary interest. Random assignment allows these coefficients to be interpreted as causal effects. In this paper we focus on the primary effect of FCC enrollment, the coefficient $\beta$ on Treatment ${ }_{i j s}$.

\footnotetext{
${ }^{41}$ Specifically, we failed to edit this part of the 2 nd (final) PAP after adding two additional minitreatments between the 1st and 2nd PAPs.

${ }^{42}$ The inclusion of the stratification cell fixed effects reduces standard errors by absorbing residual variation. Stratification is at the level of 38 matched pairs of communities within which treatment status was randomly assigned (so stratification cell fixed effects are equivalent to matched pair fixed effects).
} 


\subsection{Treatment Effect Estimates}

We first discuss balance with respect to treatment (including whether attrition is related to treatment), as well as intervention fidelity. Then we turn to treatment effect estimates.

\subsubsection{Balance and Attrition}

In Appendix Section H, we test and discuss whether there is any relationship between our randomized treatments, on the one hand, and household characteristics at the time of study enrollment, in-migration, and endline survey attrition, on the other. Balance tests are important because, as mentioned in Section 3.4, enrollment of households into the study sample occurred slightly after the start of FCC program activities in communities (Randomization Stage 1).

In Appendix Table A.5, we find no imbalance of household characteristics at study enrollment, in-migration, or attrition with respect to our primary randomized treatment of interest, assignment to Treatment (FCC-enrolled) status. In Appendix Tables A.6 and A.7, we also show analogous tests for balance and differential migration with respect to the Randomization Stage 3 minitreatments. These regressions have large numbers of coefficients, so random variation would lead some coefficients to be statistically significant by chance. We also find no indication of imbalance in these analyses: the share of statistically significant coefficients is very similar to what would be expected to occur by chance.

\subsubsection{Intervention Fidelity}

We now examine intervention fidelity - the extent to which the treatments were carried out respecting the randomized assignment. We examine intervention fidelity at three levels, reflecting the levels of randomization. Below is a summary, with detailed analyses in Appendix G.

Intervention fidelity for Randomization Stage 1, randomization of the FCC program at the community level, appears high. Reports by WEI/Bantwana to the USAID Mission in Mozambique indicate that the program was implemented in the 38 treatment communities, and not in the 38 control communities. We confirm this empirically by surveying principals of the study community schools, which were focal points for delivery of many FCC program components. There is a large positive treatment effect of being in a FCC treatment community on principal reports that they have been visited by the FCC local implementing partner (LIP) organization, and that they are receiving financial support from the LIP.

For Randomization Stage 2, randomization of study households into FCC-enrolled status, both WEI/Bantwana administrative data and our household surveys provide positive indications of implementation fidelity. There is, however, a discrepancy regarding magnitudes. WEI/Bantwana reports that $77.0 \%$ of households assigned to FCC enrollment received a 
home visit by a LIP case care worker (CCW). In our survey data, we find that FCC enrollment leads to a doubling of the share reporting having been visited by the LIP from $5.6 \%$ to $12.1 \%$. While we expected a positive effect of FCC-enrolled status on LIP household visits, there is a large difference $-12.1 \%$ vs. $77.0 \%$ - between the share of FCC-enrolled households reporting such visits in survey data compared to the WEI/Bantwana data. This discrepancy likely reflects substantial under-reporting by households of their contacts with LIPs. Households appear to imperfectly know or recall the specific NGOs with which they interact. Relatedly, household members responding to our survey may differ from the household members who interacted with the CCWs in household visits. Directly indicating such under-reporting, households report higher rates of services received (that would have been provided by LIPs), compared to rates of contact with LIPs. The nature of our survey data do not allow us to estimate more precisely the share of FCC-enrolled households actually visited by LIP CCWs. ${ }^{43}$

Finally, for Randomization Stage 3 (the minitreatments), implementation fidelity is high. These treatments were implemented by our research staff. Prompts to implement the correct treatment appeared on our staff members' computer tablets, and the survey digital metadata on the timing of survey sections indicates high adherence to treatment assignment. Our survey data also show that the minitreatments are followed by improvements in knowledge and reductions in stigmatizing attitudes.

\subsubsection{Impacts on HIV Testing}

We now test the primary hypotheses of impacts on HIV testing. Results are presented in Table 1. The coefficient on the pre-specified primary outcome of interest, the coupon-based HIV testing measure (Column 1), is negative but not statistically significantly different from zero at conventional levels. The point estimate indicates a 2.12 percentage point decline in testing rates, relative to the $26.3 \%$ rate in control communities. This treatment effect is based on Comparison B in Figure 1, comparing testing rates of all FCC-enrolled households to all households in control communities.

That estimate is not the "pure" effect of FCC enrollment, because many FCC-enrolled households were assigned the Randomization Stage 3 minitreatments before being offered the HIV testing coupons. The treatment effect in Column 1 is an average treatment effect, pooling households who received minitreatments with those who did not. If there is any interaction between the minitreatments and FCC enrollment, the estimate in Column 1 will not be identical to the pure effect of FCC enrollment.

The pure effect of FCC enrollment is given by Comparison A in Figure 1, the testing rate of FCC-enrolled households in treatment communities who did not receive any mini-

\footnotetext{
${ }^{43}$ In any case, note that all treatment effect estimates below are based on equation 8 , so they are ITT estimates and therefore not inflated by under-reported rates of contact (as they would be in IV regressions).
} 
treatment, compared to the testing rate of control community households who also did not receive any minitreatment. While we pre-specified that we would estimate Comparison A in the context of analyzing the Randomization Stage 3 minitreatments (in Section 5.2 below, Table 4), we show a simplified version of it here as well in Table 1, to emphasize the contrast between Comparisons A and B.

We estimate the pure effect of FCC enrollment (Comparison A) using the following modification of Equation 8:

$$
\begin{aligned}
\mathcal{Y}_{i j s} & =\alpha+\beta_{\text {Treatment }} \text { ijs }+\theta \text { Treatment }_{i j s} \times \text { AnyMinitreatment }_{i j s} \\
& +\lambda \text { FCCambient }_{i j s}+\rho \text { FCCambient } \\
i j s & \times \text { AnyMinitreatment }_{i j s} \\
& +\pi \text { AnyMinitreatment } \\
i j s & +\gamma_{s}+\varepsilon_{i j s}
\end{aligned}
$$

AnyMinitreatment $t_{i j s}$ is an indicator equal to 1 if a household received any of the minitreatments, and 0 otherwise. Equation 9 includes this as a main effect as well as in interaction with Treatment ${ }_{i j s}$ and FCCambient Fijs $_{\text {. }}$

We present coefficient estimates from this regression in Column 2. The coefficient $\beta$ in this regression is the pure effect of FCC enrollment on households not receiving any minitreatment. This effect is negative and statistically significantly different from zero (pvalue 0.016$)$. The coefficient indicates a -10.5 percentage-point reduction in HIV testing rates, which is very large (two-fifths of the mean HIV testing rate in control communities).

The coefficient $\theta$ on the interaction term represents how the impact of FCC enrollment changes when a household receives some minitreatment. This coefficient is positive, large in magnitude, and statistically significantly different from zero ( $\mathrm{p}$-value 0.017 ).

These coefficient estimates in Column 2 indicate that FCC enrollment by itself (the negative coefficient $\beta$ ) has a large negative effect on HIV testing. Receiving some minitreatment offsets this negative effect of FCC enrollment (the positive coefficient $\theta$ ). $\beta$ and $\theta$ are about the same magnitude, indicating that receiving any minitreatment approximately counteracts the negative effect of FCC enrollment.

Which minitreatment(s) in particular is (are) having this positive counteracting effect? We defer this to Section 5.2 when we examine the separate minitreatments in detail.

To conclude the discussion of Table 1, we proceed to Columns 3 and 4 . In Column 3 we estimate Equation 8 where the outcome variable is self-reported HIV testing from the endline survey. The coefficient is positive, small in magnitude, and not statistically significantly different from zero. We can compare this treatment effect estimate to expert predictions elicited in advance. Prior to our results being known, in DellaVigna et al. (2020) collected from subject-matter experts their forecasts of the treatment effect of being FCCenrolled on self-reported HIV testing. ${ }^{44}$ The mean expert prediction was 11.36 percentage

\footnotetext{
${ }^{44}$ DellaVigna et al. (2020) elicited predictions from 73 anonymous experts, mostly in December 2019. The online survey eliciting predictions closed on January 3, 2020.
} 
points. The actual treatment effect, 2.34 percentage points, is statistically significantly below the expert prediction ( $\mathrm{p}$-value $<0.001$ ).

The coefficient on Treatment $_{i j s}$ in Column 1 is more negative than the coefficient in Column 3, and the difference between them is marginally significant: the p-value of the F-test of equality of the coefficients is 0.1480 . Even more striking, the coefficients on Treatment ${ }_{i j s}$ in columns 2 and 3 are statistically significantly different from one another at the $1 \%$ level (p-value 0.0043). ${ }^{45}$ These statistical tests lead us to follow our pre-specified PAP decision rule to base substantive conclusions on the coupon-based HIV testing measure, rather than the self-reported HIV testing measure.

For completeness, in Column 4 we show the coefficient on Treatment ${ }_{i j s}$ from estimation of Equation 8 when the outcome variable is the composite HIV testing measure. The coefficient is positive, but modest in size and not statistically significantly different from zero.

In sum, FCC enrollment leads to lower rates of HIV testing. To explore the mechanisms through which this negative effect operates, we now turn to analyses of endline survey outcomes in Section 5.1.4, and detailed analyses of the minitreatments in Section 5.2.

\subsubsection{Potential Mechanisms Behind Negative Impacts on HIV Testing}

We now shed light on mechanisms behind the negative impact of FCC enrollment on HIV testing. We focus on two key mechanisms we pre-specified: information on HIV/AIDS, and HIV-related stigmatizing attitudes. As emphasized in the theoretical model, worsened misinformation could lead to heightened stigma and thereby lower HIV testing. The 33 information and four stigma questions are detailed in Appendix Section D.

In Table 2 we estimate Equation 8 using individual-level data, examining impacts of treatment on knowledge regarding HIV/AIDS. These regressions implement Comparison B in Figure 1, comparing outcomes of all FCC-enrolled households to all households in control communities. This is the appropriate comparison because outcomes of interest in the table are measured in the endline survey, and therefore cannot be affected by the minitreatments (which happened after the endline survey).

In Column 1, we examine impacts on an overall HIV knowledge index (the share of questions answered correctly). In Columns 2 to 6 , we examine analogous knowledge subindices by topic: correct methods of HIV transmission, myths about HIV transmission, methods to protect against HIV, and treatments for HIV. Each index is defined so that higher values represent improvements in knowledge.

Treatment status has no large impact on the overall index or any of the subindices, except

\footnotetext{
${ }^{45}$ As discussed above in Section 4.2, this difference likely emerges because the self-reported testing measure is subject to reporting biases due to experimenter demand effects, which leads HIV testing to be differentially overstated in the endline survey by treated households. By contrast, because the coupon-based measure is an administrative outcome, it is immune from reporting biases.
} 
for the outcome in Column 4, the "transmission myth index". These are questions about whether HIV can be transmitted in certain ways, all of which are not transmission channels (in other words, correct answers to these questions are all "no"): mosquito bites, shaking hands, kissing, sharing food, or witchcraft. Strikingly, the impact is negative, indicating that knowledge on this front worsens: respondents are more likely to believe myths about HIV transmission. This negative coefficient on treatment is marginally statistically significant (p-value 0.132). ${ }^{46}$

The other key mechanism through which HIV testing might be influenced by the FCC program is HIV-related stigmatizing attitudes. We examine impacts on responses to four yes/no questions from the AIDS Indicator Survey of the Demographic and Health Surveys (DHS), which have been fielded in Mozambique and other DHS countries since 2003 (INS, 2017). We examine treatment effects on an index of the four questions (Column 1), as well as on responses to each question separately (Columns 2-5). Each outcome variable is defined such that higher values indicate less stigma (Column 1 is the share of non-stigmatizing responses, and the remaining columns are indicators for giving a non-stigmatizing response.)

We report regression results in Table 3. Column 1 indicates that treatment worsens stigmatizing attitudes: the coefficient is negative and statistically significant (p-value 0.009). Treatment reduces the share of non-stigmatizing responses by 1.35 percentage points. The standard deviation of this outcome variable is 14.63 percentage points, so this treatment effect is equal to 0.092 standard deviations - not an insubstantial magnitude.

Results in the other columns of the table indicate that treatment effects on each stigma question individually are also negative, but none are individually statistically significantly different from zero at conventional levels.

\subsection{Minitreatments}

The results presented so far are consistent with the theoretical model presented above. Increased misinformation about transmission may lead people to believe the probability of transmission is higher, leading to higher stigma against people with HIV, and thus to lower HIV testing rates. However, the above results do not prove conclusively that increased misinformation and higher stigma are mechanisms or intermediate links in the causal chain linking the FCC program with testing.

The minitreatments help reveal potential mechanisms behind the negative effects of FCC enrollment more directly. If FCC-enrollment inadvertently caused misinformation about HIV to rise, leading to increases in HIV-related stigma, and as a result depressing HIV testing, then interventions providing correct HIV information and alleviating stigma concerns should raise HIV testing differentially among FCC-enrolled households.

\footnotetext{
${ }^{46}$ Regression analyses of Treatment effects on each of the 33 individual knowledge questions can be found in our Populated PAP.
} 
We first examine the effect of the minitreatments by estimating the following modification of Equation 8:

$$
\mathcal{Y}_{i j s}=\alpha+\beta \text { Treatment }_{i j s}+\lambda \text { FCCambient }_{i j s}+\boldsymbol{\delta}^{\prime} \mathbf{M}_{\mathbf{i j s}}+\gamma_{s}+\varepsilon_{i j s} .
$$

$\mathcal{Y}_{i j s}$ is the coupon-based HIV testing measure (the only outcome available after the minitreatments). $\mathbf{M}_{\mathrm{ijs}}$ is a vector of indicator variables for each of the five minitreatments. $\boldsymbol{\delta}$ is the vector of coefficients representing the intent to treat (ITT) effects of household assignment to the corresponding minitreatment.

Analyses of the minitreatments' effects on the FCC-enrolled treatment effect are conducted using the following regression equation, which is a modification of Equation 10:

$$
\begin{aligned}
\mathcal{Y}_{i j s}= & \alpha+\text { Rreatment }_{i j s}+\lambda \text { FCCambient }_{i j s}+\boldsymbol{\tau}^{\prime} \mathbf{M}_{\mathbf{i j s}}+\boldsymbol{\pi}^{\prime} \text { Treatment }_{i j s} \times \mathbf{M}_{\mathbf{i j s}} \\
& +\boldsymbol{\psi}^{\prime} \text { FCCambient }_{i j s} \times \mathbf{M}_{\mathbf{i j s}}+\gamma_{s}+\varepsilon_{i j s} .
\end{aligned}
$$

This regression is similar to Equation 10, but adds interaction terms between Treatment $_{i j s}$ and each of the minitreatments, as well as interaction terms between FCCambient Fijs $_{\text {and }}$ each of the minitreatments. These interaction terms reveal whether the effects of the minitreatments differ for FCC-enrolled and FCC-ambient households, compared to the effect in control communities. Because of the inclusion of these interaction terms, the coefficients in the vector $\tau$ represent the ITT effects of assignment to the respective minitreatment in control communities.

The coefficients in the vector $\boldsymbol{\pi}$ represent the difference in the ITT effect of the respective minitreatments for FCC-enrolled households, compared to the effect of the minitreatments for households in control communities. Alternately, they represent how the respective minitreatment changes the effect of FCC-enrollment, compared to the effect of FCC-enrollment for households receiving no minitreatment. (There are analogous coefficients related to the effects for FCC-ambient households.)

Both Equations 10 and 11 are as described in our pre-analysis plan. Results from estimating Equations 10 and 11 are displayed in Table 4.

Estimation of the average effects of minitreatments in the full sample (Equation 10, Column 1) reveals that the high-value coupon has a positive effect on HIV testing rates, 7.24 percentage points, that is statistically significantly different from zero (p-value 0.044).

Estimation of differential effects of the minitreatments across treatment groups (Equation 11, Column 2) provides explanations for the effects found in prior results tables. The coefficient on the treatment main effect (top row of Column 2) represents the impact of treatment status for individuals who did not get any of the minitreatments. The coefficient is negative, large in magnitude (10.5 percentage points), and statistically significantly different 
from zero (p-value 0.032). ${ }^{47}$

Coefficients on the interaction terms between treatment status and each minitreatment (coefficient rows 7-11 of Column 2) indicate how the minitreatments modify the main effect of FCC enrollment. Nearly all the interaction term coefficients are positive, and most are large in magnitude and statistically significantly different from zero at conventional levels. Providing HIV-related information, providing ART-related information, counteracting concerns about HIV-related stigma, and providing higher financial incentives all improve the impact of FCC-enrolled status on HIV testing. The exception to this pattern is the coefficient on the interaction term with the combined HIV and ART information treatment, which is negative, much smaller in magnitude, and not statistically significantly different from zero at conventional levels. It is possible that providing too much information to respondents reduces the effectiveness of all information provided, perhaps by causing lapses in respondents' attention or retention. ${ }^{48}$

The main effects of the minitreatments in Column (2) (coefficient rows 2-6) represent impacts in control communities. Most effects are negative, small in magnitude, and not statistically significantly different from zero. The exception is the coefficient on the antistigma treatment, which is negative and statistically significantly different from zero ( $\mathrm{p}$ value 0.025 ) in control communities (2nd row, Column 2). This may reveal that in control communities, where people may not have HIV-related stigma at top of mind, simply raising the topic of stigma may increase its salience. In control communities, people may not pay as much attention to the actual quantitative information we provide on HIV-related stigmatizing attitudes, and only increase their worry that going for an HIV test may reveal to others that they are at high risk of having HIV in their household. This then leads the anti-stigma treatment to have a negative effect on testing in control communities.

The positive interaction term on "Treatment * Anti-Stigma" in the same column could then indicate that once concerns about HIV-related stigma had previously been raised (by FCC enrollment itself), the anti-stigma treatment can have a positive effect by revealing to people that stigmatizing attitudes are not as bad as they previously thought.

The regression results in Table 11 examine impacts on an indicator for anyone in the household getting an HIV test, and so the unit of observation is the household. Because HIV testing is an individual decision, it is also possible to conduct the analysis at the individual level. We do this in Appendix Table A.8, where the unit of observation is the individual, and

\footnotetext{
${ }^{47}$ This coefficient is nearly the same as the coefficient in Table 1, Column 2, discussed previously, but is not exactly identical because Equation 11 replaces the "Any Minitreatment" indicator (and associated interaction terms) with the full set of five separate minitreatment indicators.

${ }^{48} \mathrm{In}$ pre-specified secondary analyses, we show that the finding that the information minitreatments offset the negative "pure" effect of the FCC program on HIV testing is robust to pooling the information minitreatments rather than examining their effects individually. We estimate a modified version of Equation 11 in which we pool the HIV information, ART information, and combined HIV/ART information minitreatment indicators into one "Pooled HIV and ART information" minitreatment indicator. In this analysis, which we show in the Populated PAP, the coefficient on the Treatment * "Pooled HIV and ART information" interaction term is negative and statistically significantly different from zero.
} 
the outcome variable is an indicator for the individual-level HIV testing coupon redemption. All key patterns in the household-level analyses hold in the regression for all individuals (column 1), as well as subsamples of individuals (adults, primary household respondents, children, adults aged 18-49, adults aged $49+$, adult men, and adult women). Perhaps the most apparent pattern in these results is that coefficients on the interaction terms between treatment and the minitreatments are larger in magnitude for the subsamples of children and adults aged 49+, compared to adults aged 18-49.

All told, this analysis of the minitreatments provides additional support for the interpretation of our prior results. The negative effect of FCC enrollment on HIV testing likely stems from the unintended consequence that the program worsened HIV-related misinformation, leading to increases in stigmatizing attitudes and a large decline in HIV testing. From this starting point of a negative effect of FCC enrollment, the minitreatments providing correct HIV information and countering concerns about HIV-related stigma raise HIV testing among FCC-enrolled households.

\subsection{Other Pre-specified Analyses}

In the PAP, we pre-specified some secondary analyses not reported in this paper. The Populated Pre-Analysis Plan (Populated PAP) contains results of all pre-specified analyses, including those presented in this paper. We briefly discuss them here.

We pre-specified that the impacts of FCC-ambient status were of secondary interest. FCC-ambient households are those in treatment communities who were not randomly assigned to FCC enrollment in Randomization Stage 2. FCC-ambient households are included in all samples analyzed in this paper. All regressions include an indicator for FCC-ambient status (and corresponding interaction terms with minitreatments, as appropriate) on the right-hand-side. FCC-ambient effects are generally smaller in magnitude and less statistically significant than FCC-enrolled effects. No effects of minitreatments among FCCambient households are statistically significantly different from effects of minitreatments in control communities. These patterns reflect that FCC-ambient households had less contact with the FCC program than FCC-enrolled households.

In other pre-specified analyses, we present treatment effect estimates from estimation of Equation 8 where the dependent variables are indicators for correct answers to each of 33 HIV knowledge questions, positive responses to three questions on positive attitudes related to HIV, and "safe" responses to eight questions on sexual behavior. Among these results, one that stands out is that FCC enrollment leads to a reduction in reported number of sexual partners in the last 12 months (p-value 0.060). We view this finding as related to increased fears of transmission of HIV (due to increases in beliefs in transmission myths), as well as fears of stigma should one become infected with HIV. ${ }^{49}$

\footnotetext{
${ }^{49}$ Delavande et al. (2014) offer a theoretical model explaining how increased stigma could reduce risky
} 
We also find no large or statistically significant effect of FCC enrollment on child school attendance, life satisfaction, or household asset ownership. We examine impacts on antiretroviral therapy (ART) initiation and adherence among individuals who self-report being HIV positive, and also find no large or statistically significant treatment effects. Finally, we find no evidence of spillovers (via geographic or social proximity) from FCC-enrolled to FCC-ambient households within FCC communities.

\section{Conclusion}

We study the impacts of a widespread community health program on HIV testing in Mozambique. We exploit a multilevel randomized research design to identify causal effects. We find that the program Força à Comunidade e Crianças (FCC) had a negative effect on HIV testing rates. Analysis of rich survey data on secondary outcomes suggests that the program's negative impacts are due to increased misinformation about HIV, and worsened HIV-related stigmatizing attitudes.

This interpretation is bolstered by additional treatments we administered at the household level. These additional treatments providing correct HIV-related information and countering HIV-related stigma concerns make the treatment effects of the FCC program on HIV testing rates more positive, suggesting that the FCC program was deficient in these areas.

We provide a rare glimpse into the impacts and mechanisms of a widespread communitylevel program seeking to raise HIV testing. Our results point to a thus-far neglected possibility: programs seeking to raise HIV testing may fail due to deficiencies in information provision and in counteracting HIV-related stigma. Indeed, such programs may inadvertently worsen HIV knowledge and increase stigmatizing attitudes, leading to less voluntary HIV testing.

These results suggest priority directions for future research. A key question is how exactly the program led to increased misinformation on HIV transmission, and to worsened HIVrelated stigmatizing attitudes. It is possible that providing basic information that HIV is transmitted via bodily fluids could lead people to believe in transmission myths, since some of these also involve possible sharing of bodily fluids (e.g., shaking hands, kissing, sharing food). FCC home visits could have also increased the salience of HIV and of HIV-related stigmatizing attitudes in the community, if it was known in the community that home visits by program staff (CCWs) were targeted towards households with HIV infection. ${ }^{50}$

Because we did not anticipate these negative findings, we did not collect information needed to understand how the program could have increased misinformation and worsened

sexual behavior, since stigma imposes additional social costs for HIV-positive individuals.

${ }^{50} \mathrm{CCWs}$ explicitly had responsibilities to regularly visit households with HIV-infected people, to promote adherence to antiretroviral therapy (ART). A CCW home visit could have been taken by observers as a signal that someone in the household was infected with HIV. 
stigmatizing attitudes. In future studies, it will be important to collect detailed data on what exactly program staff do, what kind of information they convey, and how people react to and interpret the information. It is also important to understand how people respond to and interpret home visits, either as recipients of visits or observers of others' visits. This could require high-frequency household surveys as the program is taking place, in combination with spot checks and direct observation of program staff. Controlled lab-in-the-field studies could also reveal mechanisms through which people come to believe incorrect information (such as transmission myths), and how they come to acquire HIV-related stigmatizing attitudes and concerns about such stigma.

A related area for future exploration is ways to improve people's knowledge about HIV and to reduce HIV-related stigmatizing attitudes. Our own findings suggest that there are simple and cheap ways to improve knowledge and to reduce stigma, as evidenced by the effects of our minitreatments (at least among households who had suffered worsened information and heightened concerns about stigma beforehand). Future work should seek to pursue these and other related research directions.

\section{References}

Akerlof, G. A., J. L. Yellen, and M. L. Katz (1996). An Analysis of Out-of-Wedlock Childbearing in the United States. The Quarterly Journal of Economics 111(2), 277-317.

Allen, J., A. Mahumane, J. Riddell IV, T. Rosenblat, D. Yang, and H. Yu (2021a). Correcting Perceived Social Distancing Norms to Combat COVID-19. NBER Working Paper (28651).

Allen, J., A. Mahumane, J. Riddell IV, T. Rosenblat, D. Yang, and H. Yu (2021b). Teaching and Incentives: Substitutes or Complements? NBER Working Paper (28976).

Almeida, R., S. Hirshleifer, D. McKenzie, C. Ridao-Cano, and A. L. Yener (2014). The Impact of Vocational Training for the Unemployed: Experimental Evidence from Turkey. Economic Journal 126(597), 21152146.

Baird, S., C. McIntosh, and B. Ozler (2011, Oct). Cash or Condition? Evidence from a Cash Transfer Experiment. The Quarterly Journal of Economics 126(4), 1709-1753.

Banerjee, A., E. La Ferrara, and V. Orozco-Olvera (2020). The Entertaining Way to Behavioral Change: Fighting HIV with MTV. Working Paper.

Barsbai, T., V. Licuanan, A. Stienmayr, E. Tiongson, and D. Yang (2020). Information and the Acquisition of Social Network Connections. NBER Working Paper 27346.

Belay, H., F. Alemseged, T. Angesom, S. Hintsa, and M. Abay (2017). Effect of Late HIV Diagnosis on HIV-Related Mortality Among Adults in General Hospitals of Central Zone Tigray, Northern Ethiopia: A Retrospective Cohort Study. HIV/AIDS - Research and Palliative Care 9, 187-192.

Bendavid, E., C. B. Holmes, J. Bhattacharya, and G. Miller (2012). HIV Development Assistance and Adult Mortality in Africa. JAMA 307(19), 2060-2067.

Bharadwaj, P., M. M. Paic, and A. Suziedelyte (2017). Mental Health Stigma. Economics Letters 159, $57-60$.

Bor, J., C. Fischer, M. Modi, B. Richman, C. Kinker, R. King, S. Calabrese, I. Mokhele, T. Sineke, T. Zuma, S. Rosen, T. Barnighausen, K. Mayer, and D. Onoya (2021). Changing knowledge and attitudes towards hiv treatment-as-prevention and undetectable $=$ untransmissible: A systematic review. AIDS and Behavior 25, 4209-4224. 
Bryant, M. and J. Beard (2016). Orphans and Vulnerable Children Affected by Human Immunodeficiency Virus in Sub-Saharan Africa. Pediatric Clinics 63(1), 131-147.

Bryant, M., J. Beard, L. Sabin, M. I. Brooks, N. Scott, B. A. Larson, G. Biemba, C. Miller, and J. Simon (2012). PEPFAR's Support for Orphans and Vulnerable Children: Some Beneficial Effects, But Too Little Data, And Programs Spread Thin. Health Affairs 31(7), 1508-1518.

Bursztyn, L., A. L. Gonzalez, and D. Yanagizawa-Drott (2020). Misperceived Social Norms: Women Working Outside the Home in Saudi Arabia. American Economic Review 110(10), 2997-3029.

Case, A., C. H. Paxson, and J. Ableidinger (2004). Orphans in Africa: Parental Death, Poverty, and School Enrollment. Demography $41(3), 483-508$.

Chen, L., X. Pan, Q. Ma, J. Yang, Y. Xu, J. Zheng, H. Wang, X. Zhou, T. Jiang, J. Jiang, L. He, and J. Jiang (2017). HIV Cause-Specific Deaths, Mortality, Risk Factors, and Combined Influence of HAART and Late Diagnosis in Zhejiang, China, 2006-2013. Scientific Reports 7, 42366.

Chong, A., M. Gonzalez-Navarro, D. Karlan, and M. Valdivia (2013). Effectiveness and Spillovers of Online Sex Education: Evidence from a Randomized Evaluation in Colombian Public Schools. NBER Working Paper Series W18776.

Ciancio, A., A. Delavande, and H.-P. Kohler (2020). Mortality Risk Information, Survival Expectations and Sexual Behaviors. University of Pennsylvania Population Center Working Paper (PSC/PARC), 2020-39 20, 817-875.

De Quidt, J., J. Haushofer, and C. Roth (2018). Measuring and Bounding Experimenter Demand. American Economic Review 108, 3266-3302.

Delavande, A. and H.-P. Kohler (2012). The Impact of HIV Testing on Subjective Expectations and Risky Behavior in Malawi. Demography 49, 1011-1036.

Delavande, A., M. Sampaio, and N. Sood (2014). Hiv-related social intolerance and risky sexual behavior in a high hiv prevalence environment. Social Science \& Medicine 111, 84-93.

DellaVigna, S., N. Otis, and E. Vivalt (2020). Forecasting the Results of Experiments: Piloting an Elicitation Strategy. American Economic Association Papers and Proceedings 110, 75-79.

Derksen, L., A. Muula, and J. van Oosterhout (2020). Love in the Time of HIV: Testing as a Signal of Risk. Natural Field Experiments.

Duflo, E., A. Banerjee, A. Finkelstein, L. Katz, B. Olken, and A. Sautmann (2020). In Praise of Moderation: Suggestions for the Scope and Use of Pre-Analysis Plan for RCTs in Economics. NBER Working Paper Series W26993.

Duflo, E., P. Dupas, and M. Kremer (2015). Education, HIV, and Early Fertility: Experimental Evidence from Kenya. American Economic Review 105(9), 2757-2797.

Dupas, P. (2011). Do Teenagers Respond to HIV Risk Information? Evidence from a Field Experiment in Kenya. American Economic Journal: Applied Economics 3(1), 1-34.

Dupas, P. and E. Miguel (2016). Impacts and Determinants of Health Levels in Low-Income Countries. Handbook of Field Experiments.

Durlauf, S. N. and L. E. Blume (2008). In The New Palgrave Dictionary of Economics. Palgrave Macmillan.

Evans, D. K. and E. Miguel (2007). Orphans and Schooling in Africa: A Longitudinal Analysis. Demography $44(1), 35-57$.

Finkelstein, A., S. Taubman, H. Allen, J. Gruber, J. Newhouse, B. Wright, and K. Baicker (2010). The Short-Run Impact of Extending Public Health Insurance to Low-Income Adults: Evidence from the First Year of the Oregon Medicaid Experiment. Analysis Plan.

Ford, N., C. Migone, A. Calmy, B. Kerschberger, S. Kanters, S. Nsanzimana, E. Mills, G. Meintjes, M. Vitoria, M. Doherty, , and Z. Shubber (2018). Benefits and Risks of Rapid Initiation of Antiretroviral Therapy. AIDS 32(1), 17-23.

Friedman, W. H. (2018). Antiretroviral Drug Access and Behavior Change. Journal of Development Economics $135,392-411$. 
Furuya, K. (2002). A Socio-economic Model of Stigmaand Related Social Problems. Journal of Economic Behavior \& Organization 48, 281-290.

Godlonton, S., A. Munthali, and R. Thornton (2016). Responding to Risk: Circumcision, Information, and HIV Prevention. Review of Economics and Statistics 98(2), 333-349.

Goldberg, R. E. and S. E. Short (2016). What Do We Know About Children Living With HIV-Infected Or AIDS-Ill Adults in Sub-Saharan Africa? A Systematic Review of The Literature. AIDS Care 28(2), $130-141$.

Gong, E. (2015). HIV Testing and Risky Sexual Behaviour. The Economic Journal 125(582), 32-60.

Granich, R. M., C. F. Gilks, C. Dye, K. M. De Cock, and B. G. Williams (2009). Universal Voluntary HIV Testing with Immediate Antiretroviral Therapy as a Strategy for Elimination of HIV Transmission: A Mathematical Model. The Lancet 373(9657), 48-57.

Greenwood, J., P. Kircher, C. Santos, and M. Tertilt (2019). An Equilibrium Model of the African HIV/AIDS Epidemic. Econometrica 87(4), 1081-1113.

Hoffmann, M., S. MacCarthy, A. Batson, A. Crawford-Roberts, J. Rasanathan, A. Nunn, L. A. Silva, and I. Dourado (2016). Barriers Along the Care Cascade of HIV-Infected Men in a Large Urban Center of Brazil. AIDS Care 28, 57-62.

INS (2017). Inquerito de Indicadoresde Imunizacao, Malaria eHIV/SIDA 2015. INS.

Ishida, J. (2003). The Role of Social Norms in a Model of Marriage and Divorce. Journal of Economic Behavior \& Organization 51, 131-142.

Ivers, L. C., J. E. Teng, J. G. Jerome, M. Bonds, K. A. Freedberg, and M. F. Franke (2014). A Randomized Trial of Ready-to-Use Supplementary Food Versus Corn-Soy Blend Plus as Food Rations for HIV-Infected Adults on Antiretroviral Therapy in Rural Haiti. Clinical Infectious Diseases 58(8), 1176-1184.

Jamison, J., D. Karlan, and P. Raffler (2013). Mixed Method Evaluation of a Passive mHealth Sexual Information Texting Service in Uganda. Information Technologies 8 International Development 9(3), $1-28$.

Kaler, A., N. Angotti, and A. Ramaiya (2016). They are Looking Just the Same": Antiretroviral Treatment as Social Danger in Rural Malawi. Social Science \& Medicine 167, 71-78.

Kiene, S. M., S. C. Kalichman, K. M. Sileo, N. A. Menzies, R. Naigino, C.-D. Lin, M. H. Bateganya, H. Lule, and R. K. Wanyenze (2017). Efficacy of An Enhanced Linkage to HIV Care Intervention at Improving Linkage to HIV Care and Achieving Viral Suppression Following Home-Based HIV Testing in Rural Uganda: Study Protocol for The Ekkubo/PATH Cluster Randomized Controlled Trial. BMC Infectious Diseases 17(1), 460.

Kim, B., B. Haile, and T. Lee (2017). Promotion and Persistence of HIV Testing and HIV/AIDS Knowledge: Evidence from a Randomized Controlled Trial in Ethiopia. Health Economics 26(11), 1394-1411.

Kranzer, K., J. Bradley, J. Musaazi, M. Nyathi, H. Gunguwo, W. Ndebele, M. Dixon, M. Ndhlovu, A. Rehman, P. Khan, F. Vogt, T. Apollo, and R. A. Ferrand (2017). Loss to Follow-up Among Children and Adolescents Growing up with HIV Infection: Age Really Matters. Journal of the International AIDS Society 20, 21737.

Kranzer, K., V. Simms, T. Bandason, E. Dauya, G. McHugh, S. Munyati, P. Chanzi, S. Dakshina, H. Mujuru, H. A. Weiss, and R. A. Ferrand (2017). Economic Incentives for HIV Testing by Adolescents in Zimbabwe: A Randomized Controlled Trail. Lancet HIV 5, 79-86.

Larson, B. A., N. Wambua, J. Masila, S. Wangai, J. Rohr, M. Brooks, and M. Bryant (2013). Exploring Impacts of Multi-Year, Community-Based Care Programs for Orphans and Vulnerable Children: A Case Study From Kenya. AIDS Care 25(sup1), S40-S45.

List, J. A., A. M. Shaikh, and Y. Xu (2019). Multiple Hypothesis Testing in Experimental Economics. Experimental Economics 22(4), 773-793.

Lubega, P., F. Nakakawa, G. Narciso, C. Newman, and C. Kityo (2019). HIV Status, Role Models and Attainable Goals: Experimental Evidence on Inspiring Women in Uganda. Working Paper. 
Mahajan, A. P., J. N. Sayles, V. A. Patel, R. H. Remien, S. R. Sawires, D. J. Ortiz, G. Szekeres, and T. J. Coates (2008). Stigma in the HIV/AIDS Epidemic: A Review of the Literature and Recommendations for the Way Forward. AIDS 22 2, S67-S79.

McCoy, S. I., P. F. Njau, C. Fahey, N. Kapologwe, S. Kadiyala, N. P. Jewell, W. H. Dow, and N. S. Padian (2017). Cash vs. Food Assistance to Improve Adherence to Antiretroviral Therapy Among HIV-Infected Adults in Tanzania. AIDS 31(6), 815-825.

Moffitt, R. (1983). An Economic Model of Welfare Stigma. The American Economic Review 73(5), 1023-35.

Moulton, B. R. (1986). Random Group Effects and The Precision of Regression Estimates. Journal of Econometrics 32(3), 385-397.

Nyberg, B. J., D. D. Yates, R. Lovich, D. Coulibaly-Traore, L. Sherr, T. R. Thurman, A. Sampson, and B. Howard (2012). Saving Lives for A Lifetime: Supporting Orphans and Vulnerable Children Impacted by HIV/AIDS. JAIDS Journal of Acquired Immune Deficiency Syndromes 60, S127-S135.

Orne, M. T. (1962). On the Social Psychology of the Psychological Experiment: With Particular Reference to Demand Characteristics and Their Implications. American Psychologist 17, 776-783.

O'Flaherty, B. and R. Sethi (2008). Racial Stereotypes and Robbery. Journal of Economic Behavior and Organization 68(3-4), 511-524.

PEPFAR (2006). Orphans and Other Vulnerable Children: Programming Guidance for United States Government In-Country Staff and Implementing Partners. Washington, USA: PEPFAR.

PEPFAR (2017). 2017 Annual Report to Congress. Washington, USA: PEPFAR.

PEPFAR (2020). PEPFAR 2020 Annual Report to Congress. Washington, USA: Washington, USA: United States Department of State.

Rodger, A., V. Cambiano, T. Bruun, P. Vernazza, S. Collins, O. Degen, G. M. Corbelli, V. Estrada, A. Geretti, and A. Beloukas (2019). Risk of HIV Transmission Through Condomless Sex in Serodifferent Gay Couples with the HIV-Positive Partner Taking Suppressive Antiretroviral Therapy (PARTNER): Final Results of a Multicentre, Prospective, Observational Study. The Lancet 393(10189), 2428-2438.

Rosenthal, R. (1966). Experimenter Effects in Behavioral Research. New York, USA: Appleton-CenturyCrofts.

Schultz, P. W., J. M. Nolan, R. B. Cialdini, N. J. Goldstein, and V. Griskevicius (2007). The Constructive, Destructive, and Reconstructive Power of Social Norms. Psychological Science 18, 429-434.

Shann, M. H., M. H. Bryant, M. I. Brooks, P. Bukuluki, D. Muhangi, J. Lugalla, and G. Kwesigabo (2013). The Effectiveness of Educational Support to Orphans and Vulnerable Children in Tanzania and Uganda. ISRN Public Health 2013, 1-9.

Simmons, R. D., B. C. Ciancio, M. M. Kall, B. D. Rice, and V. C. Delpech (2013). Ten-year Mortality Trends Among Persons Diagnosed with HIV Infection in England and Wales in the Era of Antiretroviral Therapy: AIDS Remains a Silent Killer. HIV Medicine 14, 596-604.

Smith, P., A. Buttenheim, L. Schmucker, L.-G. Bekker, H. Thirumurthy, and D. L. J. Davey (2021). Undetectable $=$ untransmissible $(\mathrm{u}=\mathrm{u})$ messaging increases uptake of hiv testing among men: Results from a pilot cluster randomized trial. AIDS and Behavior 25, 3128-3136.

Ssewamala, F. M., C.-K. Han, and T. B. Neilands (2009). Asset Ownership and Health and Mental Health Functioning Among AIDS-Orphaned Adolescents: Findings from A Randomized Clinical Trial in Rural Uganda. Social Science 83 Medicine 69(2), 191-198.

Stangl, A. L., J. K. Lloyd, L. M. Brady, C. E. Holland, and S. Baral (2013). A Systematic Review of Interventions to Reduce HIV-Related Stigma and Discrimination from 2002 to 2013: How Far Have We Come? Journal of the International AIDS Society 16, 18734.

Thornton, R. L. (2008). The Demand for, and Impact of, Learning HIV Status. American Economic Review 98(5), 1829-1863.

UNAIDS (2019). UNAIDS Data 2018. Geneva, Switzerland:: Joint United Nations Programme on HIV/AIDS. 
UNAIDS (2020). UNAIDS Data 2019. Geneva, Switzerland:: Joint United Nations Programme on HIV/AIDS.

United Nations (2016). Political Declaration on HIV and AIDS: On the Fast Track to Accelerating the Fight Against HIV and to Ending the AIDS Epidemic by 2030. New York, USA: United Nations General Assembly.

US State Department (2015). PEPFAR Country/Regional Operational Plan (COP/ROP) 2016 Guidance. The U.S. President's Emergency Plan for AIDS Relief. PEPFAR.

US State Department (2019). Congressional Budget Justification: Department of State, Foreign Operations, and Related Programs Fiscal Year 2020. District of Columbia, USA: United States Department of State.

USAID (2012). Guidance for Orphans and Vulnerable Children Programming. The U.S. President's Emergency Plan for AIDS Relief. PEPFAR.

Vishwanath, T. (1989). Job Search, Stigma Effect, and Escape Rate from Unemployment. Journal of Labor Economics 7(4), 487-502.

Whetten, K., J. Ostermann, B. W. Pence, R. A. Whetten, L. C. Messer, S. Ariely, K. O'Donnell, A. I. Wasonga, V. Vann, D. Itemba, M. Eticha, I. M. andN. M. Thielman, and POFO (2015). Three-Year Change in The Well being of Orphaned and Separated Children in Institutional and Family-Based Care Settings in Five Low-And Middle-Income Countries. PLOS One 9(8), 1-10.

WHO (2017). Mozambique: HIV Country Profile: 2016. WHO.

World Bank (2020). Work Bank Open Data.

Yang, D., A. Mahumane, J. Riddell, and H. Yu (2019). Direct and Spillover Impacts of a CommunityLevel HIV/AIDS Program: Evidence from a Randomized Controlled Trail in Mozambique. Journal of Development Economics, Pre-Results Review Paper, Stage 1.

Yotebieng, M., K. E. Moracco, H. Thirumurthy, A. Edmonds, M. Tabala, B. Kawende, L. K. Wenzi, E. W. Okitolonda, and F. Behets (2017). Conditional Cash Transfers Improve Retention in PMTCT Services by Mitigating the Negative Effect of Not Having Money to Come to The Clinic. Journal of Acquired Immune Deficiency Syndromes 74(2), 150-157.

$\mathrm{Yu}$, H. (2021). Social Stigma as a Barrier to HIV Testing: Evidence from a Randomized Experiment in Mozambique. Peking University Working Paper.

Zizzo, D. J. (2010). Experimenter Demand Effects in Economic Experiments. Experimental Economics 13, $75-98$. 
Figure 1: Randomization Design and Timeline

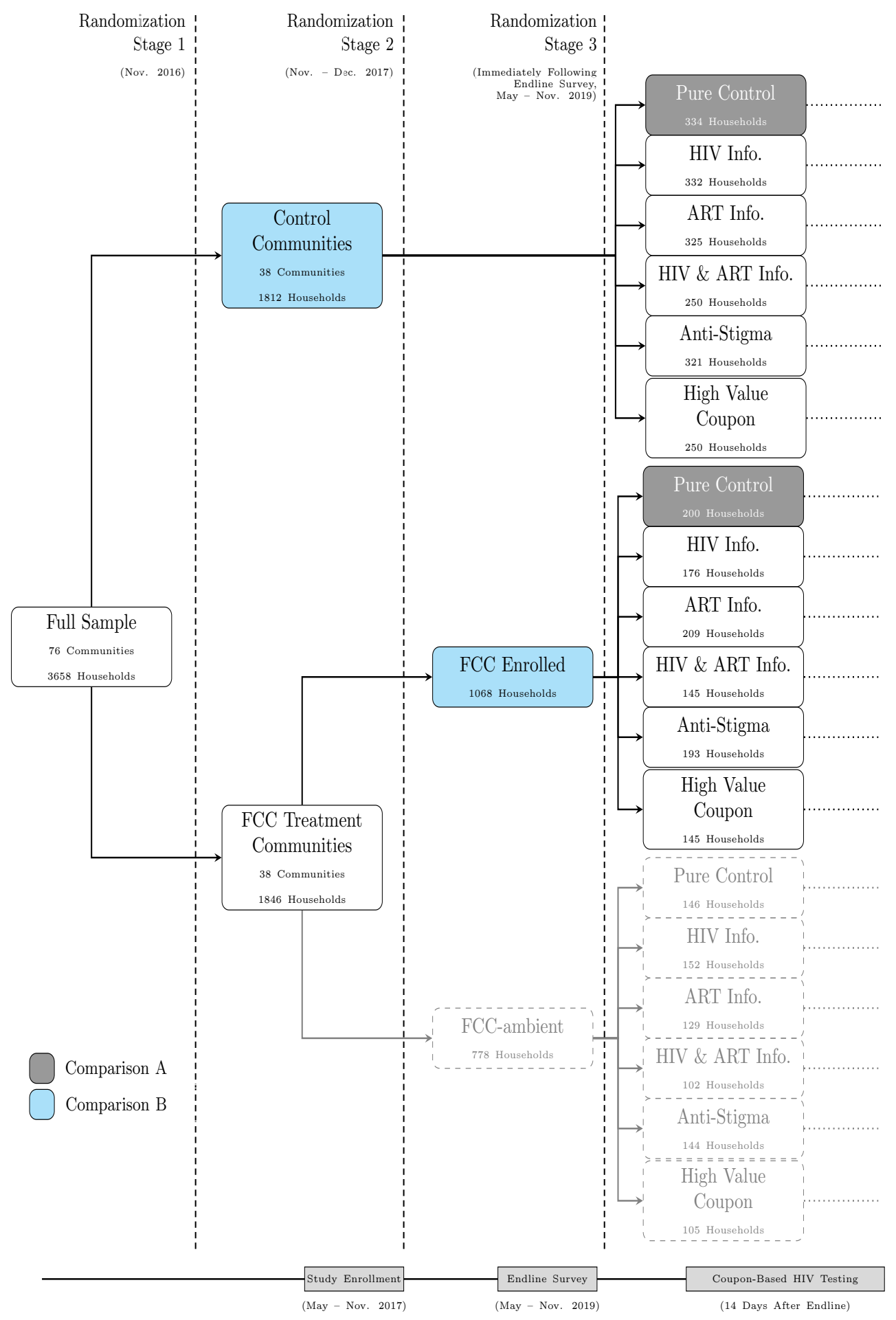


Figure 2: Stigma Environment Measures in Mozambique over Time

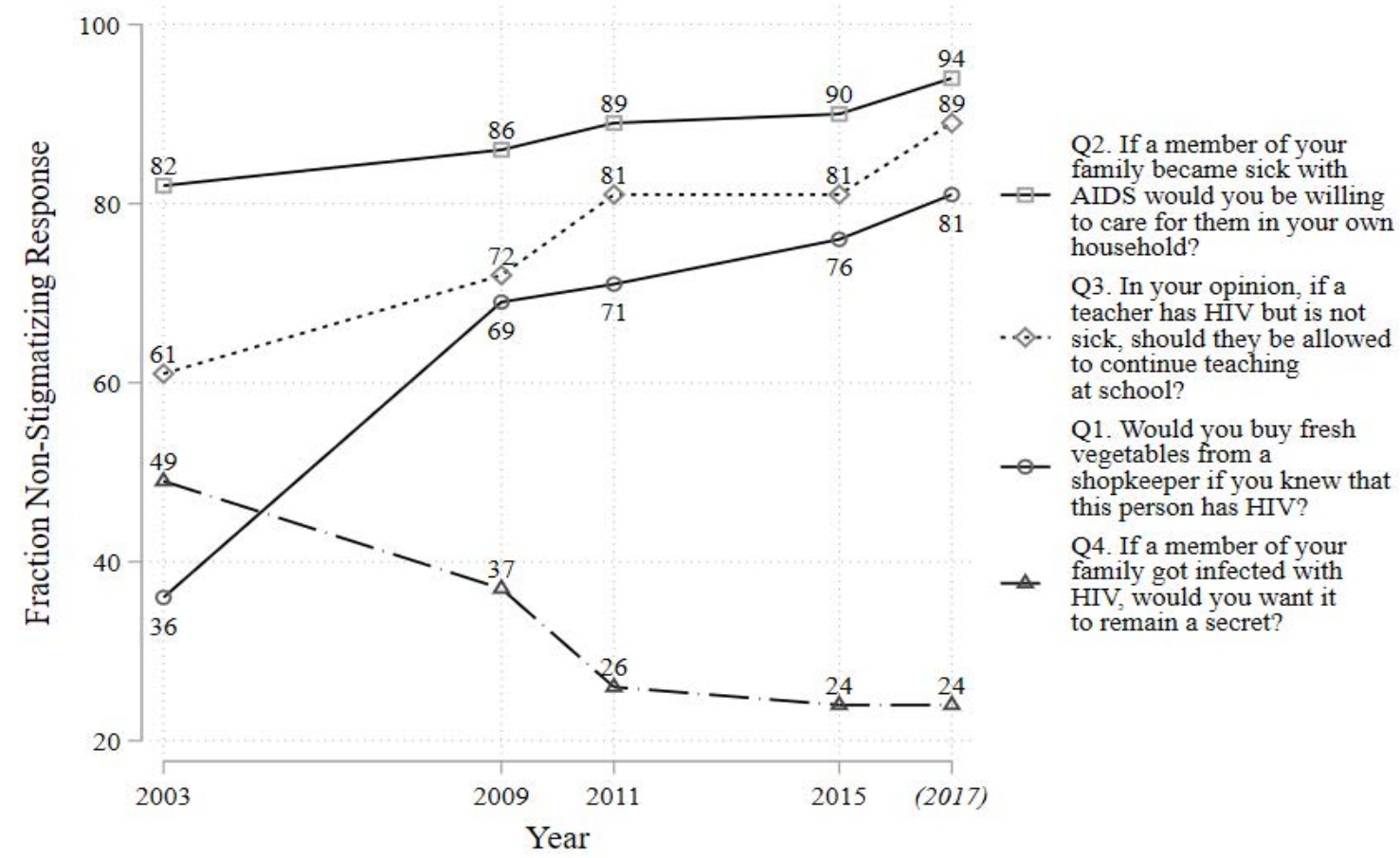

Source: Data points for 2003, 2009, 2011, 2015 are calculated from the nationally representative sample of Mozambique AIDS Indicator Survey (AIS) under the Demographic and Health Surveys program (www.dhsprogram.com) funded by USAID. Data points for 2017 are calculated by taking simple averages from the baseline survey of this study. 
Table 1: HIV Testing

\begin{tabular}{lcccc}
\hline VARIABLES & $\begin{array}{c}(1) \\
\text { Coupon Redemption } \\
\text { for HIV Testing }\end{array}$ & $\begin{array}{c}(2) \\
\text { Coupon Redemption } \\
\text { for HIV Testing }\end{array}$ & $\begin{array}{c}(3) \\
\text { Self-Reported } \\
\text { HIV Testing }\end{array}$ & $\begin{array}{c}\text { Combined HIV } \\
\text { Testing Measure }\end{array}$ \\
\hline Treatment & -0.0212 & $-0.105^{* * *}$ & 0.0234 & 0.0222 \\
& $(0.0182)$ & $(0.0386)$ & $(0.0233)$ & $(0.0193)$ \\
& {$[0.371]$} & {$[0.016]$} & {$[0.420]$} & {$[0.253]$} \\
Any Minitreatment & & -0.0256 & & \\
& & $(0.0259)$ & & \\
Treatment * Any minitreatment & & {$[0.337]$} & & \\
& & $0.103 * *$ & & \\
& & $(0.0403)$ & & \\
Observations & & {$[0.017]$} & & \\
R-squared & 3,658 & 3,658 & 0.038 & \\
Obs level & 0.058 & 0.060 & 0.031 \\
Control Mean Dep. Var. & Household & Household & Household & Household \\
\hline
\end{tabular}

Notes: Dependent variables are as follows. Columns 1-2: indicator equal to one if someone in household got an HIV test at local health clinic (based on redemption of encouragement coupon for HIV testing), and zero otherwise. Column 3: indicator equal to one if someone in household self-reported in endline survey having gotten an HIV test in last 12 months, and zero otherwise. Column 4: indicator that either the coupon-based or self-reported HIV testing measures is equal to one, and zero otherwise. "Treatment" defined in Table A.3. "Any Minitreatment" is indicator equal to one if household was assigned to any minitreatment after the endline survey in Randomization Stage 3, and zero otherwise. See Section 5.2 for definition of minitreatments. All regressions control for indicator for "FCC ambient" status and matched pair fixed effects. Regression in Column 2 also includes interaction term between "Any Minitreatment" and indicator for "FCC ambient" status. Standard errors clustered at the community level in parentheses. P-values adjusted for multiple hypothesis testing (as described in Section 4.4) in square brackets. 
Table 2: HIV-Related Knowledge

\begin{tabular}{|c|c|c|c|c|c|c|}
\hline & (1) & $(2)$ & $(3)$ & (4) & (5) & (6) \\
\hline VARIABLES & $\begin{array}{c}\text { HIV } \\
\text { Knowledge } \\
\text { Index }\end{array}$ & $\begin{array}{l}\text { General HIV } \\
\text { Knowledge } \\
\text { Index }\end{array}$ & $\begin{array}{c}\text { Correct Methods } \\
\text { of Transmission } \\
\text { Index }\end{array}$ & $\begin{array}{c}\text { Transmission } \\
\text { Myth } \\
\text { Index }\end{array}$ & $\begin{array}{l}\text { Protection } \\
\text { Methods } \\
\text { Index }\end{array}$ & $\begin{array}{c}\text { Knowledge about } \\
\text { HIV Treatment } \\
\text { Index }\end{array}$ \\
\hline Treatment & $\begin{array}{c}-0.00598 \\
(0.00828) \\
{[0.472]}\end{array}$ & $\begin{array}{c}-0.00602 \\
(0.00961) \\
{[0.616]}\end{array}$ & $\begin{array}{c}-0.00788 \\
(0.0134) \\
{[0.653]}\end{array}$ & $\begin{array}{c}-0.0302^{* *} \\
(0.0148) \\
{[0.132]}\end{array}$ & $\begin{array}{c}0.00199 \\
(0.00906) \\
{[0.859]}\end{array}$ & $\begin{array}{c}0.00234 \\
(0.00989) \\
{[0.846]}\end{array}$ \\
\hline Observations & 3,940 & 3,940 & 3,940 & 3,940 & 3,940 & 3,940 \\
\hline R-squared & 0.062 & 0.052 & 0.039 & 0.071 & 0.051 & 0.065 \\
\hline Obs level & Adult & Adult & Adult & Adult & Adult & Adult \\
\hline Control Mean Dep. Var. & 0.756 & 0.623 & 0.831 & 0.747 & 0.823 & 0.772 \\
\hline
\end{tabular}

Notes: Dependent variables are as follows. Column 1: fraction of all 33 HIV knowledge questions answered correctly. Columns 2-6: fraction of subsets of HIV knowledge questions answered correctly. For full list of knowledge questions and groupings by subcategory, see Appendix Section D. "Treatment" defined in Table A.3. All regressions control for indicator for "FCC ambient" status and matched pair fixed effects. Standard errors clustered at the community level in parentheses. $\mathrm{P}$-values adjusted for multiple hypothesis testing in square brackets.

Table 3: HIV-Related Stigmatizing Attitudes

\begin{tabular}{lccccc}
\hline VARIABLES & $\begin{array}{c}(1) \\
\text { HIV Stigma } \\
\text { Attitude } \\
\text { Index }\end{array}$ & $\begin{array}{c}\text { Buy Groceries } \\
\text { from Infected } \\
\text { Person }\end{array}$ & $\begin{array}{c}(3) \\
\text { Not Keep } \\
\text { Infected Family } \\
\text { Member a Secret }\end{array}$ & $\begin{array}{c}(4) \\
\text { Care for Infected } \\
\text { Family Member } \\
\text { in Own Home }\end{array}$ & $\begin{array}{c}\text { Infected Teacher } \\
\text { Should be } \\
\text { Allowed to Teach }\end{array}$ \\
\hline Treatment & & & & & \\
& $-0.0135^{* * *}$ & -0.0139 & -0.0281 & -0.00506 & -0.00330 \\
& $(0.00505)$ & $(0.00991)$ & $(0.0196)$ & $(0.00313)$ & $(0.00657)$ \\
& {$[0.009]$} & {$[0.272]$} & {$[0.288]$} & {$[0.176]$} & {$[0.708]$} \\
Observations & & & & & 3,748 \\
R-squared & 3,820 & 3,756 & 3,777 & 3,801 & 0.028 \\
Obs level & 0.025 & 0.039 & 0.048 & 0.017 & Adult \\
Control Mean Dep. Var. & Adult & Adult & Adult & Adult & 0.965 \\
\hline
\end{tabular}

Notes: Dependent variables are as follows. Column 1: fraction of four questions on HIV-related stigma answered in a non-stigmatizing way. Columns 2-5: for each separate question on HIVrelated stigmatizing attitudes, indicator equal to one if answered in a non-stigmatizing way, and zero otherwise. For full detail on each stigmatizing attitudes question, see Appendix Section D. "Treatment" defined in Table A.3. All regressions control for indicator for "FCC ambient" status and matched pair fixed effects. Standard errors clustered at the community level in parentheses. P-values adjusted for multiple hypothesis testing (as described in Section 4.4) in square brackets. 
Table 4: Minitreatment Impacts on HIV Testing Coupon Redemption

\begin{tabular}{|c|c|c|}
\hline VARIABLES & $\begin{array}{l}(1) \\
\text { HIV Testing } \\
\text { Coupon Redemption }\end{array}$ & $\begin{array}{l}(2) \\
\text { HIV Testing } \\
\text { Coupon Redemption }\end{array}$ \\
\hline Treatment & $\begin{array}{l}-0.0212 \\
(0.0183)[0.485]\end{array}$ & $\begin{array}{l}-0.105^{* * *} \\
(0.0387)[0.032]\end{array}$ \\
\hline Anti-Stigma & $\begin{array}{l}0.00427 \\
(0.0230)[0.649]\end{array}$ & $\begin{array}{l}-0.0521^{*} \\
(0.0283)[0.025]\end{array}$ \\
\hline HIV Info. & $\begin{array}{l}-0.0136 \\
(0.0233)[0.618]\end{array}$ & $\begin{array}{l}-0.0474 \\
(0.0329)[0.113]\end{array}$ \\
\hline ART Info. & $\begin{array}{l}-0.00810 \\
(0.0245)[0.312]\end{array}$ & $\begin{array}{l}-0.0282 \\
(0.0330)[0.163]\end{array}$ \\
\hline High Value Coupon & $\begin{array}{l}0.0724^{* *} \\
(0.0288)[0.044]\end{array}$ & $\begin{array}{l}0.0342 \\
(0.0450)[0.492]\end{array}$ \\
\hline HIV and ART Info. & $\begin{array}{l}-0.0224 \\
(0.0242)[0.349]\end{array}$ & $\begin{array}{l}-0.0136 \\
(0.0368)[0.826]\end{array}$ \\
\hline Treatment $*$ Anti-Stigma & & $\begin{array}{l}0.142^{* * *} \\
(0.0491)[0.008]\end{array}$ \\
\hline Treatment $*$ HIV Info. & & $\begin{array}{l}0.119 * * \\
(0.0525)[0.025]\end{array}$ \\
\hline Treatment $*$ ART Info. & & $\begin{array}{l}0.120^{* *} \\
(0.0548)[0.032]\end{array}$ \\
\hline Treatment $*$ High Value Coupon & & $\begin{array}{l}0.118^{*} \\
(0.0592)[0.062]\end{array}$ \\
\hline Treatment $*$ HIV and ART Info. & & $\begin{array}{l}-0.00895 \\
(0.0556)[0.644]\end{array}$ \\
\hline Observations & 3,658 & 3,658 \\
\hline R-squared & 0.062 & 0.067 \\
\hline Obs level & Household & Household \\
\hline Control Mean Dep. Var. & 0.263 & 0.263 \\
\hline
\end{tabular}

Notes: Dependent variable in both columns is indicator equal to one if someone in household got an HIV test at local health clinic (based on redemption of encouragement coupons for HIV testing), and zero otherwise. "Treatment" defined in Table A.3. See Section 5.2 for definition of minitreatments. All regressions control for indicator for "FCC ambient" status and matched pair fixed effects. Column 2 regression also controls for "FCC-Ambient" indicator interacted with each minitreatment indicator. Coefficients on "FCC-Ambient" main effect and interaction terms reported in Populated PAP. Standard errors clustered at the community level in parentheses. Pvalues adjusted for multiple hypothesis testing (as described in Section 4.4) in square brackets. 


\section{For Online Publication: Appendix}

\section{A Proof of Proposition 1}

We characterize the pure strategy Perfect Bayesian Equilibria of our theoretical model. In Section 2 the main text, we analyzed the partially separating equilibrium of Proposition 1. We now analyze the pooling equilibrium.

In this equilibrium, a fraction $P \in(0,1]$ of individuals in $\mathcal{B}$ interact if and only if $A$ has sought an HIV test. The remaining fraction $1-P$ of player B interact with all matches. The equilibrium is based on some extreme off-equilibrium beliefs about those who do not test, and $P$ must be large enough to induce universal HIV testing.

To characterize the pooling equilibrium, first consider the strategy of player $A$ given the fraction $P$. $A$ chooses his strategy to

$$
\max _{t_{a} \in\{0,1\}}\left(\theta_{a} v-c+P y_{a}\right) t_{a}+(1-P) y_{a} .
$$

He will test if and only if

$$
y_{a}>\frac{c-\theta_{a} v}{P} .
$$

Assumption (1) yields that $c-\theta_{H} v<0$, so all high-risk individuals in $\mathcal{A}$ will test. We next show that, for a pooling equilibrium to exist, all low-risk individuals must also choose to test, or equivalently,

$$
\operatorname{Pr}\left(y_{a}>\frac{c-\theta_{L} v}{P}\right)=1 .
$$

To see why, assume that some low-risk players choose not to test, players in $\mathcal{B}$ will then conclude that the non-test-taker's type is $\theta_{a}=\theta_{L}$. According to Assumption (4), every $B \in \mathcal{B}$ will choose to interact with a low-risk $A$, and therefore $P=0$, which is a contradiction. For Equation (A.1) to hold, $P$ needs to be large enough such that

$$
P>\frac{c-\theta_{L} v}{\mathrm{y}}
$$

To sum up, given a $P \in(0,1]$ that satisfies the restriction in (A.2), all individuals in $\mathcal{A}$ choose to take tests (universal testing).

Now consider $B$ 's best responses given universal testing in $\mathcal{A}$. By Assumption (4), individuals in $\mathcal{B}$ will interact with any matched $A$.

Since the best response of all player $A \in \mathcal{A}$ is to get tested, $B$ 's belief about an untested match can take any value. In fact, this action is off the equilibrium path. A belief that maximizes $P$ is $\hat{\theta}_{b}(0)=1$. In this case, $B$ will interact with an untested $A$ if and only if 
$y>\hat{\tau} z$ and $P$ is given by

$$
P=\int_{\underline{\mathrm{y}}}^{\hat{\tau} z} \mathrm{~d} \mathcal{G}
$$

A pooling equilibrium exists if and only if parameters in this model allow both (A.2) and (A.3) to hold.

The final step in proving Proposition 1 is ruling out two other types of potential equilibria: (i) $S=P=0$, (ii) $S, P>0$.

First, consider $S=P=0$, which means that all individuals in $\mathcal{B}$ interact whether or not $A$ has been tested. Now the optimization problem $A$ faces becomes

$$
\max _{t_{a} \in\{0,1\}}\left(\theta_{a} v-c\right) t_{a}+y_{a}
$$

Assumption (1) implies that the high-risk type will test and the low-risk type will not. So a player $B$ will update her belief to $\hat{\theta}_{b}(1)=\theta_{H}$. By Assumption (4), some $B \in \mathcal{B}$ will then reject $A$ that has been tested, which contradicts $S=0$.

Then, consider the case where $S, P>0$. In this case, $A$ faces the problem of

$$
\max _{t_{a} \in\{0,1\}}\left[\theta_{a} v-c+(P-S) y_{a}\right] t_{a}+(1-P) y_{a} .
$$

Suppose $P>S>0$, we consider two subcases. First, when $P-S$ is not large enough to induce universal testing, that is,

$$
\operatorname{Pr}\left(y_{a}>\frac{c-\theta_{L} v}{P-S}\right)<1,
$$

some low-risk $A$ will not test. Hence, individuals in $\mathcal{B}$ will update their beliefs to $\hat{\theta}_{b}(0)=\theta_{L}$. By assumption (4), $\mathcal{B}$ will always interact with untested $A$, which contradicts $P>0$.

Second, if $P-S$ is large enough to induce universal testing, i.e.,

$$
\operatorname{Pr}\left(y_{a}>\frac{c-\theta_{L} v}{P-S}\right)=1,
$$

then, the rational belief about those who get tested is the average risk level $\hat{\theta}_{b}(1)=\bar{h}$. So, $B$ will accept every tested $A$, thus $S=0$, which also leads to contradiction.

Suppose $S \geq P>0$, a low-risk $A$ will never test. If some high-risk $A$ choose to test, then, $B$ will update her belief to $\hat{\theta}_{b}(0)<\bar{h}$, which leads to $P=0$. If no high-risk $A$ takes a test either, $B$ will hold the belief of $\hat{\theta}_{b}(0)=\bar{h}$, which again leads to $P=0$. In sum, there is no equilibrium such that $S=P=0$ or $S, P>0$. 


\section{B Other Components of FCC Program}

The other FCC program components are as follows. These other components reached only a relatively small fraction of those reached by home visits.

- Education subsidies for girls: The FCC program provides a limited amount of funding to support school participation among girls considered particularly at-risk of dropping out of school. LIPs select the most at-risk girls in a particular community after consultation with school officials and the Community Child Protection Committee (CCPC). Beneficiary secondary school-age girls each receive up to US $\$ 75$ in school fees, and elementary school-age girls up to US\$50 in school materials (books and uniforms). The exact amounts and funded items vary by community and LIP. In FCC communities, $6.33 \%$ of households in the endline survey reported benefiting from the education subsidies for girls component of FCC. The corresponding share among FCC-enrolled households is $6.36 \%$.

- Child Rights Clubs (CRCs): These are school-based clubs for both girls and boys aiming to equip children with knowledge and skills related to child protection, genderbased violence, and psychosocial support. Topics covered include early marriage, teen pregnancy, reproductive and sexual health, and HIV/AIDS. Participants learn how to report abuse and how to make healthy choices. Activities are child-facilitated with adult oversight. Girls concurrently also take part in associated "Girls' Empowerment Clubs" which provide additional mentoring and support tailored to girls. In FCC communities, exactly $0 \%$ of households (whether FCC-enrolled or overall) in the endline survey reported any participation by their children in the Child Rights Clubs (CRCs) component of FCC.

- Health and Nutrition Assessments: Using an established protocol, LIP staff conduct nutritional screenings of OVCs aged 6 months to 14 years. Screenings occur in school and community settings. Children identified as malnourished may be provided with food supplements for a limited period, and the most severely malnourished are referred to health clinics. In FCC communities, 3.95\% of households reported in the endline survey that some child in the household participated in the health and nutrition assessments component of FCC; the corresponding figure for FCC-enrolled households was $4.40 \%$.

- Youth Economic Strengthening (YES) clubs: YES clubs are a community-based financial education program for both girls and boys who are out-of-school OVCs aged 15-18. Separate clubs are established for girls and boys. The program provides livelihood and entrepreneurship training, aimed at small-scale commercial rather than subsistence agriculture. In FCC communities, $0.92 \%$ of households reported in the endline survey 
that some child in the household participated in the Youth Economic Strengthening (YES) component of FCC; the corresponding figure for FCC-enrolled households was $0.75 \%$.

- Village Savings and Loan (VSL) groups: VSL programs involve facilitating and training individuals to organize themselves into simple savings and credit groups, with the aim of improving access to savings and credit in populations that are poorly served by formal institutions. Members can take loans from the communal pool of savings, upon review and approval by the group. Loans are repaid with interest, at an interest rate decided upon by the group. Groups manage their own funds, which are all internally generated from savings and interest earnings from loans. LIP staff formed VSL groups with a mixture of OVC and non-OVC households, as well as youth participating in YES clubs. In FCC communities, $4.23 \%$ of households reported participating in the Village Savings and Loan (VSL) groups component of FCC; the corresponding figure for FCC-enrolled households was 3.93\%. 


\section{Details of Data Sources}

Key data sources are a vulnerability assessment survey administered at household enrollment in the study, an endline survey, and HIV testing as observed from redemption of testing encouragement coupons.

\section{C.1 Vulnerabilty Assessment, Household Study Enrollment, and Baseline Survey}

The target population of this study is OVCs and the households in which they live. OVC households were identified via door-to-door enumeration of households with a predefined list of questions to identify orphans and vulnerable children. Due to the sensitive nature of such questions, the protocol for identifying OVCs and their households was designed in close consultation with FCC program local implementing partner (LIP) organizations, and field-tested to ensure cultural acceptance.

Within both treatment and control communities, creation of the study household sample proceeded in several stages. First, 120 households were selected for administration of a vulnerability assessment (VA), whose purpose was to identify OVC households (intended beneficiaries of the FCC program). In communities surrounding eligible schools, households were selected for VAs using random-route sampling. ${ }^{1}$ The VA consisted of a short set of questions to determine the household's OVC status. Households were defined as OVC households if any of the following conditions were true: a grandparent was head of the household (with no parents present); the ratio of children to adults was greater than four; at least one school-aged child was not attending school; the household ate fewer than two meals per day; the household goes some days without food; the household has illegal income or no income; the household has a chronically ill member, an HIV infected member, or a member receiving antiretroviral therapy (ART); there are orphans in the household (one or both parents deceased); or an adult died of a chronic illness in the last five years. ${ }^{2}$ We administered vulnerability assessment (VA) surveys to 10,056 households. Of these, we

\footnotetext{
${ }^{1}$ From the focal school in each of 76 study communities, interviewers were given a starting point from which they followed routing instructions that defined travel directions and selection of households to interview. Directions were randomly assigned, as were distances between successive surveyed households. This procedure resulted in households distributed as far as two kilometers from the focal school in each community.

${ }^{2}$ This definition was agreed upon with USAID's Mozambique Mission and World Education/Bantwana, and captures households disadvantaged for reasons beyond the narrow definition of an OVC according to PEPFAR. PEPFAR's definition (PEPFAR, 2006) of an OVC is a child, 0-17 years old, who is either orphaned or made more vulnerable because of HIV/AIDS. An "orphan" is a child who has lost one or both parents to $\mathrm{HIV} / \mathrm{AIDS}$. A child is considered "vulnerable" if he or she: (a) is HIV-positive; (b) lives without adequate adult support (e.g., in a household with chronically ill parents, a household that has experienced a recent death from chronic illness, a household headed by a grandparent, and/or a household headed by a child); (c) lives outside of family care (e.g., in residential care or on the streets); or (d) is marginalized, stigmatized, or discriminated against.
} 
classified $71.7 \%$ as OVC households. These OVC households are the population of interest in this study.

We then selected a subset of households for administration of a household baseline survey. Within the set of OVC households in a community (typically numbering 80-90), 40 were randomly selected as baseline survey households. The baseline survey asked a comprehensive set of questions at household and individual levels on demographics, health (morbidity, mortality, and child anthropometric measurements), schooling, assets, income, labor supply, migration, financial access (credit and savings), and financial decision-making. It also included a comprehensive set of questions on beliefs about HIV, HIV testing and treatment, and sexual behavior. These baseline data were mainly used to provide an understanding of the general characteristics of households in the sample. Because the baseline was not administered to all households, we make limited use of it in the present study. The baseline survey's main use for the present paper is as the data source for community-specific information on HIV-related stigmatizing attitudes, for the anti-stigma minitreatment (see Appendix Section F.1 below).

All surveys were conducted in the main local languages spoken in the study districts by a Mozambican survey research firm under the supervision of the co-authors. The survey respondent for household-level questions was the adult (aged above 18) household head. Other adult household members were administered certain survey sections (such as on health and sexual activity) with individual responses, if they were present at the time of the survey. For children (aged 0-18), their parent or guardian was asked to answer health questions on their behalf.

Survey responses in the field were recorded on digital tablets using SurveyCTO software with internal logic checks to reduce data entry error. Real-time digital data collection eliminated the need for separate data entry from paper surveys, eliminating one important source of data entry error. Data collected in the field were uploaded to a secure cloud server at the end of each workday, for immediate review and processing. Exact geo-coordinates (latitude and longitude) of each household were recorded using the tablet's GPS functionality, greatly easing the process of locating households between the vulnerability assessment, baseline survey, and endline survey. ${ }^{3}$

Vulnerability assessments and administration of informed consent for household enrollment in the study occurred from May to November 2017, with the exception of 46 sample households (1.3\%) in one community that were enrolled in March 2018 due to an implementation delay. Figure A.1 shows the number of households in our study sample by month of enrollment.

\footnotetext{
${ }^{3}$ See our research website (https://fordschool.umich.edu/mozambique-research/fcc-hiv-aids) for our survey instruments.
} 
Figure A.1: Number of Study Sample Households Enrolled, by Month

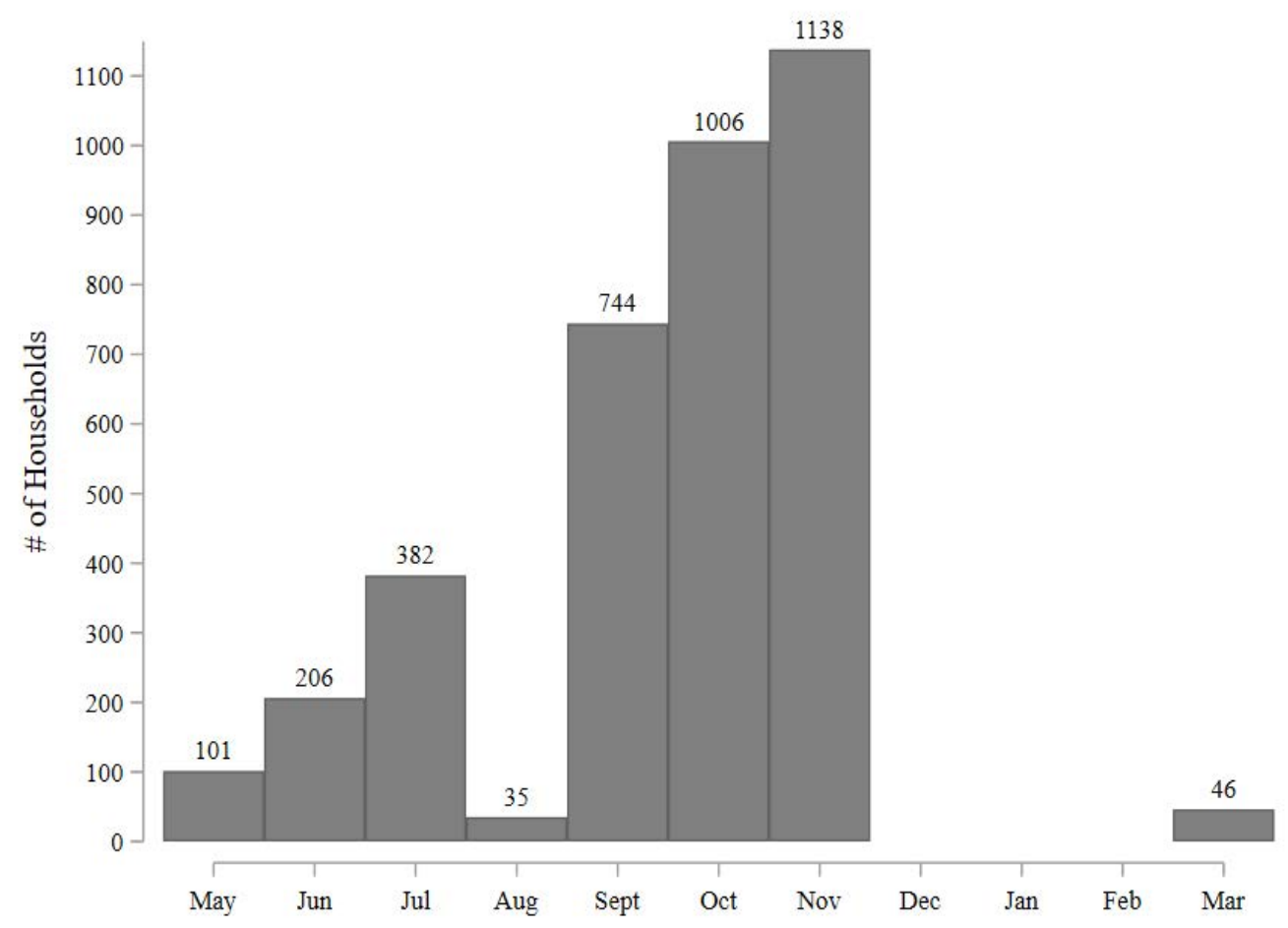

Notes: Number of study sample households administered vulnerability assessment for determination of OVC status and consenting to participation in this research study, by month from May 2017 to March 2018. 98.7\% of sample households were enrolled in study by November 2017 .

The baseline survey was administered to a randomly-selected subset of households enrolled in the study. It was fielded on a rolling basis from May 2017 to March 2018.

\section{C.2 Endline Survey}

The endline household survey was administered from May to November 2019. The endline survey collected data on an array of intermediate and final outcomes. Communities were surveyed in the same order they were contacted for the vulnerability assessment and study enrollment in 2017-18.

Due to budget limitations, we aimed to survey at endline only a subset of households who had been enrolled in the study in 2017. We first designated for inclusion in the endline survey all households that had been randomly assigned to be fielded the baseline survey, numbering approximately 40 per community. We then randomly selected another 20 households from among study-enrolled households that had been administered only the vulnerability assess- 
ment but not the full baseline survey. This resulted in a pre-defined sample of study-enrolled households to include in the endline survey. ${ }^{4}$

A total of 4,546 households ( 59.8 households per community) were targeted for endline surveying in May-Nov 2019. The sample for analysis in this paper are the 3,658 (80.5\%) who we were able to reach in the endline survey in the first week of endline survey fieldwork in each community (the endline survey "first round"). We show in Table A.5 in the main text that there is no imbalance in survey success rates among FCC-enrolled households and control households.

The $19.5 \%$ of households that we were not able to survey in the first few days of endline fieldwork were subject to intensive follow-up efforts some weeks later (the endline survey "intensive follow-up round"), and will be included in future papers that examine longer-term effects of the FCC program. We eventually were able to find and survey $62.5 \%$ of these remaining households. These households surveyed in the "intensive follow-up round" cannot be included in this paper's analysis because we do not have data for them on our primary outcome variable of interest, coupon-based HIV testing. Redemption of the encouragement coupons for HIV-testing was organized by our research staff, whom we could not afford to keep posted at local health clinics beyond the 14-day period after the endline survey "first round". Households surveyed in the "intensive follow-up round" were not provided with the encouragement coupons for HIV testing.

Table A.1: Sample Households by Treatment

\begin{tabular}{lccc|c}
\hline & \multicolumn{2}{c|}{ FCC Treatment } & FCC Control & Total \\
\hline Randomization Stage 3 Treatments & FCC Enrolled & FCC-ambient & & \\
\hline Anti-Stigma & 193 & 144 & 321 & 658 \\
HIV/AIDS Information & 176 & 152 & 332 & 660 \\
ART Information & 209 & 129 & 325 & 663 \\
Combined HIV/AIDS and ART Information & 145 & 102 & 250 & 497 \\
High Testing Incentive & 145 & 105 & 250 & 500 \\
Pure Control & 200 & 146 & 334 & 680 \\
\hline Total & 1068 & 778 & 1812 & 3658 \\
\hline
\end{tabular}

\section{C.3 Coupon-based Measure of HIV Testing}

The outcome variables in the endline survey are all self-reported. With self-reported measures, there are concerns about reporting bias. In particular, there is a worry that those in the treatment group will tend to falsely overstate outcomes in the direction of being more

\footnotetext{
${ }^{4}$ We defined these households for inclusion in the endline survey in November and December 2017, immediately prior to implementation of Randomization Stage 2 which randomly assigned FCC-enrolled status among these households.
} 
"compliant" with expectations for HIV testing. We therefore measure HIV testing via direct observation of behavior. We also measure self-reported HIV testing in the endline survey. We state in our pre-analysis plan that if estimated treatment effects point in different directions for the survey-reported and directly-observed coupon-based HIV testing outcomes, we will base conclusions on the coupon-based HIV testing outcome.

The directly-observed HIV testing measure is based on redemption of HIV testing coupons at health clinics. ${ }^{5}$ At the time of the endline survey, our survey team recommended that individuals in the household be tested for HIV (if they had not had a test performed within the past three months) at a specified local health clinic within the next 14 days. To allow tracking of those who follow through with testing, households were given coupons redeemable for a small financial incentive (50 MZN) at the health clinic after having the HIV test. To receive the financial incentive after having their HIV test, individuals had to present the coupon to our research staff (also stationed at the health clinic), along with a form signed by clinic staff that the individual had just gotten an HIV test. Coupons had a unique household code, allowing us to track redemption of the coupons. Coupons were offered in all households, whether in treatment or control communities, and irrespective of FCC enrollment status. ${ }^{6}$ 11,304 coupons were distributed to individuals in our study communities. $28.6 \%$ of these coupons were redeemed at their local health clinic for an HIV test within the following 14 days.

An indicator for at least one of a household's coupons being redeemed (indicating at least one household member had an HIV test in the 14-day window) is our directly observed HIV testing outcome variable. Because this outcome represents a real, administratively recorded health behavior, it avoids potential reporting biases associated with survey-reported HIV testing. Conceptually, it captures a household's receptiveness to a recommendation to be HIV tested.

\section{C.4 Blinding}

There is no blinding of treatment status. Participants are aware that the research project aims to evaluate the FCC program, but are not explicitly informed of trial hypotheses. Households randomized into FCC-enrolled status (Randomization Stage 2) were not explic-

\footnotetext{
${ }^{5}$ Our protocols are modeled on Kranzer et al. (2017), who successfully implemented this approach to measuring HIV testing rates in neighboring Zimbabwe.

${ }^{6}$ We gave households as many coupons as needed, for however many individuals did not know their status or reported being HIV negative but were tested more than three months in the past. In the informed consent process, households were informed of this invitation to be tested for HIV, that the unique code on the coupon allowed the study to know if it was redeemed, and of controls in place to ensure the confidentiality of the coupon redemption data. We allowed study participants to opt out of being offered coupons, and remain in the study. In the rare case of a household in which all individuals are reported to be HIV positive in the survey, the recommendation to undergo HIV testing was not extended and the coupons not offered. The coupon-based HIV testing outcome variable is coded as zero for households refusing incentive coupons, and in households where everyone had been tested within the last three months or in which everyone was already (known and reported to be) HIV-positive.
} 
itly told their $\mathrm{CCW}$ home visit resulted from being randomly assigned to FCC-enrolled status. While FCC-ambient households in FCC communities may not realize their community has the FCC program, this information is not withheld from them. Households randomly selected for minitreatments (Randomization Stage 3) were not explicitlyold their minitreatment was provided as the result of random assignment.

Treatment effect estimates related to Randomization Stages 1 and 2 may be subject to biases in self-reporting in the endline survey. For example, there may be experimenter demand effects if respondents realize that the FCC program is intended to raise rates of HIV testing, leading them to falsely overstate this outcome. (Treatments administered during Randomization Stage 3 were administered only after administration of the endline survey and so cannot influence endline survey data.) The possibility of such biased self-reporting motivates the coupon-reported measure of HIV testing. 


\section{Questions on HIV-Related Stigmatizing Attitudes and on HIV Knowledge}

We use four questions on HIV-related stigmatizing attitudes that we adopted from the worldwide panel AIDS Indicator Survey of the DHS Program. ${ }^{7}$ The questions have been fielded in Mozambique as well as other DHS countries since 2003. The most recent round with data available is from 2015. We asked these questions in the baseline survey (administered to a randomly selected subset of sample households) and the endline survey (administered to all sample households). Answers taken to be non-stigmatizing are indicated in parentheses.

- J17: Would you buy fresh vegetables from a shopkeeper or vendor if you knew that this person had HIV? (Yes)

- J18: If a member of your family got infected with HIV, would you want it to remain a secret? (No)

- J19: If a member of your family became sick with AIDS would you be willing to care for them in your own household? (Yes)

- J20: In your opinion, if a teacher has HIV but is not sick, should they be allowed to continue teaching at school? (Yes)

Responses to these questions from our baseline survey, shown in Table A.2 and used for implementation of the anti-stigma minitreatment, are consistent with the findings from the Mozambique AIS panel. Figure 2 presents the four rounds of AIS and our baseline sample together. For questions J17, J19, and J20, the four rounds of AIS between 2003 and 2015 show falling stigmatizing attitudes. For the question on keeping a relative's HIV secret (J18), stigmatizing attitudes (the desire to keep a relative's HIV secret) have worsened over time.

We also ask 33 questions on HIV-related knowledge. Questions are indicators and are coded as 1 if answered correctly, and 0 otherwise. (Correct answers are in parentheses below, with additional detail as needed.) The subgroups of these knowledge questions are: general HIV knowledge, correct methods of transmission, transmission myths, protection methods, and knowledge about HIV treatment.

- General HIV Knowledge

- J03: Have you ever heard of an infection called HIV? (Yes)

- J16: Is it possible for a person who looks healthy to have HIV? (Yes)

- J16a: Is it possible for a person who feels healthy to have HIV? (Yes)

\footnotetext{
${ }^{7}$ https://dhsprogram.com/methodology/survey/survey-display-467.cfm
} 
- J29: Can HIV be cured? (No)

- J28: If HIV is left untreated can it cause AIDS (deficiency of the immune system that can lead to severe infections and death)? (Yes)

- JA11: If not treated, how long do you think it takes for an HIV infected person to develop AIDS (deficiency of the immune system that can lead to severe infections and death)? (Exact answer is 10 years. Coded as correct if absolute difference between respondent's answer and 10 is below sample median in endline survey.)

- JA12: If not treated, how long can a person sick with AIDS survive? (Exact answer is 3 years. Coded as correct if absolute difference between respondent's answer and 3 is below sample median in endline survey.)

- Correct Methods of Transmission

- J05: Can HIV be transmitted from one person to another through sex behaviors? (Yes)

- JA9: Can HIV be transmitted from one person to another through blood contact? (Yes)

- J21: Can HIV be transmitted from a mother to her baby during pregnancy? (Yes)

- J22: Can HIV be transmitted from a mother to her baby during delivery? (Yes)

- J23: Can HIV be transmitted from a mother to her baby by breastfeeding? (Yes)

\section{- Transmission Myths}

- J07: Can people get HIV from mosquito bites? (No)

- J07a: Can people get HIV from shaking hands with an infected person? (No)

- J07b: Can people get HIV from kissing an infected person? (No)

- J14: Can people get HIV from sharing food with a person who has HIV? (No)

- J15: Can people get HIV via witchcraft or other supernatural means? (No)

\section{- Protection Methods}

- J06: Can people reduce their chance of getting HIV by having just one uninfected sexual partner who has had no other sexual partners? (Yes)

- J06a: Can people reduce their chance of getting HIV by not having sexual intercourse at all? (Yes)

- J08: Have you ever heard of a condom? (Yes)

- J09: Do you know where to buy condoms? (Yes) 
- J10: Do you know where to obtain free condoms? (Yes)

- J11: Do you think people can reduce the risk of transmission of HIV if they use condoms whenever they have sex? (Yes)

\section{- Knowledge about HIV Treatment}

- Indicator for knowing where one can get tested for HIV. Coded from question J24: Do you know of a place where people can go to get tested for HIV? (and answering Yes), and J25: If yes, where can people get tested for HIV? (correctly naming a nearby ART site).

- JA1: Do you know if there are any special medicines that a doctor or nurse can give a woman infected with HIV, to reduce the risk of mother-to-baby transmission? (Yes)

- J26: Is there an effective treatment for HIV? (Yes)

- J26a: If yes, do you know what the treatment is called? (Antiretroviral therapy, or ART)

- J27: Do you know of a place where people can receive treatment for HIV? (Yes)

- JA5: Do you think treatment for HIV will be expensive at the local health center? (No)

- JA6: Do you think treatment for HIV at the local health center can help patients stay healthy? (Yes)

- JA7: Do you think treatment for HIV at the local health center can help patients live for as long as uninfected people? (Yes)

- JA8: Do you think treatment for HIV at the local health center can prevent HIV transmission? (Yes)

- JA13: For people infected with HIV, should they take medication even if they don't feel sick? (Yes)

\section{E Geographic Locations of Study Communities}

This study operated in central and northern Mozambique in Sofala, Manica, and Zambezia provinces. Study communities were in Manica, Chimoio, and Gondola districts in Manica province; Dondo and Nhamatanda districts in Sofala province; and Namacurra and Nicoadala districts in Zambezia province. Figure A.2 shows the locations of the study districts in a map of central Mozambique. Figures A.3, A.4, and A.5 show study communities by province in greater detail. Maps display assignment of communities to FCC treatment or control status (Randomization Stage 1). 
Figure A.2: All Study Communities

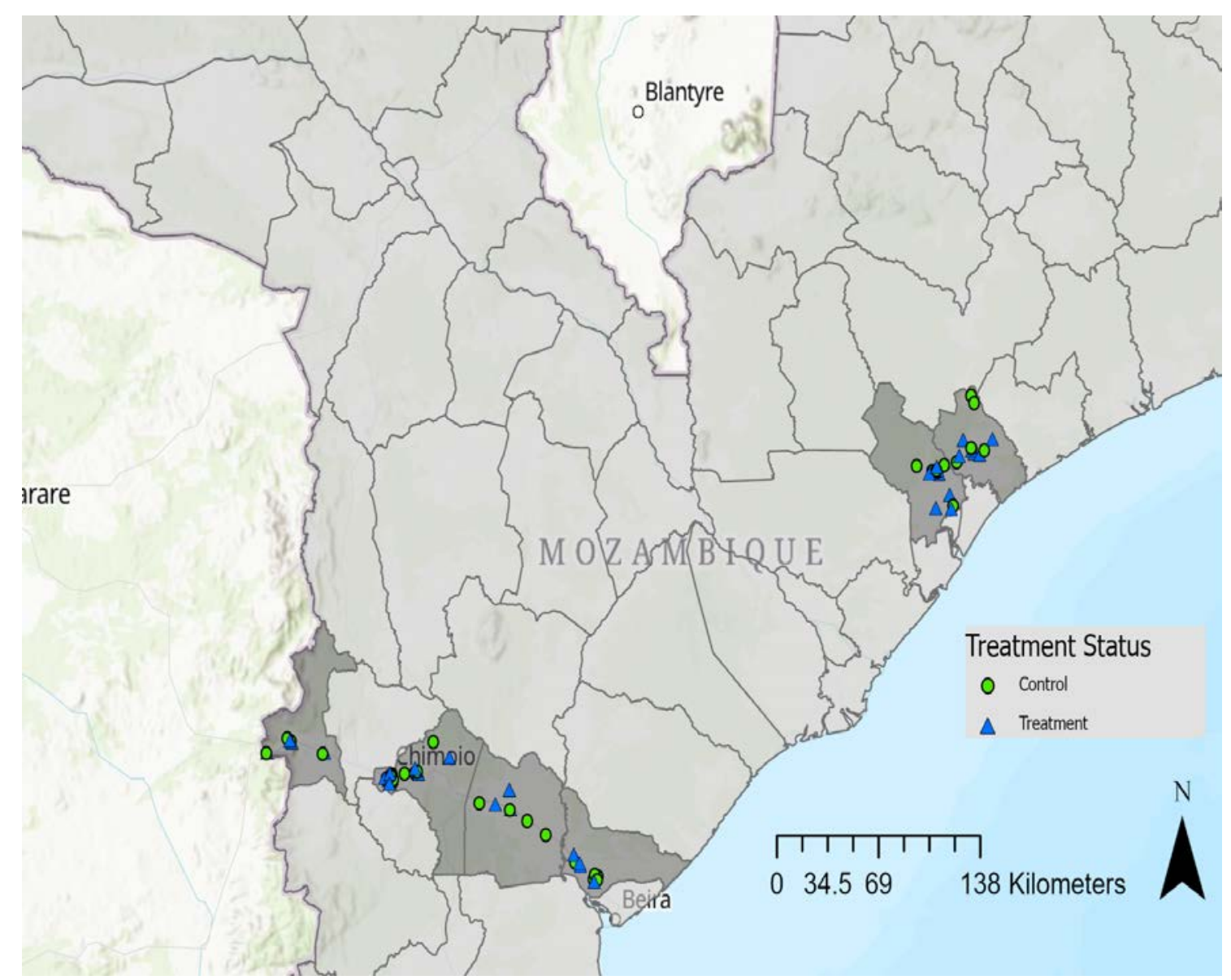


Figure A.3: Study Communities in Sofala Province

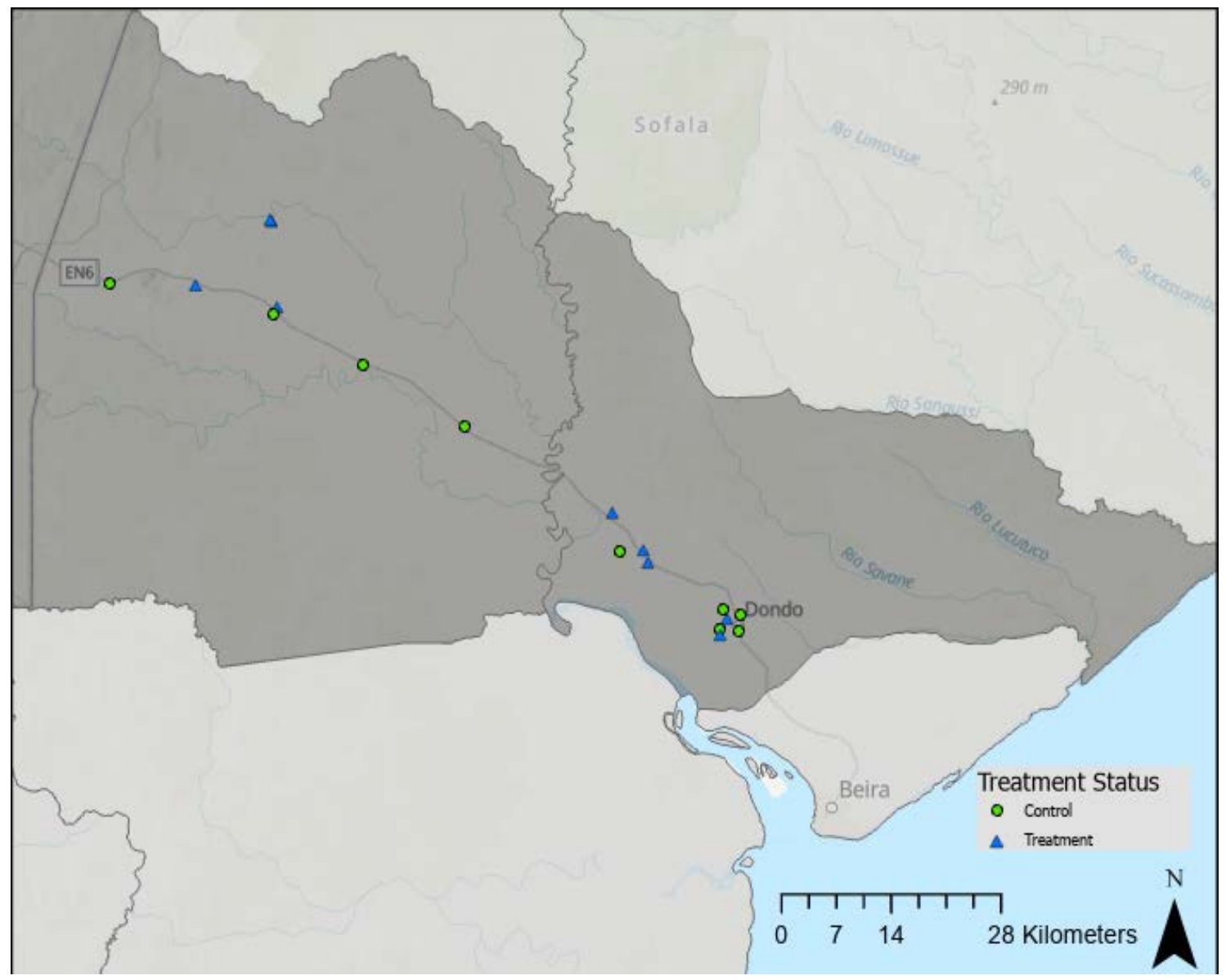


Figure A.4: Study Communities in Manica Province

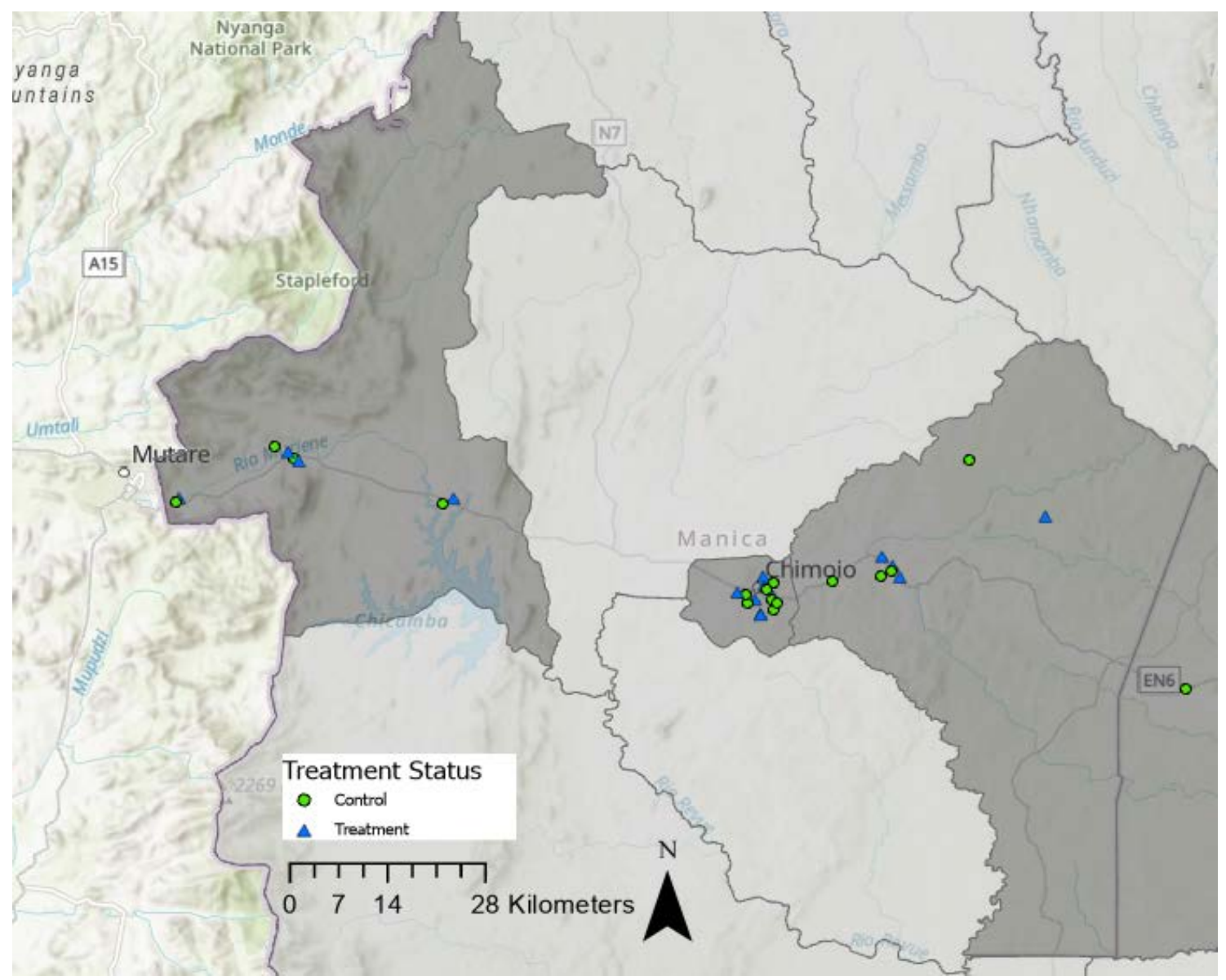


Figure A.5: Study Communities in Zambezia Province

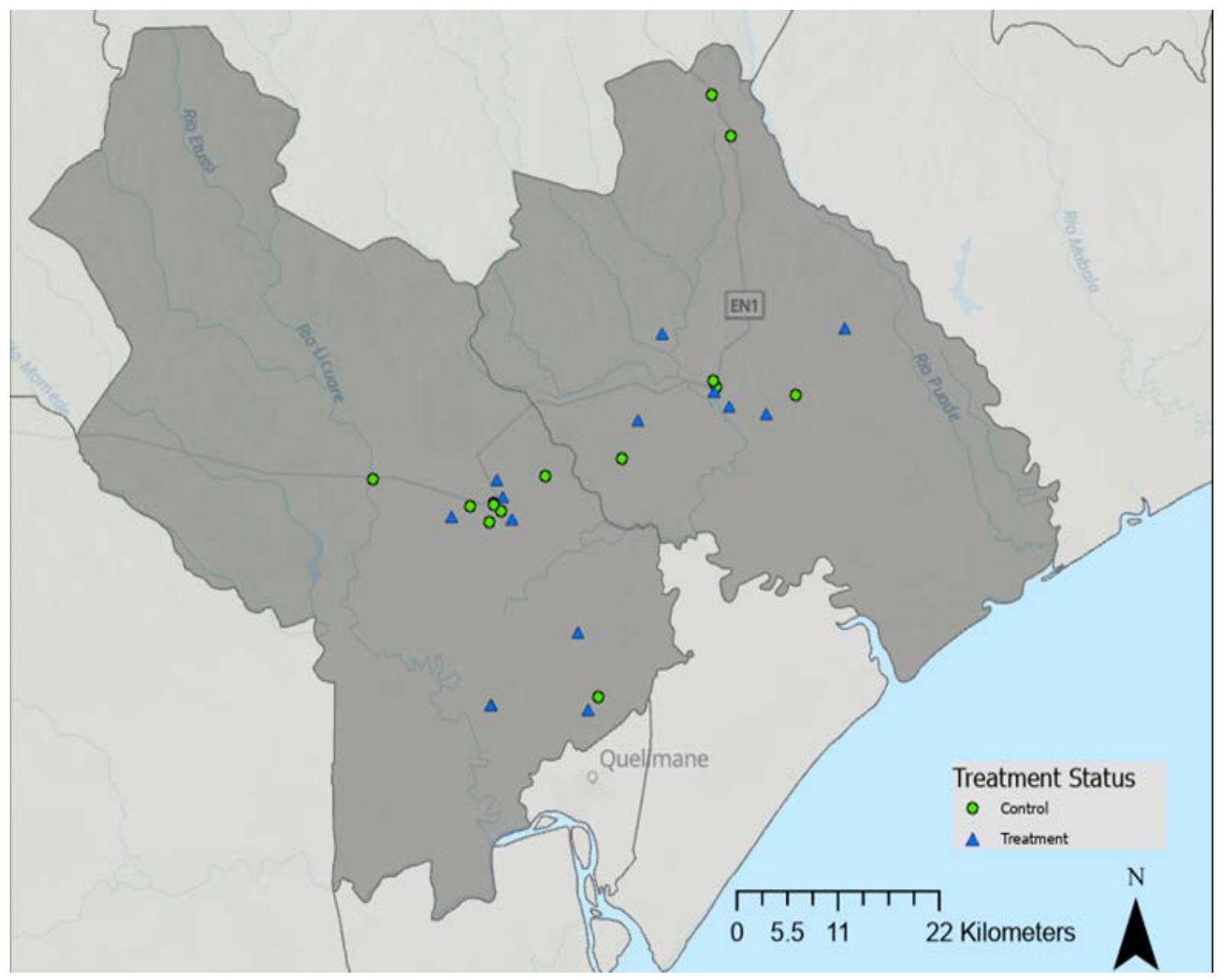




\section{F Details of Minitreatments}

In this section, we provide details of the minitreatments randomly assigned in Randomization Stage 3: (1) Anti-Stigma, (2) HIV/AIDS Information, (3) ART Information, (4) Combined HIV/AIDS and ART Information, and (5) High Incentive for HIV Testing.

\section{F.1 Anti-Stigma Treatment}

In this treatment, the household is given information intended to reduce their concerns about HIV-related stigma in their community. Households are asked in the endline survey about the fraction of households in their community they think hold specific stigmatizing attitudes related to HIV. For questions on which they overestimate the fraction of households with stigmatizing attitudes, they are then told the true (lower) rate in their community.

We provide below the implementation details for this treatment. This treatment focuses on following three questions on HIV-related stigma that were asked in the baseline survey. ${ }^{8}$

- J1\%: Would you buy fresh vegetables from a shopkeeper or vendor if you knew that this person had HIV?

- J19: If a member of your family became sick with AIDS would you be willing to care for them in your own household?

- J20: In your opinion, if a teacher has HIV but is not sick, should they be allowed to continue teaching at school?

Let $\mathrm{x} 17, \mathrm{x} 19$, and $\mathrm{x} 20$ be the shares of respondents answering "yes" to question J17, J18, and J19, respectively, in the baseline survey. ${ }^{9}$ Appendix Table D.2 below shows the values of $x 17, x 18$, and x19 in each study community. For each of these questions, very high shares of respondents answered "yes", indicating relatively low rates of HIV-related stigma. The anti-stigma treatment reveals these very low rates of stigmatizing attitudes to respondents, potentially reducing stigma concerns and thereby raising HIV testing rates.

In the endline survey, respondents are asked to guess the share of people in their community answering "yes" to each of the three questions above (i.e., we ask them to guess the values of $\mathrm{x} 17, \mathrm{x} 19$, and $\mathrm{x} 20$ ). Specifically, in the endline survey, the respondent is asked the following three questions:

\footnotetext{
${ }^{8}$ Our pre-specified measure of stigmatizing attitudes includes four questions, as described in Appendix Section D, but for the anti-stigma treatment we focused on the subset of three questions that have been improving over time and for which we can report that majorities of households express non-stigmatizing attitudes. The fourth question, on keeping an HIV-infected relative's HIV status secret, is not answered in a non-stigmatizing manner by majorities of households, and so we measure it in the surveys but do not include it in the anti-stigma treatment.

${ }^{9}$ As described in Appendix Section C.1, the baseline was administered to a randomly-selected subset of households enrolled in the study, and so their responses can be taken as representative of study communities.
} 
- J17a: If I ask the question, "Would you buy fresh vegetables from a shopkeeper or vendor if you knew that this person had HIV?", to 10 people in your neighborhood, how many of them would you expect to say "Yes"? (guess the value of x17)

- J19a: If I ask the question, "If a member of your family became sick with AIDS would you be willing to care for them in your own household?", to 10 people in your neighborhood, how many of them would you expect to say "Yes"? (guess the value of $\mathrm{x} 19)$

- J20a: If I ask the question, "In your opinion, if a teacher has HIV but is not sick, should they be allowed to continue teaching at school?", to 10 people in your neighborhood, how many of them would you expect to say "Yes"? (guess the value of x20)

Let the answers of the respondent to question J17a, J19a, and J20a in the endline survey be $\mathrm{y} 17, \mathrm{y} 19$, and $\mathrm{y} 20,{ }^{10}$ respectively. If $\mathrm{y} 17<\mathrm{x} 17$, the respondent has overestimated HIVrelated stigma in their community. In this case, we reveal to the respondent the true value of $\mathrm{x} 17$ in the respondent's community. If $\mathrm{y} 17 \geq \mathrm{x} 17$, we do not reveal $\mathrm{x} 17$. The same rule applies to pairs $(\mathrm{y} 19, \mathrm{x} 19)$ and $(\mathrm{y} 20, \mathrm{x} 20)$.

If a respondent answered the survey in such a way that $\mathrm{y} 17 \geq \mathrm{x} 17, \mathrm{y} 19 \geq \mathrm{x} 19$, and $\mathrm{y} 20$ $\geq \mathrm{x} 20$, then, the anti-stigma treatment is not implemented for this respondent.

The enumerator for administering this treatment was as follows. Survey software automatically implemented these rules and inserted the bracketed items. ("Rounded value" means the relevant value from Table A.2, rounded to the nearest 10 percentage points, and expressed as an integer value out of 10.)

In the baseline survey, we asked people in your neighborhood questions about their attitudes towards HIV/AIDS. We would like to share with you how people responded to these questions.

If $\mathrm{y} 17 \geq \mathrm{x} 17$ for this respondent, the next two paragraphs are skipped. Otherwise, the enumerator says:

In the survey we just finished, you guessed that [insert respondent's answer to question J17a] out of 10 people in your community would answer "yes" to the question, "Would you buy fresh vegetables from a shopkeeper or vendor if you knew that this person had HIV?".

We did ask this question to people in your community in the baseline survey. They answered "yes" to this question more often than you thought they would. Our data show that [insert rounded value of $x 17$ for the respondent's community from table below] out of 10 of the people answered "yes", indicating that most respondents are supportive of people living with HIV.

\footnotetext{
${ }^{10} \mathrm{y} 17=100 \%$ if, when answering question J17a, the respondent guesses that "10 out of 10 " people will say "yes"; y17 = 90\% if, when answering question J17a, the respondent guesses that "9 out of 10" people will say "yes"; and so on. The same rules apply for y19 and y20.
} 
If $\mathrm{y} 19 \geq \mathrm{x} 19$ for this respondent, the next two paragraphs are skipped. Otherwise, the enumerator says:

In the survey we just finished, you guessed that [insert respondent's answer to question J19a] out of 10 people in your community would answer "yes" to the question, "If a member of your family became sick with AIDS would you be willing to care for them in your own household?".

We did ask this question to people in your community in the baseline survey. They answered "yes" to this question more often than you thought they would. Our data show that [insert rounded value of 19 for the respondent's community from table below] of the people answered "yes", indicating that most respondents are supportive of people living with HIV.

If $\mathrm{y} 20 \geq \mathrm{x} 20$ for this respondent, the next two paragraphs are skipped. Otherwise, the enumerator says:

In the survey we just finished, you guessed that [insert respondent's answer to question J20a] out of 10 people in your community would answer "yes" to the question, "In your opinion, if a teacher has HIV but is not sick, should they be allowed to continue teaching at school?".

We did ask this question to people in your community in the baseline survey. They answered "yes" to this question more often than you thought they would. Our data show that (insert rounded value of x20 for the respondent's community from table below) of the people answered "yes", indicating that most of the respondents are supportive of people living with $H I V$. 
Table A.2: Rates of Non-Stigmatizing Attitudes Related to HIV

\begin{tabular}{|c|c|c|c|}
\hline Community Name & $\begin{array}{l}\text { Share of respondents } \\
\text { answering "yes" to } \\
\text { question J17 } \\
\text { (i.e. x17) }\end{array}$ & $\begin{array}{l}\text { Share of respondents } \\
\text { answering "yes" to } \\
\text { question J19 } \\
\text { (i.e. x19) }\end{array}$ & $\begin{array}{l}\text { Share of respondents } \\
\text { answering "yes" to } \\
\text { question J20 } \\
\text { (i.e. x20) }\end{array}$ \\
\hline EPC de Chipinde & $92.5 \%$ & $96.8 \%$ & $92.3 \%$ \\
\hline EPC de Munhonha & $93.6 \%$ & $99.1 \%$ & $96.3 \%$ \\
\hline ES do Dondo & $86.8 \%$ & $96.2 \%$ & $91.4 \%$ \\
\hline ES de Macharote & $75.0 \%$ & $94.3 \%$ & $85.4 \%$ \\
\hline EPC 25 de Setembro CFM & $81.3 \%$ & $98.9 \%$ & $95.4 \%$ \\
\hline EPC 7 de Abril - Matadouro & $87.5 \%$ & $99.0 \%$ & $93.8 \%$ \\
\hline EPC de Centro de Acomodação - Mach & $75.0 \%$ & $91.8 \%$ & $87.5 \%$ \\
\hline EPC C.A.de Cheringoma - Dondo & $68.4 \%$ & $85.4 \%$ & $75.0 \%$ \\
\hline EPC Samora M. Machel & $72.6 \%$ & $84.3 \%$ & $76.3 \%$ \\
\hline EPC de Mussassa & $67.5 \%$ & $85.7 \%$ & $71.4 \%$ \\
\hline EPC de Monte Siluvo & $87.1 \%$ & $100.0 \%$ & $87.5 \%$ \\
\hline EPC de Nharuchonga & $79.2 \%$ & $98.6 \%$ & $89.7 \%$ \\
\hline EPC de 3 de Fevereiro & $88.9 \%$ & $95.5 \%$ & $85.7 \%$ \\
\hline EPC 25 de Setembro & $91.5 \%$ & $96.7 \%$ & $94.2 \%$ \\
\hline EPC 12 de Outubro & $89.3 \%$ & $98.2 \%$ & $91.1 \%$ \\
\hline EPC Acordos de Lusaka & $81.8 \%$ & $100.0 \%$ & $89.5 \%$ \\
\hline ES de Tica & $93.3 \%$ & $96.8 \%$ & $93.7 \%$ \\
\hline ES de Metuchira & $79.0 \%$ & $98.5 \%$ & $84.9 \%$ \\
\hline EPC de Muda - Gondola & $71.6 \%$ & $89.7 \%$ & $87.0 \%$ \\
\hline EPC 1 de Maio - Gondola & $81.1 \%$ & $96.1 \%$ & $94.7 \%$ \\
\hline EPC de Eduardo Mondlane - Mucorodzi & $72.6 \%$ & $82.8 \%$ & $88.9 \%$ \\
\hline EPC de Cafumpe & $75.0 \%$ & $95.9 \%$ & $90.4 \%$ \\
\hline ES Josina Machel & $88.1 \%$ & $95.3 \%$ & $93.8 \%$ \\
\hline ES de Macombe & $72.8 \%$ & $94.1 \%$ & $91.7 \%$ \\
\hline EPC de Mussiquir & $64.5 \%$ & $87.5 \%$ & $87.1 \%$ \\
\hline EPC de Bela Vista - Gondola & $72.4 \%$ & $93.2 \%$ & $86.0 \%$ \\
\hline EPC de Cabeça do Velho & $83.6 \%$ & $80.9 \%$ & $86.8 \%$ \\
\hline EPC da Fepom & $89.2 \%$ & $97.3 \%$ & $93.2 \%$ \\
\hline EPC de Nhamaonha & $79.7 \%$ & $89.4 \%$ & $87.9 \%$ \\
\hline EPC 25 de Setembro & $86.9 \%$ & $100.0 \%$ & $96.6 \%$ \\
\hline EPC do Centro Hípico & $78.7 \%$ & $95.2 \%$ & $91.9 \%$ \\
\hline EPC de Nhamadjessa & $74.3 \%$ & $90.3 \%$ & $91.5 \%$ \\
\hline EPC 7 de Setembro & $81.2 \%$ & $97.1 \%$ & $88.4 \%$ \\
\hline EPC 7 de Abril & $89.2 \%$ & $95.5 \%$ & $98.4 \%$ \\
\hline EPC 1 de Junho & $80.3 \%$ & $92.4 \%$ & $88.3 \%$ \\
\hline EPC de Mudzingadzi & $92.8 \%$ & $94.5 \%$ & $93.2 \%$ \\
\hline ES da Soalpo & $73.1 \%$ & $94.2 \%$ & $86.8 \%$ \\
\hline ES Eduardo Mondlane & $83.3 \%$ & $84.6 \%$ & $83.3 \%$ \\
\hline ES da Vila Nova & $72.2 \%$ & $91.3 \%$ & $86.1 \%$ \\
\hline ES 7 de Abril & $73.5 \%$ & $95.7 \%$ & $95.4 \%$ \\
\hline ES de Messica & $62.9 \%$ & $88.2 \%$ & $79.4 \%$ \\
\hline EPC Eduardo Mondlane & $77.3 \%$ & $80.3 \%$ & $81.5 \%$ \\
\hline EPC de Vumba & $82.0 \%$ & $86.0 \%$ & $84.0 \%$ \\
\hline EPC Messica Aldeia & $78.9 \%$ & $89.5 \%$ & $84.2 \%$ \\
\hline EPC de Manhate & $72.2 \%$ & $79.2 \%$ & $83.3 \%$ \\
\hline EPC Estevao Dimaka & $75.0 \%$ & $72.9 \%$ & $71.4 \%$ \\
\hline EPC de Manica & $71.7 \%$ & $87.0 \%$ & $92.5 \%$ \\
\hline
\end{tabular}




\section{F.2 HIV/AIDS Information Treatment}

Enumerators showed a video about HIV/AIDS after the conclusion of the endline survey. This video was two minutes and nine seconds in length. Respondents were asked to choose the language for the audio track of the video (Portuguese, Sena, Tewe, Echuabo, or Chimankya). The videos for each language can be found on our research website at the following link: https://fordschool.umich.edu/mozambique-research/fcc-hiv-aids. The English translation of the transcript of the HIV/AIDS video is as follows:

HIV stands for Human Immunodeficiency Virus. When this virus infects someone, it attacks and eventually destroys the immune system over several years. The immune system is the part of your body that protects you from diseases. Most people with HIV look and feel normal at first until their immune system is destroyed and they develop severe infections and cancers that may be fatal.

$H I V$ is not caused by witchcraft or supernatural power. HIV is a viral infection transmitted from one person to another through semen, vaginal fluid or, blood. It can also be transmitted from a mother to a baby during pregnancy, delivery or breastfeeding. HIV is not transmitted through mosquito bites, kissing, shaking hands or sharing dishes.

If a person with HIV does not receive treatment, HIV will multiply in the body very quickly. As the viruses multiply, they can damage the body's defenses against infections and cancers and eventually cause AIDS. Without treatment, an infected person develops AIDS in ten years on average. Common symptoms of AIDS include rapid weight loss; recurring fever; extreme tiredness; long-lasting diarrhea; swelling of the lymph glands; blotches on or under the skin or inside the mouth, nose, or eyelids; and memory loss. Without treatment, someone with AIDS typically survives about three years before they die.

The Portuguese version of the transcript of the HIV/AIDS video is as follows:

HIV significa Vírus da Imunodeficiência Humana. Quando esse vírus infecta alguém, ele ataca e, eventualmente, destrói o sistema imunológico ao longo de vários anos. O sistema imunológico é a parte do corpo que o protege de doenças. A maioria das pessoas com HIV parece e se sente normal no início, até que seu sistema imunológico seja destruído e elas desenvolvam infecções graves e cânceres que podem ser fatais.

O HIV não é causado por bruxaria ou poder sobrenatural. O HIV é uma infecção viral transmitida de uma pessoa para outra através do sêmen, fluido vaginal ou sangue. Também pode ser transmitido de mãe para bebê durante a gravidez, parto ou amamentação. O HIV não é transmitido por picadas de mosquito, beijos, apertos de mão ou compartilhando pratos.

Se uma pessoa com HIV não recebe tratamento, o HIV se multiplica no corpo muito rapidamente. À medida que os vírus se multiplicam, eles podem danificar as defesas do corpo contra infecções e cânceres e, eventualmente, causar AIDS. Sem tratamento, uma 
pessoa infectada desenvolve AIDS em dez anos, em média. Os sintomas comuns da AIDS incluem rápida perda de peso; febre recorrente; Cansaço extremo; diarreia de longa duração; inchaço das glândulas linfáticas; manchas na pele ou dentro da boca, nariz ou pálpebras; e perda de memória. Sem tratamento, uma pessoa com AIDS geralmente sobrevive cerca de três anos antes de morrer.

\section{F.3 ART Information Treatment}

Enumerators showed a video about ART after the conclusion of the endline survey. This video was one minute and thirty nine seconds in length. Respondents were asked to choose the language for the audio track of the video (Portuguese, Sena, Tewe, Echuabo, or Chimankya). The videos for each language can be found on our research website at the following link: https://fordschool.umich.edu/mozambique-research/fcc-hiv-aids. The English translation of the transcript of the ART video is as follows:

$H I V$ is no longer considered to be a death sentence. We now have a free and very effective treatment for $H I V$.

Antiretroviral therapy (also known as ART) is medication that stops HIV dead in its tracks. It keeps an infected person healthy by preventing HIV from destroying their immune system. It does not eliminate the virus from the body but prevents it from harming the infected person and making it less likely for them to transmit the virus to others.

Starting medication at an earlier stage of infection will greatly improve an infected person's survival rate. So, it is important for people who are at risk to take an HIV test even if they still feel healthy and start ART treatment immediately if the test result is positive. People who are diagnosed with HIV early and who start medication quickly have a better chance of staying healthy and can live as long as uninfected people. Also, the earlier someone is diagnosed and starts treatment, the less likely they are to spread HIV to loved ones.

The Portuguese version of the transcript of the ART video is as follows:

O HIV não é mais considerado uma sentença de morte. Agora temos um tratamento gratuito e muito eficaz para o HIV.

A terapia anti-retroviral (também conhecida como ART) é um medicamento que impede o HIV em seu caminho. Ele mantém uma pessoa infectada saudável ao impedir que o HIV destrua seu sistema imunológico. Não elimina o vírus do corpo, mas evita que ele prejudique a pessoa infectada, tornando menos provável que ela transmita o vírus a outras pessoas.

Iniciar a medicação em um estágio inicial da infecção melhorará muito a taxa de sobrevivência de uma pessoa infectada. Portanto, é importante que as pessoas em risco façam um teste de HIV, mesmo que ainda se sintam saudáveis, e iniciem o tratamento ART imediatamente se o resultado do teste for positivo. Pessoas que são diagnosticadas com HIV precocemente e que iniciam a medicação rapidamente têm mais chances de permanecer saudáveis e 
podem viver tanto quanto as pessoas não infectadas. Além disso, quanto mais cedo alguém for diagnosticado e começar o tratamento, menor será a probabilidade de transmitir o HIV a seus entes queridos.

\section{F.4 Combined HIV/AIDS and ART Information Treatment}

Enumerators showed two videos after the conclusion of the endline survey. The two videos are the HIV/AIDS video used for the "HIV/AIDS Information Treatment" group and the ART video used for the "ART Information Treatment" group, and were shown in this order.

\section{F.5 High Incentive for HIV Testing}

Each HIV testing coupon offered to the household provided a financial incentive of 100 MZN (instead of the 50 MZN per coupon offered to all other households). 


\section{G Intervention Fidelity}

We provide here further information regarding intervention fidelity.

To investigate intervention fidelity for Randomization Stage 1, randomization of communities to treatment (FCC program) or control status, we examine responses in surveys of school principals. Schools are a focal point for delivery of many FCC program components, so school principal reports should indicate whether the program was differentially operating in treatment vs. control communities.

We regress principal survey reports on an indicator for community-level "Treatment" and matched pair fixed effects. Results are in columns 1-3 of Table A.3. Each regression has 74 observations, because principals in two out of the 76 communities could not be reached for the survey. There is no large or statistically significant effect on an indicator for principal having heard of FCC local implementing partner (LIP) organization (column 1). This is unsurprising, since the LIPs are pre-existing organizations in communities with other responsibilities and programs aside from the FCC program work (which they implemented under contract with the WEI/Bantwana). Treatment does, however, lead principals to be more likely to have been contacted by the LIP (column 2); this probability goes from $13.5 \%$ in the control communities to $88.5 \%$ in the treatment communities. In addition, principals in treatment communities are 38.9 percentage points more likely to report that the school receives financial support from the LIP (compared to a base of $40.5 \%$ in control communities). In sum, it appears that Randomization Stage 1 was implemented with high fidelity.

We then turn to examining intervention fidelity for Randomization Stage 2: random assignment of households to "FCC enrolled" status. In columns 4-6 of Table A.3, the unit of observation is the household, and outcomes are as reported by the primary respondent. In these columns, "Treatment" is an indicator for the household being randomly assigned to "FCC enrolled" status.

We examine an indicator for a household having heard of the LIP, an indicator for a household having been visited by a Case Care Worker (CCW) of the LIP, and an indicator for a household having been referred to or received any services from the LIP. The latter indicator is constructed from several survey questions asking about services received from non-government organizations (NGOs), and which organization provided these services. Regression results indicate that treatment (FCC enrollment) leads to higher rates of having heard of, been contacted by, or received services referred by the LIP. Each coefficient is statistically significantly different from zero.

These results indicate that the FCC program did differentially reach households in treatment communities compared to households in control communities. ${ }^{11}$ That said, these

\footnotetext{
${ }^{11}$ The means of the outcome variables are nonzero in control communities. This is to be expected, because LIPs are established local organizations with other activities separate from the FCC program.
} 
treatment effect estimates imply contact and referral rates for treated households that are lower than reported by the implementing agency. WEI/Bantwana reported (based on data collected from LIPs) that $77.0 \%$ of households assigned to FCC-enrolled status were successfully administered a home visit by a CCW. By contrast, our estimates imply that $12.1 \%$ of FCC-enrolled households were contacted by LIPs, and $20.7 \%$ were referred to any service by LIPs (these figures are the sum of the mean in the control group and the coefficient on Treatment in Columns 2 and 3). It is possible that households under-report interactions with LIPs. The fact that the share of FCC-enrolled households saying they were referred to any service by LIPs is larger than the share saying they were contacted by LIPs is one indication of under-reporting. Reasons for under-reporting may include that CCWs interacted with a different household member than the survey respondent, the survey respondent has forgotten the interaction with the LIPs, or the survey respondent did not correctly recall the identity of the organization with which the household had a contact or referral. ${ }^{12}$

\footnotetext{
${ }^{12}$ When presented with these results, WEI/Bantwana also suggested that some households may have received only brief evaluative visits by CCWs, were found to no longer meet OVC criteria, and were not visited again. These visits could then have been imperfectly recalled in the endline survey.
} 
Table A.3: Knowledge of, Contact with, and Services Provided by FCC LIPs

\begin{tabular}{lcccccc}
\hline \multirow{2}{*}{ VARIABLES } & $\begin{array}{c}(1) \\
\text { Heard of } \\
\text { LIP }\end{array}$ & $\begin{array}{c}(2) \\
\text { Contacted } \\
\text { by LIP }\end{array}$ & $\begin{array}{c}(3) \\
\text { Receives Financial } \\
\text { Support from LIP }\end{array}$ & $\begin{array}{c}(4) \\
\text { Heard of } \\
\text { FCC }\end{array}$ & $\begin{array}{c}(5) \\
\text { Visited by } \\
\text { Case Worker }\end{array}$ & $\begin{array}{c}(6) \\
\text { Received Services } \\
\text { by LIP }\end{array}$ \\
\hline Treatment & & & & & & \\
& 0.0556 & $0.750^{* * *}$ & $0.389^{* * *}$ & $0.137^{* * *}$ & $0.0646^{* * *}$ & $0.107^{* * *}$ \\
& $(0.0563)$ & $(0.0742)$ & $(0.101)$ & $(0.0253)$ & $(0.0112)$ & $(0.0209)$ \\
& {$[0.336]$} & {$[0.000]$} & {$[0.000]$} & {$[0.001]$} & {$[0.000]$} & {$[0.003]$} \\
Observations & & & & & & \\
R-squared & 74 & 74 & 74 & 3,658 & 3,658 & 3,658 \\
Obs level & 0.486 & 0.817 & 0.644 & 0.118 & 0.072 & 0.101 \\
Control Mean Dep. Var. & School & School & School & Household & Household & Household \\
\hline
\end{tabular}

Notes: Outcomes in columns 1-3 are from surveys of the principal of each focal school in Jul-Dec 2019. Column 1: indicator for principal having heard of FCC local implementing partner (LIP) organization. Column 2: indicator for principal having been contacted by LIP. Column 3: indicator for principal reporting financial support from LIP. Outcomes in columns 4-6 are from surveys of the primary respondent in each household. Column 4: indicator for having heard of the LIP. Column 5: indicator for having been visited by the LIP Case Care Worker (CCW). Column 6: indicator for having received any services from the FCC program. In cols. 1-3, "Treatment" is indicator equal to one if community was randomly assigned to treatment status (receiving the FCC program) in Randomization Stage 1, and zero otherwise. In cols. 4-6, "Treatment" is indicator equal to one if household randomly assigned to "FCC enrolled" status in Randomization Stage 2, and zero otherwise. All regressions control for matched pair fixed effects. Household-level regressions in cols. 4-6 also control for indicator for "FCC ambient" status. Standard errors clustered at the community level in parentheses. P-values adjusted for multiple hypothesis testing (as described in Section 4.4) in square brackets.

For Randomization Stage 3, the minitreatments, implementation fidelity is high. These treatments were implemented by our research staff. Prompts to implement the correct treatment appeared on our staff members' computer tablets, and the survey digital metadata on the timing of survey sections indicates high adherence to treatment assignment. The vast majority of time-stamps in our survey metadata indicate that sufficient time was spent in the section of the endline survey in which the minitreatments were implemented.

We also directly confirm in the endline that the information and anti-stigma minitreatments are followed by improvements in knowledge and in beliefs that more others hold non-stigmatizing attitudes. After implementing the minitreatments in the context of administering the endline survey, we re-assessed respondents' HIV/ART knowledge and beliefs about stigmatizing attitudes of others by re-asking the relevant knowledge and stigma beliefs questions. We did this re-assessment 15-30 minutes after the minitreatment had been implemented. In the interval between the minitreatment implementation and the re-assessment, the participant was occupied with answering other survey questions unrelated to health or 
HIV. Due to implementation delays, this re-assessment procedure was only implemented in Sofala and Zambezia provinces (Manica province is excluded). In these two provinces, we re-assessed HIV/ART knowledge for those in any of the information treatments, and re-assessed beliefs of others' stigma for those who received the anti-stigma minitreatment and who had previously overestimated others' stigmatizing attitudes. In Appendix Table A.4, we show the mean of respondents' initial answers, and the mean of their answers in the re-assessment. The rightmost column displays the difference between the initial answers and the re-assessment answers, and a p-value of the test of the null that the change in answers was zero.

Panel A shows answers to HIV/ART knowledge questions, and Panel B beliefs about others' stigmatizing attitudes. For both sets of questions, responses move in the direction we would expect due to the minitreatments. In Panel A, the overall knowledge index and responses to all individual questions show more correct answers in the re-assessment than in the initial response. For the overall index as well as for most of the individual questions, the changes in the initial and re-assessment responses are statistically significantly different from zero. In Panel B, re-assessed responses show greater belief that others hold non-stigmatizing attitudes, compared to the initial responses. The changes in the index as well as the three separate stigma questions are all statistically significantly different from zero. 
Table A.4: Changes in HIV/AIDS Knowledge and Beliefs About Others' Stigmatizing Attitudes

\begin{tabular}{|c|c|c|c|c|c|}
\hline Outcome & Stat. & \# of Obs. & Pre-treatment & Post-treatment & Change (p-value) \\
\hline \multicolumn{6}{|c|}{ Panel A: HIV/AIDS Knowledge } \\
\hline \# correct answers (out of 11) & $\begin{array}{c}\text { Mean } \\
\text { SD }\end{array}$ & 1,042 & $\begin{array}{c}7.036 \\
(2.228)\end{array}$ & $\begin{array}{c}8.474 \\
(1.649)\end{array}$ & $\begin{array}{c}1.439 \\
(0.000)\end{array}$ \\
\hline $\begin{array}{l}\text { Can HIV be transmitted from a mother to her baby } \\
\text { during delivery? }\end{array}$ & $\begin{array}{c}\text { Mean } \\
\text { SD }\end{array}$ & 1,042 & $\begin{array}{c}0.781 \\
(0.414)\end{array}$ & $\begin{array}{c}0.798 \\
(0.401)\end{array}$ & $\begin{array}{c}0.017 \\
(0.289)\end{array}$ \\
\hline $\begin{array}{l}\text { Can HIV be transmitted from a mother to her baby } \\
\text { by breastfeeding? }\end{array}$ & $\begin{array}{l}\text { Mean } \\
\text { SD }\end{array}$ & 1,042 & $\begin{array}{c}0.830 \\
(0.376)\end{array}$ & $\begin{array}{c}0.864 \\
(0.343)\end{array}$ & $\begin{array}{c}0.034 \\
(0.013)\end{array}$ \\
\hline $\begin{array}{l}\text { Do you think people can reduce the risk of transmission } \\
\text { of HIV if they use condoms during sexual intercourse? }\end{array}$ & $\begin{array}{c}\text { Mean } \\
\text { SD }\end{array}$ & 1,042 & $\begin{array}{c}0.819 \\
(0.386)\end{array}$ & $\begin{array}{c}0.881 \\
(0.324)\end{array}$ & $\begin{array}{c}0.062 \\
(0.000)\end{array}$ \\
\hline Can people get HIV from mosquito bites? & $\begin{array}{l}\text { Mean } \\
\text { SD }\end{array}$ & 1,042 & $\begin{array}{c}0.605 \\
(0.489)\end{array}$ & $\begin{array}{c}0.910 \\
(0.287)\end{array}$ & $\begin{array}{c}0.305 \\
(0.000)\end{array}$ \\
\hline Can people get HIV from kissing an infected person? & $\begin{array}{l}\text { Mean } \\
\text { SD }\end{array}$ & 1,042 & $\begin{array}{c}0.645 \\
(0.479)\end{array}$ & $\begin{array}{c}0.884 \\
(0.321)\end{array}$ & $\begin{array}{c}0.239 \\
(0.000)\end{array}$ \\
\hline $\begin{array}{l}\text { If not treated, how long do you think it takes for } \\
\text { an HIV infected person to develop into AIDS? }\end{array}$ & $\begin{array}{c}\text { Mean } \\
\text { SD }\end{array}$ & 1,042 & $\begin{array}{c}0.101 \\
(0.301)\end{array}$ & $\begin{array}{c}0.393 \\
(0.489)\end{array}$ & $\begin{array}{c}0.293 \\
(0.000)\end{array}$ \\
\hline $\begin{array}{l}\text { If not treated, how long can a person sick with AIDS } \\
\text { survive? }\end{array}$ & $\begin{array}{l}\text { Mean } \\
\text { SD }\end{array}$ & 1,042 & $\begin{array}{c}0.150 \\
(0.357)\end{array}$ & $\begin{array}{c}0.298 \\
(0.458)\end{array}$ & $\begin{array}{c}0.149 \\
(0.000)\end{array}$ \\
\hline Can HIV be cured? & $\begin{array}{l}\text { Mean } \\
\text { SD }\end{array}$ & 1,042 & $\begin{array}{c}0.684 \\
(0.465)\end{array}$ & $\begin{array}{c}0.823 \\
(0.381)\end{array}$ & $\begin{array}{c}0.139 \\
(0.000)\end{array}$ \\
\hline Is there an effective treatment for HIV? & $\begin{array}{l}\text { Mean } \\
\text { SD }\end{array}$ & 1,042 & $\begin{array}{c}0.879 \\
(0.326)\end{array}$ & $\begin{array}{c}0.918 \\
(0.274)\end{array}$ & $\begin{array}{c}0.039 \\
(0.000)\end{array}$ \\
\hline $\begin{array}{l}\text { Do you think treatment for HIV at the local health } \\
\text { center can help patients stay alive? }\end{array}$ & $\begin{array}{l}\text { Mean } \\
\text { SD }\end{array}$ & 1,042 & $\begin{array}{c}0.867 \\
(0.340)\end{array}$ & $\begin{array}{c}0.951 \\
(0.216)\end{array}$ & $\begin{array}{c}0.084 \\
(0.000)\end{array}$ \\
\hline $\begin{array}{l}\text { Do you think treatment for HIV at the local health } \\
\text { center can prevent HIV transmission? }\end{array}$ & $\begin{array}{c}\text { Mean } \\
\text { SD }\end{array}$ & 1,042 & $\begin{array}{c}0.676 \\
(0.468)\end{array}$ & $\begin{array}{c}0.752 \\
(0.432)\end{array}$ & $\begin{array}{c}0.077 \\
(0.000)\end{array}$ \\
\hline \multicolumn{6}{|c|}{ Panel B: Beliefs About Others' Stigmatizing Attitudes } \\
\hline Average of the three questions below & $\begin{array}{c}\text { Mean } \\
\text { SD }\end{array}$ & 248 & $\begin{array}{c}0.714 \\
(0.199)\end{array}$ & $\begin{array}{c}0.794 \\
(0.189)\end{array}$ & $\begin{array}{c}0.080 \\
(0.000)\end{array}$ \\
\hline $\begin{array}{l}\text { Would you buy fresh vegetables from a shopkeeper or } \\
\text { vendor if you knew that this person had HIV or AIDS? }\end{array}$ & $\begin{array}{c}\text { Mean } \\
\text { SD }\end{array}$ & 244 & $\begin{array}{c}0.639 \\
(0.288)\end{array}$ & $\begin{array}{c}0.747 \\
(0.250)\end{array}$ & $\begin{array}{c}0.109 \\
(0.000)\end{array}$ \\
\hline $\begin{array}{l}\text { If a member of your family became sick with AIDS, } \\
\text { would you be willing to care for them in your own home? }\end{array}$ & $\begin{array}{c}\text { Mean } \\
\text { SD }\end{array}$ & 245 & $\begin{array}{c}0.743 \\
(0.264)\end{array}$ & $\begin{array}{c}0.820 \\
(0.227)\end{array}$ & $\begin{array}{c}0.077 \\
(0.000)\end{array}$ \\
\hline $\begin{array}{l}\text { In your opinion, if a teacher has HIV but is not sick, } \\
\text { should they be allowed to teach? }\end{array}$ & $\begin{array}{l}\text { Mean } \\
\text { SD }\end{array}$ & 247 & $\begin{array}{c}0.762 \\
(0.244)\end{array}$ & $\begin{array}{c}0.817 \\
(0.220)\end{array}$ & $\begin{array}{c}0.055 \\
(0.000)\end{array}$ \\
\hline
\end{tabular}

Notes: Table presents mean responses pre- and post-minitreatment (means, standard deviations in parentheses), and change in responses from pre to post ( $p$-value of test that change equals zero). HIV/AIDS knowledge questions asked of all individuals in information minitreatment groups; row 1 is number of correct answers out of 11; rows 2-12 are indicators for giving correct answer. Stigma belief questions asked of all respondents in stigma minitreatment group who overestimated share of others with stigmatizing attitudes; row 1 is average of rows 2-4 (average share of others respondent believes will answer in a non-stigmatizing way); rows 2-4 are share of others respondent believes will answer the question in a non-stigmatizing way. Sofala and Zambezia province observations only; implementation delays led Manica province observations to be excluded from sample for these re-assessment questions. 


\section{H Balance with Respect to Treatments}

In this section we test whether our randomized treatments of primary interest are balanced with respect to respondent household characterstics and attrition from the survey. ${ }^{13}$ We first check whether characteristics of households are balanced with respect to Treatment (FCCenrolled status). We examine eleven variables that were collected in the course of enrollment of households into the study from May-Nov 2017 (see Appendix Section C.1). These are dependent variables in estimation of Equation 8. We report the results in Appendix Table A.5. None of the coefficients on the treatment coefficient are large or statistically significant at conventional levels.

Second, we check for the possibility of bias due to selective in-migration to study communities (say, if households moved to treatment communities due to initiation of the program there). In column 12, we examine whether treatment was associated with any recent (last 12 months) in-migration into the study communities, and find no evidence of this either. ${ }^{14}$ In sum, there is no indication of selection biases stemming from an impact of treatment on the characteristics of sample households or on in-migration into study communities.

Another key question is whether success in locating households in the endline survey (which determines inclusion in the analysis sample) is affected by treatment status. If so, this raises concerns about selection bias due to differential attrition. We examine this by estimating equation 8 where the outcome variable is an indicator for being included in the endline survey. Coefficient estimates are in column (13) of the table. The mean of the dependent variable in the control communities is 0.800 . The coefficient on the indicator for treatment in the FCC program is very small in magnitude and not statistically significantly different from zero at conventional levels. These results indicate no concern with selection bias due to differential attrition for our pre-specified primary coefficient of interest.

We also conduct analogous tests for balance with respect to the Randomization Stage 3 minitreatments and interaction terms with Treatment (FCC-enrolled) status. In Table A.6, each regression uses the specification of Equation 10, while in Table A.7 we use the interaction-term specification of Equation $11 .^{15}$ In both sets of tables the share of statistically significant coefficients on randomized right-hand-side variables is not substantially different from the number we would expect to occur by chance. In Table A.6, nine out of 72 coefficients are statistically significant at the $10 \%$ level or higher. In Table A.7, the corresponding number is 14 out of 132 . Neither set of regressions suggests concerns about

\footnotetext{
${ }^{13}$ We focus here on Treatment (FCC-enrolled) status as well as its interactions with minitreatments. For balance tests with respect FCC-ambient status, please see the Populated PAP.

${ }^{14}$ This regression has a smaller sample size because the in-migration variable was collected only for the subset of study households who were randomly selected to be administered a comprehensive baseline survey, running from May 2017 to Mar 2018.

${ }^{15}$ Compared to Appendix Table A.5, these tables exclude the attrition outcome variable. Randomization Stage 3 (the minitreatments) was implemented only once households successfully completed the endline survey, it is not possible to examine the impacts of minitreatments on attrition: minitreatment status is not defined for households that attrited from the sample.
} 
imbalance of baseline characteristics or differential attrition with respect to the randomized treatments. 
Table A.5: Balance and Attrition by Treatment Status

\begin{tabular}{|c|c|c|c|c|c|c|c|c|c|c|c|c|c|}
\hline & \multicolumn{11}{|c|}{ Balance Tests } & \multirow{2}{*}{$\frac{\text { Migration }}{(12)}$} & \multirow{2}{*}{$\begin{array}{c}\text { Attrition } \\
(13) \\
\end{array}$} \\
\hline & (1) & (2) & (3) & (4) & (5) & (6) & (7) & (8) & (9) & (10) & (11) & & \\
\hline & $\begin{array}{c}\text { Child or } \\
\text { Grandparent } \\
\text { as Household } \\
\text { Head }\end{array}$ & $\begin{array}{c}\text { Ratio of } \\
\text { Children } \\
\text { to Adult } \\
\geq 4\end{array}$ & $\begin{array}{l}\text { School Aged } \\
\text { Children } \\
\text { not in } \\
\text { School }\end{array}$ & $\begin{array}{c}\text { Household } \\
\text { Eats } \\
2 \text { Meals } \\
\text { a Day }\end{array}$ & $\begin{array}{l}\text { Household } \\
\text { go some } \\
\text { Days w/o } \\
\text { Food }\end{array}$ & $\begin{array}{c}\text { Primary } \\
\text { Income } \\
\text { Illegal or } \\
\text { None }\end{array}$ & $\begin{array}{c}\text { Have } \\
\text { Chronically } \\
\text { Ill Household } \\
\text { Member }\end{array}$ & $\begin{array}{c}\text { HIV }+ \\
\text { Household } \\
\text { Member }\end{array}$ & $\begin{array}{c}\text { Have a } \\
\text { Household } \\
\text { Member } \\
\text { on ART }\end{array}$ & $\begin{array}{c}\text { Have } \\
\text { Orphaned } \\
\text { Children }\end{array}$ & $\begin{array}{l}\text { Adult Died } \\
\text { of Chronic } \\
\text { Illness in } \\
\text { Past } 5 \text { Years }\end{array}$ & $\begin{array}{c}\text { Baseline } \\
\text { In-Migration }\end{array}$ & $\begin{array}{c}\text { Followup } \\
\text { Survey Success }\end{array}$ \\
\hline Treatment & $\begin{array}{l}0.00407 \\
(0.0154)\end{array}$ & $\begin{array}{c}0.0194 \\
(0.0137)\end{array}$ & $\begin{array}{c}0.0234 \\
(0.0175)\end{array}$ & $\begin{array}{l}-0.00248 \\
(0.00364)\end{array}$ & $\begin{array}{c}0.0195 \\
(0.0276)\end{array}$ & $\begin{array}{l}-0.00662 \\
(0.00634)\end{array}$ & $\begin{array}{r}-0.00731 \\
(0.0196)\end{array}$ & $\begin{array}{l}-0.00583 \\
(0.0146)\end{array}$ & $\begin{array}{l}0.00916 \\
(0.0137)\end{array}$ & $\begin{array}{c}0.0105 \\
(0.0198)\end{array}$ & $\begin{array}{c}-0.000209 \\
(0.0110)\end{array}$ & $\begin{array}{l}-0.00633 \\
(0.00877)\end{array}$ & $\begin{array}{l}-0.00587 \\
(0.0120)\end{array}$ \\
\hline Observations & 3,658 & 3,658 & 3,658 & 3,658 & 3,658 & 3,658 & 3,658 & 3,658 & 3,658 & 3,658 & 3,658 & 2,370 & 4,546 \\
\hline R-squared & 0.041 & 0.048 & 0.077 & 0.012 & 0.062 & 0.031 & 0.034 & 0.038 & 0.036 & 0.046 & 0.023 & 0.014 & 0.062 \\
\hline $\begin{array}{l}\text { Obs level } \\
\text { Control Mean Dep. Var. }\end{array}$ & $\begin{array}{c}\text { Household } \\
0.297\end{array}$ & $\begin{array}{c}\text { Household } \\
0.0706\end{array}$ & $\begin{array}{c}\text { Household } \\
0.300\end{array}$ & $\begin{array}{c}\text { Household } \\
0.0149\end{array}$ & $\begin{array}{c}\text { Household } \\
0.601\end{array}$ & $\begin{array}{c}\text { Household } \\
0.0215\end{array}$ & $\begin{array}{c}\text { Household } \\
0.227\end{array}$ & $\begin{array}{c}\text { Household } \\
0.155\end{array}$ & $\begin{array}{c}\text { Household } \\
0.121\end{array}$ & $\begin{array}{c}\text { Household } \\
0.268\end{array}$ & $\begin{array}{c}\text { Household } \\
0.0911\end{array}$ & $\begin{array}{c}\text { Household } \\
0.0370\end{array}$ & $\begin{array}{c}\text { Household } \\
0.800\end{array}$ \\
\hline
\end{tabular}

Notes: Dependent variables in columns 1-11 are indicators for household characteristics reported during enrollment of household in the study (May to Nov 2017). Dependent variable in column 12 is indicator that household migrated into the community within the last 12 months

(available only for randomly selected subset of households asked more extensive set of baseline survey questions, administered May 2017 to March 2018). Dependent variable in column 13 is an indicator that a household was successfully surveyed in the endline survey and included in this paper's analyses (see Appendix section C.2 for details). "Treatment" is indicator equal to one if household randomly assigned to "Treatment" status in Randomization Stage 2, and zero otherwise. Coefficient on Treatment was pre-specified as of primary interest in this study. All regressions control for indicator for "FCC ambient" status, matched pair fixed effects. Standard errors clustered at the community level in parentheses. Significance levels: $* * * \mathrm{p}<0.01, * * \mathrm{p}<0.05, * \mathrm{p}<0.1$. 
Table A.6: Balance with Respect to Minitreatment Status

\begin{tabular}{|c|c|c|c|c|c|c|c|c|c|c|c|c|}
\hline & (1) & (2) & (3) & (4) & (5) & (6) & (7) & $(8)$ & (9) & (10) & (11) & $(12)$ \\
\hline & $\begin{array}{c}\text { Child or } \\
\text { Grandparent } \\
\text { as Household } \\
\text { Head } \\
\end{array}$ & $\begin{array}{c}\text { Ratio of } \\
\text { Children } \\
\text { to Adult } \\
\geq 4 \\
\end{array}$ & $\begin{array}{c}\text { School Aged } \\
\text { Children } \\
\text { not in } \\
\text { School }\end{array}$ & $\begin{array}{c}\text { Household } \\
\text { Eats < } \\
2 \text { Meals } \\
\text { a Day } \\
\end{array}$ & $\begin{array}{c}\text { Household } \\
\text { go some } \\
\text { Days w/o } \\
\text { Food }\end{array}$ & $\begin{array}{c}\text { Primary } \\
\text { Income } \\
\text { Illegal or } \\
\text { None }\end{array}$ & $\begin{array}{c}\text { Have } \\
\text { Chronically } \\
\text { Ill Household } \\
\text { Member } \\
\end{array}$ & $\begin{array}{c}\text { HIV }+ \\
\text { Household } \\
\text { Member }\end{array}$ & $\begin{array}{c}\text { Have a } \\
\text { Household } \\
\text { Member } \\
\text { on ART }\end{array}$ & $\begin{array}{c}\text { Have } \\
\text { Orphaned } \\
\text { Children }\end{array}$ & $\begin{array}{c}\text { Adult Died } \\
\text { of Chronic } \\
\text { Illness in } \\
\text { Past } 5 \text { Years }\end{array}$ & $\begin{array}{c}\text { Baseline } \\
\text { In-Migration }\end{array}$ \\
\hline Treatment & $\begin{array}{l}0.00388 \\
(0.0154)\end{array}$ & $\begin{array}{c}0.0202 \\
(0.0138)\end{array}$ & $\begin{array}{c}0.0239 \\
(0.0175)\end{array}$ & $\begin{array}{c}-0.00245 \\
(0.00364)\end{array}$ & $\begin{array}{c}0.0188 \\
(0.0276)\end{array}$ & $\begin{array}{l}-0.00676 \\
(0.00635)\end{array}$ & $\begin{array}{r}-0.00705 \\
(0.0196)\end{array}$ & $\begin{array}{r}-0.00575 \\
(0.0145)\end{array}$ & $\begin{array}{l}0.00886 \\
(0.0136)\end{array}$ & $\begin{array}{l}0.00985 \\
(0.0198)\end{array}$ & $\begin{array}{c}-0.000601 \\
(0.0110)\end{array}$ & $\begin{array}{l}-0.00688 \\
(0.00873)\end{array}$ \\
\hline Anti-Stigma & $\begin{array}{r}-0.00626 \\
(0.0226)\end{array}$ & $\begin{array}{l}0.00699 \\
(0.0136)\end{array}$ & $\begin{array}{l}-0.0223 \\
(0.0254)\end{array}$ & $\begin{array}{c}0.00613 \\
(0.00595)\end{array}$ & $\begin{array}{r}-0.00983 \\
(0.0248)\end{array}$ & $\begin{array}{l}-0.00296 \\
(0.00917)\end{array}$ & $\begin{array}{l}-0.0291 \\
(0.0247)\end{array}$ & $\begin{array}{l}-0.0114 \\
(0.0181)\end{array}$ & $\begin{array}{r}-0.00933 \\
(0.0170)\end{array}$ & $\begin{array}{l}0.00617 \\
(0.0304)\end{array}$ & $\begin{array}{l}0.0299^{*} \\
(0.0160)\end{array}$ & $\begin{array}{l}-0.00281 \\
(0.0151)\end{array}$ \\
\hline HIV Info. & $\begin{array}{l}-0.0153 \\
(0.0242)\end{array}$ & $\begin{array}{c}0.0181 \\
(0.0151)\end{array}$ & $\begin{array}{l}-0.0162 \\
(0.0265)\end{array}$ & $\begin{array}{c}0.00866 \\
(0.00627)\end{array}$ & $\begin{array}{l}-0.0193 \\
(0.0264)\end{array}$ & $\begin{array}{l}-0.0146^{*} \\
(0.00793)\end{array}$ & $\begin{array}{c}-0.00623 \\
(0.0255)\end{array}$ & $\begin{array}{c}0.0178 \\
(0.0174)\end{array}$ & $\begin{array}{l}0.00473 \\
(0.0159)\end{array}$ & $\begin{array}{l}-0.0201 \\
(0.0268)\end{array}$ & $\begin{array}{c}0.000953 \\
(0.0147)\end{array}$ & $\begin{array}{c}-0.00644 \\
(0.0134)\end{array}$ \\
\hline ART Info. & $\begin{array}{l}0.00302 \\
(0.0236)\end{array}$ & $\begin{array}{l}-0.0192 \\
(0.0124)\end{array}$ & $\begin{array}{c}-0.0476^{* *} \\
(0.0228)\end{array}$ & $\begin{array}{l}0.0108^{* *} \\
(0.00493)\end{array}$ & $\begin{array}{c}0.0222 \\
(0.0242)\end{array}$ & $\begin{array}{l}-0.00798 \\
(0.00840)\end{array}$ & $\begin{array}{l}-0.0125 \\
(0.0238)\end{array}$ & $\begin{array}{c}0.0218 \\
(0.0188)\end{array}$ & $\begin{array}{c}0.0235 \\
(0.0180)\end{array}$ & $\begin{array}{c}0.0224 \\
(0.0249)\end{array}$ & $\begin{array}{c}0.0231 \\
(0.0146)\end{array}$ & $\begin{array}{c}0.0126 \\
(0.0147)\end{array}$ \\
\hline High Value Coupon & $\begin{array}{l}0.00350 \\
(0.0217)\end{array}$ & $\begin{array}{l}0.0267^{*} \\
(0.0159)\end{array}$ & $\begin{array}{l}-0.0121 \\
(0.0276)\end{array}$ & $\begin{array}{c}0.0114^{*} \\
(0.00639)\end{array}$ & $\begin{array}{c}0.0263 \\
(0.0282)\end{array}$ & $\begin{array}{l}-0.00491 \\
(0.00953)\end{array}$ & $\begin{array}{c}0.0271 \\
(0.0265)\end{array}$ & $\begin{array}{l}0.00929 \\
(0.0216)\end{array}$ & $\begin{array}{r}-0.00989 \\
(0.0217)\end{array}$ & $\begin{array}{c}0.0262 \\
(0.0295)\end{array}$ & $\begin{array}{c}0.0235 \\
(0.0170)\end{array}$ & $\begin{array}{c}-0.0262^{*} \\
(0.0132)\end{array}$ \\
\hline HIV and ART Info. & $\begin{array}{c}0.0357 \\
(0.0275)\end{array}$ & $\begin{array}{c}0.0223 \\
(0.0166)\end{array}$ & $\begin{array}{l}-0.0161 \\
(0.0261)\end{array}$ & $\begin{array}{l}0.0132^{* *} \\
(0.00514)\end{array}$ & $\begin{array}{l}-0.0174 \\
(0.0261)\end{array}$ & $\begin{array}{l}-0.00168 \\
(0.00931)\end{array}$ & $\begin{array}{l}-0.0163 \\
(0.0282)\end{array}$ & $\begin{array}{c}0.0151 \\
(0.0189)\end{array}$ & $\begin{array}{l}0.00200 \\
(0.0177)\end{array}$ & $\begin{array}{c}0.0136 \\
(0.0283)\end{array}$ & $\begin{array}{l}0.00736 \\
(0.0172)\end{array}$ & $\begin{array}{c}-0.0271^{* *} \\
(0.0133)\end{array}$ \\
\hline Observations & 3,658 & 3,658 & 3,658 & 3,658 & 3,658 & 3,658 & 3,658 & 3,658 & 3,658 & 3,658 & 3,658 & 2,370 \\
\hline R-squared & 0.042 & 0.051 & 0.078 & 0.013 & 0.063 & 0.032 & 0.036 & 0.039 & 0.037 & 0.047 & 0.025 & 0.019 \\
\hline $\begin{array}{l}\text { Obs level } \\
\text { Control Mean }\end{array}$ & $\begin{array}{c}\text { Household } \\
0.297\end{array}$ & Household & $\begin{array}{c}\text { Household } \\
0.300\end{array}$ & $\begin{array}{c}\text { Household } \\
0.0149\end{array}$ & $\begin{array}{c}\text { Household } \\
0.601\end{array}$ & Household & $\begin{array}{c}\text { Household } \\
0.227\end{array}$ & $\begin{array}{c}\text { Household } \\
0.155\end{array}$ & $\begin{array}{c}\text { Household } \\
0.121\end{array}$ & $\begin{array}{c}\text { Household } \\
0.268\end{array}$ & Household & Household \\
\hline
\end{tabular}

Notes: Dependent variables in columns 1-11 are indicator variables for household characteristics reported during enrollment of household in the study (May to Nov 2017). Dependent variable in column 12 is indicator that household migrated into the community within the last 12 months (available only for randomly selected subset of households asked more extensive set of baseline survey questions, administered May 2017 to March 2018). "Treatment" is indicator equal to one if household randomly assigned to "Treatment" status in Randomization Stage 2, and zero otherwise. Coefficient on Treatment was pre-specified as of primary interest in this study. See Section 5.2 for definition of minitreatments. All regressions control for indicator for "FCC ambient" status, matched pair fixed effects. Standard errors clustered at the community level in parentheses. Significance levels: ${ }^{* * *} \mathrm{p}<0.01,{ }^{* *} \mathrm{p}<0.05,{ }^{*} \mathrm{p}<0.1$. 
Table A.7: Balance with Respect to Minitreatment Status and Interactions

\begin{tabular}{|c|c|c|c|c|c|c|c|c|c|c|c|c|}
\hline & (1) & (2) & (3) & (4) & (5) & (6) & (7) & (8) & (9) & (10) & (11) & (12) \\
\hline & $\begin{array}{c}\text { Child or } \\
\text { Grandparent } \\
\text { as Household } \\
\text { Head } \\
\end{array}$ & $\begin{array}{c}\text { Ratio of } \\
\text { Children } \\
\text { to Adult } \\
\geq 4 \\
\end{array}$ & $\begin{array}{l}\text { School Aged } \\
\text { Children } \\
\text { not in } \\
\text { School } \\
\end{array}$ & $\begin{array}{c}\text { Household } \\
\text { Eats }< \\
2 \text { Meals } \\
\text { a Day }\end{array}$ & $\begin{array}{l}\text { Household } \\
\text { go some } \\
\text { Days w/o } \\
\text { Food } \\
\end{array}$ & $\begin{array}{c}\text { Primary } \\
\text { Income } \\
\text { Illegal or } \\
\text { None } \\
\end{array}$ & $\begin{array}{c}\text { Have } \\
\text { Chronically } \\
\text { Ill Household } \\
\text { Member } \\
\end{array}$ & $\begin{array}{c}\text { HIV + } \\
\text { Household } \\
\text { Member }\end{array}$ & $\begin{array}{c}\text { Have a } \\
\text { Household } \\
\text { Member } \\
\text { on ART }\end{array}$ & $\begin{array}{c}\text { Have } \\
\text { Orphaned } \\
\text { Children }\end{array}$ & $\begin{array}{l}\text { Adult Died } \\
\text { of Chronic } \\
\text { Illness in } \\
\text { Past } 5 \text { Years }\end{array}$ & $\begin{array}{c}\text { Baseline } \\
\text { In-Migration }\end{array}$ \\
\hline Treatment & $\begin{array}{l}-0.0323 \\
(0.0380)\end{array}$ & $\begin{array}{c}0.0355 \\
(0.0249)\end{array}$ & $\begin{array}{c}-0.0116 \\
(0.0396)\end{array}$ & $\begin{array}{l}-0.00623 \\
(0.00464)\end{array}$ & $\begin{array}{l}0.108^{* *} \\
(0.0450)\end{array}$ & $\begin{array}{l}-0.0104 \\
(0.0149)\end{array}$ & $\begin{array}{c}0.0156 \\
(0.0443)\end{array}$ & $\begin{array}{l}-0.0361 \\
(0.0274)\end{array}$ & $\begin{array}{l}-0.0236 \\
(0.0258)\end{array}$ & $\begin{array}{c}0.0461 \\
(0.0420)\end{array}$ & $\begin{array}{l}-0.0152 \\
(0.0222)\end{array}$ & $\begin{array}{l}-0.0106 \\
(0.0184)\end{array}$ \\
\hline Anti-Stigma & $\begin{array}{c}-0.0327 \\
(0.0307)\end{array}$ & $\begin{array}{l}0.00523 \\
(0.0155)\end{array}$ & $\begin{array}{l}-0.0262 \\
(0.0342)\end{array}$ & $\begin{array}{c}0.00644 \\
(0.00973)\end{array}$ & $\begin{array}{l}0.00925 \\
(0.0400)\end{array}$ & $\begin{array}{l}0.00255 \\
(0.0150)\end{array}$ & $\begin{array}{l}-0.0219 \\
(0.0287)\end{array}$ & $\begin{array}{l}-0.0299 \\
(0.0263)\end{array}$ & $\begin{array}{l}-0.0346 \\
(0.0249)\end{array}$ & $\begin{array}{l}0.0634^{*} \\
(0.0371)\end{array}$ & $\begin{array}{c}0.0246 \\
(0.0226)\end{array}$ & $\begin{array}{c}0.0150 \\
(0.0218)\end{array}$ \\
\hline HIV Info. & $\begin{array}{l}-0.0449 \\
(0.0321)\end{array}$ & $\begin{array}{c}0.0215 \\
(0.0175)\end{array}$ & $\begin{array}{l}-0.0268 \\
(0.0321)\end{array}$ & $\begin{array}{l}0.0142 \\
(0.0104)\end{array}$ & $\begin{array}{c}0.0390 \\
(0.0386)\end{array}$ & $\begin{array}{l}-0.0144 \\
(0.0138)\end{array}$ & $\begin{array}{c}0.0119 \\
(0.0351)\end{array}$ & $\begin{array}{c}0.0243 \\
(0.0269)\end{array}$ & $\begin{array}{c}-0.00264 \\
(0.0239)\end{array}$ & $\begin{array}{c}0.0182 \\
(0.0294)\end{array}$ & $\begin{array}{l}-0.00673 \\
(0.0205)\end{array}$ & $\begin{array}{l}-0.00137 \\
(0.0190)\end{array}$ \\
\hline ART Info. & $\begin{array}{l}-0.00341 \\
(0.0325)\end{array}$ & $\begin{array}{c}-0.00267 \\
(0.0136)\end{array}$ & $\begin{array}{c}-0.0587^{* *} \\
(0.0278)\end{array}$ & $\begin{array}{c}0.00608 \\
(0.00617)\end{array}$ & $\begin{array}{c}0.0431 \\
(0.0326)\end{array}$ & $\begin{array}{l}-0.0139 \\
(0.0131)\end{array}$ & $\begin{array}{l}0.00809 \\
(0.0301)\end{array}$ & $\begin{array}{c}-0.00538 \\
(0.0260)\end{array}$ & $\begin{array}{c}-0.00672 \\
(0.0252)\end{array}$ & $\begin{array}{c}0.0249 \\
(0.0341)\end{array}$ & $\begin{array}{c}0.0105 \\
(0.0179)\end{array}$ & $\begin{array}{c}0.0344 \\
(0.0209)\end{array}$ \\
\hline High Value Coupon & $\begin{array}{l}-0.0117 \\
(0.0314)\end{array}$ & $\begin{array}{c}0.0312 \\
(0.0208)\end{array}$ & $\begin{array}{l}-0.0478 \\
(0.0365)\end{array}$ & $\begin{array}{c}0.0148 \\
(0.00999)\end{array}$ & $\begin{array}{c}0.0431 \\
(0.0416)\end{array}$ & $\begin{array}{c}-0.0166 \\
(0.0140)\end{array}$ & $\begin{array}{c}0.0328 \\
(0.0420)\end{array}$ & $\begin{array}{l}0.00353 \\
(0.0323)\end{array}$ & $\begin{array}{c}-0.0182 \\
(0.0332)\end{array}$ & $\begin{array}{c}0.0665 \\
(0.0440)\end{array}$ & $\begin{array}{c}0.0398 \\
(0.0253)\end{array}$ & $\begin{array}{c}-0.00332 \\
(0.0200)\end{array}$ \\
\hline HIV and ART Info. & $\begin{array}{c}0.0182 \\
(0.0379)\end{array}$ & $\begin{array}{c}0.0434^{* *} \\
(0.0212)\end{array}$ & $\begin{array}{l}-0.0454 \\
(0.0389)\end{array}$ & $\begin{array}{c}0.0153^{*} \\
(0.00770)\end{array}$ & $\begin{array}{c}0.0115 \\
(0.0381)\end{array}$ & $\begin{array}{c}-0.00342 \\
(0.0149)\end{array}$ & $\begin{array}{l}-0.0258 \\
(0.0383)\end{array}$ & $\begin{array}{l}0.00674 \\
(0.0274)\end{array}$ & $\begin{array}{l}-0.0159 \\
(0.0268)\end{array}$ & $\begin{array}{c}0.0248 \\
(0.0388)\end{array}$ & $\begin{array}{c}0.0255 \\
(0.0256)\end{array}$ & $\begin{array}{c}-0.0354^{* * *} \\
(0.0116)\end{array}$ \\
\hline Treatment * Anti-Stigma & $\begin{array}{c}0.0730 \\
(0.0586)\end{array}$ & $\begin{array}{l}0.00773 \\
(0.0300)\end{array}$ & $\begin{array}{c}-0.00990 \\
(0.0548)\end{array}$ & $\begin{array}{l}0.00433 \\
(0.0123)\end{array}$ & $\begin{array}{l}-0.0840 \\
(0.0537)\end{array}$ & $\begin{array}{l}-0.0176 \\
(0.0186)\end{array}$ & $\begin{array}{r}-0.00320 \\
(0.0592)\end{array}$ & $\begin{array}{c}0.0284 \\
(0.0410)\end{array}$ & $\begin{array}{c}0.0335 \\
(0.0382)\end{array}$ & $\begin{array}{l}-0.0576 \\
(0.0664)\end{array}$ & $\begin{array}{c}0.0132 \\
(0.0339)\end{array}$ & $\begin{array}{l}-0.0116 \\
(0.0326)\end{array}$ \\
\hline Treatment * HIV Info. & $\begin{array}{c}0.0947 \\
(0.0578)\end{array}$ & $\begin{array}{l}-0.0125 \\
(0.0364)\end{array}$ & $\begin{array}{c}0.0502 \\
(0.0599)\end{array}$ & $\begin{array}{l}-0.00286 \\
(0.0130)\end{array}$ & $\begin{array}{l}-0.108^{*} \\
(0.0584)\end{array}$ & $\begin{array}{l}-0.00637 \\
(0.0165)\end{array}$ & $\begin{array}{l}-0.0341 \\
(0.0633)\end{array}$ & $\begin{array}{l}-0.0258 \\
(0.0375)\end{array}$ & $\begin{array}{c}-0.00119 \\
(0.0356)\end{array}$ & $\begin{array}{l}-0.0975^{*} \\
(0.0516)\end{array}$ & $\begin{array}{c}0.0456 \\
(0.0316)\end{array}$ & $\begin{array}{c}0.0201 \\
(0.0341)\end{array}$ \\
\hline Treatment * ART Info. & $\begin{array}{l}-0.00321 \\
(0.0565)\end{array}$ & $\begin{array}{c}-0.0221 \\
(0.0322)\end{array}$ & $\begin{array}{c}0.0323 \\
(0.0546)\end{array}$ & $\begin{array}{c}0.0137 \\
(0.0112)\end{array}$ & $\begin{array}{l}-0.106^{*} \\
(0.0561)\end{array}$ & $\begin{array}{c}0.0128 \\
(0.0164)\end{array}$ & $\begin{array}{l}-0.0571 \\
(0.0584)\end{array}$ & $\begin{array}{l}0.106^{* *} \\
(0.0425)\end{array}$ & $\begin{array}{c}0.0934^{* *} \\
(0.0422)\end{array}$ & $\begin{array}{c}0.0109 \\
(0.0559)\end{array}$ & $\begin{array}{c}0.0416 \\
(0.0309)\end{array}$ & $\begin{array}{l}0.00301 \\
(0.0359)\end{array}$ \\
\hline Treatment * High Value Coupon & $\begin{array}{l}0.00973 \\
(0.0516)\end{array}$ & $\begin{array}{c}-0.0464 \\
(0.0314)\end{array}$ & $\begin{array}{c}0.102 \\
(0.0663)\end{array}$ & $\begin{array}{c}-0.00604 \\
(0.0119)\end{array}$ & $\begin{array}{c}-0.145^{* *} \\
(0.0626)\end{array}$ & $\begin{array}{c}0.0327 \\
(0.0214)\end{array}$ & $\begin{array}{c}-0.0393 \\
(0.0680)\end{array}$ & $\begin{array}{c}0.0361 \\
(0.0474)\end{array}$ & $\begin{array}{c}0.0285 \\
(0.0464)\end{array}$ & $\begin{array}{c}-0.0631 \\
(0.0595)\end{array}$ & $\begin{array}{c}-0.0199 \\
(0.0383)\end{array}$ & $\begin{array}{c}-0.0181 \\
(0.0242)\end{array}$ \\
\hline Treatment * HIV and ART Info. & $\begin{array}{c}0.0458 \\
(0.0633)\end{array}$ & $\begin{array}{c}-0.0306 \\
(0.0385)\end{array}$ & $\begin{array}{c}0.0645 \\
(0.0577)\end{array}$ & $\begin{array}{c}0.0133 \\
(0.0144)\end{array}$ & $\begin{array}{c}-0.111^{*} \\
(0.0570)\end{array}$ & $\begin{array}{l}0.00686 \\
(0.0201)\end{array}$ & $\begin{array}{c}0.000709 \\
(0.0688)\end{array}$ & $\begin{array}{c}0.0326 \\
(0.0435)\end{array}$ & $\begin{array}{c}0.0353 \\
(0.0409)\end{array}$ & $\begin{array}{c}-0.0199 \\
(0.0608)\end{array}$ & $\begin{array}{r}-0.00459 \\
(0.0395)\end{array}$ & $\begin{array}{c}0.0303 \\
(0.0242)\end{array}$ \\
\hline Observations & 3,658 & 3,658 & 3,658 & 3,658 & 3,658 & 3,658 & 3,658 & 3,658 & 3,658 & 3,658 & 3,658 & 2,370 \\
\hline R-squared & 0.043 & 0.054 & 0.080 & 0.015 & 0.069 & 0.034 & 0.037 & 0.043 & 0.041 & 0.051 & 0.027 & 0.025 \\
\hline Obs level & Household & Household & Household & Household & Household & Household & Household & Household & Household & Household & Household & Household \\
\hline Control Mean Dep. Var. & 0.297 & 0.0706 & 0.300 & 0.0149 & 0.601 & 0.0215 & 0.227 & 0.155 & 0.121 & 0.268 & 0.0911 & 0.0370 \\
\hline
\end{tabular}

Notes: Dependent variables in columns 1-11 are indicator variables for household characteristics reported during enrollment of household in the study (May to Nov 2017). Dependent variable in column 12 is indicator that household migrated into the community within the last 12 months (available only for randomly selected subset of households asked more extensive set of baseline survey questions, administered May 2017 to March 2018). "Treatment" is indicator equal to one if household randomly assigned to "Treatment" status in Randomization Stage 2, and zero otherwise. Coefficient on Treatment was pre-specified as of primary interest in this study. See Section 5.2 for definition of minitreatments. All regressions control for indicator for "FCC ambient" status, "FCC ambient" interacted with each minitreatment indicator, matched pair fixed effects. Standard errors clustered at the community level in parentheses. Significance levels: $* * * \mathrm{p}<0.01, * * \mathrm{p}<0.05, * \mathrm{p}<0.1$. 


\section{Minitreatment Regressions at Individual Level}

Table A.8: Minitreatment Effects on Individual Coupon Redemption

\begin{tabular}{|c|c|c|c|c|c|c|c|c|}
\hline VARIABLES & $\begin{array}{c}1) \\
\text { HIV Testing } \\
\text { Coupon Redemption }\end{array}$ & $\begin{array}{c}(2) \\
\text { HIV Testing } \\
\text { Coupon Redemption }\end{array}$ & $\begin{array}{c}(3) \\
\text { HIV Testing } \\
\text { Coupon Redemption }\end{array}$ & $\begin{array}{c}(4) \\
\text { HIV Testing } \\
\text { Coupon Redemption }\end{array}$ & $\begin{array}{c}\text { (5) } \\
\text { HIV Testing } \\
\text { Coupon Redemption }\end{array}$ & $\begin{array}{c}(6) \\
\text { HIV Testing } \\
\text { Coupon Redemption }\end{array}$ & $\begin{array}{c}(7) \\
\text { HIV Testing } \\
\text { Coupon Redemption }\end{array}$ & $\begin{array}{c}(8) \\
\text { HIV Testing } \\
\text { Coupon Redemption }\end{array}$ \\
\hline Treatment & $\begin{array}{c}-0.0579^{*} \\
(0.0307)\end{array}$ & $\begin{array}{c}-0.0669^{* * *} \\
(0.0248)\end{array}$ & $\begin{array}{c}-0.0729^{* *} \\
(0.0301)\end{array}$ & $\begin{array}{l}-0.0509 \\
(0.0375)\end{array}$ & $\begin{array}{c}-0.0619^{* *} \\
(0.0262)\end{array}$ & $\begin{array}{l}-0.0931 \\
(0.0615)\end{array}$ & $\begin{array}{l}-0.0571 \\
(0.0362)\end{array}$ & $\begin{array}{c}-0.0689^{* *} \\
(0.0280)\end{array}$ \\
\hline Anti-Stigma & $\begin{array}{c}-0.0535 * * \\
(0.0205)\end{array}$ & $\begin{array}{l}0.00353 \\
(0.0229)\end{array}$ & $\begin{array}{l}-0.0170 \\
(0.0245)\end{array}$ & $\begin{array}{c}-0.0800^{* * *} \\
(0.0245)\end{array}$ & $\begin{array}{l}0.00528 \\
(0.0241)\end{array}$ & $\begin{array}{l}0.00311 \\
(0.0682)\end{array}$ & $\begin{array}{c}0.0393 \\
(0.0298)\end{array}$ & $\begin{array}{c}-0.00989 \\
(0.0292)\end{array}$ \\
\hline HIV Info & $\begin{array}{l}-0.0401 \\
(0.0282)\end{array}$ & $\begin{array}{l}-0.0151 \\
(0.0272)\end{array}$ & $\begin{array}{l}-0.0231 \\
(0.0314)\end{array}$ & $\begin{array}{l}-0.0510 \\
(0.0309)\end{array}$ & $\begin{array}{l}-0.0108 \\
(0.0289)\end{array}$ & $\begin{array}{l}-0.0352 \\
(0.0714)\end{array}$ & $\begin{array}{c}-0.00724 \\
(0.0410)\end{array}$ & $\begin{array}{l}-0.0150 \\
(0.0345)\end{array}$ \\
\hline ART Info & $\begin{array}{l}-0.0393 \\
(0.0259)\end{array}$ & $\begin{array}{c}0.0130 \\
(0.0235)\end{array}$ & $\begin{array}{l}0.00185 \\
(0.0267)\end{array}$ & $\begin{array}{l}-0.0628^{*} \\
(0.0316)\end{array}$ & $\begin{array}{c}0.0132 \\
(0.0272)\end{array}$ & $\begin{array}{c}0.0190 \\
(0.0666)\end{array}$ & $\begin{array}{c}-0.00495 \\
(0.0390)\end{array}$ & $\begin{array}{c}0.0243 \\
(0.0306)\end{array}$ \\
\hline High Value Coupon & $\begin{array}{c}0.0426 \\
(0.0355)\end{array}$ & $\begin{array}{c}0.0201 \\
(0.0343)\end{array}$ & $\begin{array}{l}0.00465 \\
(0.0405)\end{array}$ & $\begin{array}{c}0.0482 \\
(0.0400)\end{array}$ & $\begin{array}{c}0.0263 \\
(0.0351)\end{array}$ & $\begin{array}{c}0.0111 \\
(0.0742)\end{array}$ & $\begin{array}{c}0.0109 \\
(0.0522)\end{array}$ & $\begin{array}{c}0.0226 \\
(0.0375)\end{array}$ \\
\hline HIV and ART Info & $\begin{array}{l}0.00283 \\
(0.0354)\end{array}$ & $\begin{array}{l}0.00818 \\
(0.0254)\end{array}$ & $\begin{array}{l}-0.00605 \\
(0.0246)\end{array}$ & $\begin{array}{l}-0.00298 \\
(0.0457)\end{array}$ & $\begin{array}{c}0.0278 \\
(0.0249)\end{array}$ & $\begin{array}{l}-0.0546 \\
(0.0723)\end{array}$ & $\begin{array}{c}0.0225 \\
(0.0374)\end{array}$ & $\begin{array}{l}0.00249 \\
(0.0313)\end{array}$ \\
\hline Treatment * Anti-Stigma & $\begin{array}{l}0.103^{* *} \\
(0.0395)\end{array}$ & $\begin{array}{l}0.0522 \\
(0.0356)\end{array}$ & $\begin{array}{c}0.0784^{* *} \\
(0.0379)\end{array}$ & $\begin{array}{c}0.125^{* * *} \\
(0.0469)\end{array}$ & $\begin{array}{c}0.0372 \\
(0.0372)\end{array}$ & $\begin{array}{c}0.110 \\
(0.0843)\end{array}$ & $\begin{array}{l}0.0399 \\
(0.0641)\end{array}$ & $\begin{array}{c}0.0591 \\
(0.0436)\end{array}$ \\
\hline Treatment * HIV Info & $\begin{array}{l}0.0882^{*} \\
(0.0479)\end{array}$ & $\begin{array}{l}0.0804^{*} \\
(0.0424)\end{array}$ & $\begin{array}{l}0.0768 \\
(0.0471)\end{array}$ & $\begin{array}{l}0.0919^{*} \\
(0.0537)\end{array}$ & $\begin{array}{l}0.0580 \\
(0.0427)\end{array}$ & $\begin{array}{c}0.167^{*} \\
(0.0929)\end{array}$ & $\begin{array}{c}0.0988 \\
(0.0646)\end{array}$ & $\begin{array}{c}0.0662 \\
(0.0512)\end{array}$ \\
\hline Treatment * ART Info & $\begin{array}{c}0.0941^{* *} \\
(0.0429)\end{array}$ & $\begin{array}{c}0.0692^{* *} \\
(0.0331)\end{array}$ & $\begin{array}{c}0.0836^{* *} \\
(0.0381)\end{array}$ & $\begin{array}{c}0.103^{*} \\
(0.0533)\end{array}$ & $\begin{array}{c}0.0354 \\
(0.0381)\end{array}$ & $\begin{array}{c}0.163^{*} \\
(0.0879)\end{array}$ & $\begin{array}{c}0.0673 \\
(0.0599)\end{array}$ & $\begin{array}{c}0.0653 \\
(0.0422)\end{array}$ \\
\hline Treatment * High Value Coupon & $\begin{array}{l}0.0946^{*} \\
(0.0548)\end{array}$ & $\begin{array}{l}0.0899^{*} \\
(0.0469)\end{array}$ & $\begin{array}{l}0.0964^{*} \\
(0.0526)\end{array}$ & $\begin{array}{c}0.0984 \\
(0.0647)\end{array}$ & $\begin{array}{c}0.0570 \\
(0.0475)\end{array}$ & $\begin{array}{l}0.214^{*} \\
(0.117)\end{array}$ & $\begin{array}{l}0.148^{* *} \\
(0.0705)\end{array}$ & $\begin{array}{c}0.0671 \\
(0.0518)\end{array}$ \\
\hline Treatment * HIV and ART Info & $\begin{array}{l}-0.0493 \\
(0.0511)\end{array}$ & $\begin{array}{l}-0.0261 \\
(0.0423)\end{array}$ & $\begin{array}{l}-0.0264 \\
(0.0474)\end{array}$ & $\begin{array}{l}-0.0569 \\
(0.0613)\end{array}$ & $\begin{array}{l}-0.0343 \\
(0.0410)\end{array}$ & $\begin{array}{l}0.0396 \\
(0.102)\end{array}$ & $\begin{array}{l}-0.0389 \\
(0.0594)\end{array}$ & $\begin{array}{l}-0.0185 \\
(0.0470)\end{array}$ \\
\hline Observations & 15,005 & 4,501 & 3,645 & 10,504 & 3,528 & 1,011 & 1,389 & 3,112 \\
\hline R-squared & 0.055 & 0.047 & 0.051 & 0.063 & 0.053 & 0.091 & 0.068 & 0.052 \\
\hline Obs level & Individual & Individual & Individual & Individual & Individual & Individual & Individual & Individual \\
\hline Sample & All & Adult & $\begin{array}{c}\text { Primary } \\
\text { Respondent }\end{array}$ & Children & Age $18-49$ & Age $>49$ & Adult Men & Adult Women \\
\hline Control Mean Dep. Var. & 0.213 & 0.143 & 0.150 & 0.242 & 0.138 & 0.163 & 0.139 & 0.145 \\
\hline
\end{tabular}

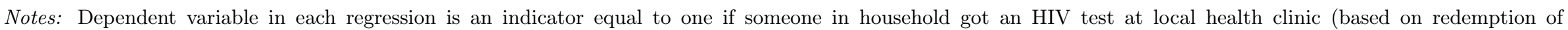

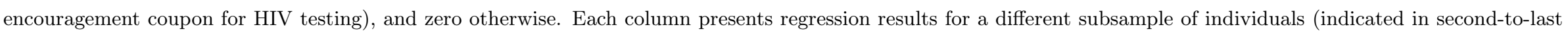

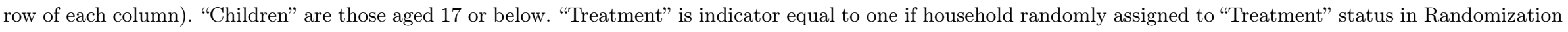

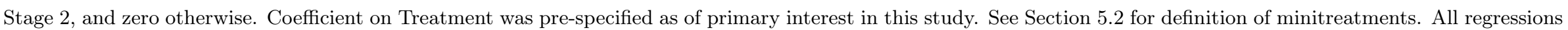

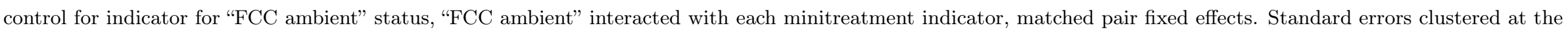
community level in parentheses. Significance levels: ${ }^{* * *} \mathrm{p}<0.01,{ }^{* *} \mathrm{p}<0.05,{ }^{*} \mathrm{p}<0.1$. 